Portland State University

PDXScholar

6-1-1964

\title{
Some factors influencing case classification in a public welfare agency
}

\author{
Miriam Berry \\ Portland State University \\ Hattie Gaskin \\ Glen Gilden \\ Robert Guerrero \\ Leo Henry
}

See next page for additional authors

Follow this and additional works at: https://pdxscholar.library.pdx.edu/open_access_etds Let us know how access to this document benefits you.

\section{Recommended Citation}

Berry, Miriam; Gaskin, Hattie; Gilden, Glen; Guerrero, Robert; Henry, Leo; Metzger, Joanna; Nelson, Delois; Newstrum, Dick; and Olson, Maxine, "Some factors influencing case classification in a public welfare agency" (1964). Dissertations and Theses. Paper 232.

https://doi.org/10.15760/etd.232

This Thesis is brought to you for free and open access. It has been accepted for inclusion in Dissertations and Theses by an authorized administrator of PDXScholar. Please contact us if we can make this document more accessible: pdxscholar@pdx.edu. 


\section{Author}

Miriam Berry, Hattie Gaskin, Glen Gilden, Robert Guerrero, Leo Henry, Joanna Metzger, Delois Nelson, Dick Newstrum, and Maxine Olson 


\title{
SOMB FACTORS INFLUENCING CASE CLASSIFICATION
}

IN A PUBLIC WELFARE AGENCY

$$
\text { by }
$$

MIRIAM BERRY

HATTIE GASKIN

GLBN GILDEN
ROBERT GUERRERO

LEO HENRY

JOANNA METZGER
DELOIS NELSON

DICK NEWSTRUM

MAXINE OLSON

\author{
A GROUP RESEARCH PROJECT \\ Presented to the School of Social Work \\ of Portland State College \\ in partial fulfillment \\ of the requirements for the degree of \\ Master of Social Work \\ June 1964
}




\section{ABSTRACT}

This group project represented an attempt to study some factors pertaining to the formation of a system of case classification in a county public welfare agency, Multnomah County Public Welfare Commission, Portland, Oregon. The classification tool was a Case Planning Schedule intended to encourage diagnostic thinking on the part of the caseworker and to enhance planning and service for the client.

The focus of the study was limited to two areas: (1) whether or not the use of the Schedule resulted in agreement among caseworkers in classification and in consistency on prognoses, (2) the attitudes of the caseworkers in various departments toward the Case Classification Program and the Case Planning Schedule.

Background for the study involved a search of the literature surrounding new approaches to the problems of "multi-problem families" and public assistance caseloads. Consideration was given to agency structure and the circumstances surrounding the creation of the Oregon Program for Case Classification. Five main hypotheses were tested. With one a comparison was made between classification and prognostication of cases with and without a case classification Schedule.

The other testable hypotheses were dealt with by administration of an interviewing schedule designed to gather data regarding staff attitudes toward the Program and the Schedule. Appropriate statistical tests of significance were employed and a content analysis was used in connection with an openended attitudinal question.

Qualitative and quantitative findings were consistent in demonstrating that caseworkers tended to be favorable toward the intent of the Program but critical toward implementation procedures. Divergent viewpoints were shown in comparing responses of workers by categories of work-load assignments, departmental assignments, and length of service in the agency. These findings suggest that additional research include an evaluation of the validity of such systems. 


\section{ACKNOWLEDGMENTS}

We gratefully acknowledge the contributions of the following persons: Mr. Harold Miller, Director of the Oregon Program for Case Classification and Planning, who helped in providing background material for the project; Mr. Gordon Gilbertson, Administrator, Mr. John Burch, Assistant Administrator, and Mrs. Lenore Reese, of the Multnomah County Public Welfare Commission staff, who cooperated in furnishing opportunity for the collection of data; a11 other members of the county staff who assisted in the study and the staff members of the Oregon Public Welfare Commission library who supplied bibliographical material; and our faculty advisers, especially Dr. Frank Miles. 
DEDICATION

We dedicate this project to the memory of Dolores Crystal. 
TABLE OF CONTENTS

PAGE

ACKNOWLEDGMENTS .................... . . 11

LIST OF TABLES .............................. vi

CHAPTER

I. INTRODUCTION ................... 1

II. REVIEW OF STUDIES, PROJECTS AND LITERATURE . . . . . . 14

III. THE AGENCY AND THE OREGON PROGRAM ............ 36

IV. METHODOLOGY ................. 58

V. QUANTITATIVE FINDINGS ................ 70

VI. QUALITATIVE FINDINGS ............. 86

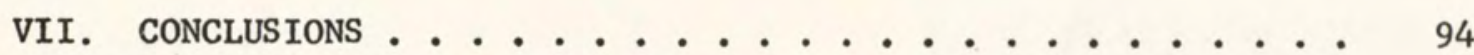

BIBLIOGRAPHY .......................... 108

APPENDIXES

A. EXHIBIT A - CASE PLANNING SCHEDULE . . . . . . . 115

B. EXHIBIT B - INSTRUCTIONS FOR THE COMPLETION OF THE

CASE PLANNING SCHEDULE (SPV 444) . . . . . . . . 116

C. EXHIBIT C - QUESTIONNAIRE . . . . . . . . . . 117

D. INSTRUCTIONS TO INTERVIEWERS ............ 118

E. INTRODUCTION TO QUESTIONNAIRE . . . . . . . . . . 119

F. STATISTICAL TABLE 1 - RESULTS OF " $t$ " TEST USING .05 LEVEL

OF SIGNIFICANCE FOR INTAKE WORKERS COMPARED TO R. S.,

I. S., E. S., AND TOTAL OF F. S. WORKERS . . . . . . 120

G. STATISTICAL TABLE 1a - ADDITIONAL INFORMATION OF " $t$ " TEST

FOR INTAKE WORKERS COMPARED TO OTHER GROUPS OF WORKERS

UNDER $\mathrm{H}_{\mathrm{O}}$ III . . . . . . . . . . . . . . . . 121 
H. STATISTICAL TABLE 2 - MODAL RESPONSES OF ADULT, FAMILY, AND INTAKE SERVICES, AND THE COMBINED MODAL RESPONSES OF THESE SERVICES TO THE PARTS OF C.P.S. FOR Ho VI . • 122

I. STATISTICAL TABLE 2a - A PERCENTAGE RANKING OF ALL RES PONSES TO PARTS OF CASE PLANNING SCHEDULE BY FREQUENCY OF (a) RESPONSES .............

J. STATISTICAL TABLE 2b - THE MODAL ORDER BY FREQUENCY OF POSITIVE RESPONSES OF ALL CASEWORKERS TO ITEM 23 FOR $\mathrm{H}_{\mathrm{O}} \mathrm{VI}$. . . . . . . . . . . . . . . 


\section{LIST OF TABLES}

TABLE

PAGE

A. Results of Chi-square Test Using .05 Leve1 of Significance

for Classification and Prognosis With and Without the

Case Planning Schedule .............. 71

B. Results of Extended Median Test Using .05 Level of

Significance for $\mathrm{H}_{\mathrm{O}}$ III .............. 73

C. Results of Extended Median Test Using .05 Leve1 of

Significance for Corollary $\mathrm{H}_{\mathrm{o}}$ III . . . . . . . . 77

D. Results of Extended Median Test Using .05 Leve1 of

Significance for $\mathrm{H}_{\mathrm{o}} \mathrm{IV}$............... 79

E. Results of Extended Median Test Using .05 Level of

Significance for $\mathrm{H}_{\mathrm{O}} \mathrm{V}$............... 80

F. Results of Chi-square Test Using .05 Level of Significance

for Items 17 and 22 under $\mathrm{H}_{\mathrm{o}} \mathrm{V}$........... 81 


\section{CHAPTER I}

\section{INTRODUCTION}

The tremendous social problems our culture currently faces are reflected in the statistics regarding mental illness, poverty and family breakdown. The challenge to social work to alleviate these ailments is almost overwhelming, and the field is casting about for new ways to meet the challenge of these and related problems. One rapidly growing development in social work is the use of diagnostic categories intended to set up uniform standards for case diagnosis. With caseloads increasing, particularly in public welfare, the trend toward developing and using diagnostic categories has become a major one in the field of social welfare today. Some of the assumed benefits include a better ordering to our casework knowledge, identification of problem areas for the purposes of preventive treatment and rehabilitation, and better utilization of casework and administrative time. It is also hoped that it will be an especially useful tool for the untrained caseworker.

With this as a national trend, therefore, and with a number of other states experimenting with the use of such categories, the State of Oregon entered into the movement and began the process of instituting a program of diagnostic classification. The program was implemented in a number of county public welfare departments throughout 
the state, and was called "The Oregon Program for Case Classification and Planning." Eventually, the expectation was that every public welfare department in the state would be part of the Program. The case classification Program in Oregon, while in the planning stage and early implementation stage, did not receive the backing and financial participation of the federal government. However, on September 1, 1962, Public Law 87-543, Section 101(a) came into effect as part of the 1962 amendments to the Social Security Act. At that time criteria were set up for federal financial participation in state welfare programs attempting to give rehabilitative "services to needy families with children." 1 After evaluating the Oregon Program the federal government's Department of Health, Education and Welfare concluded that the Oregon Program qualified for federal matching funds, and the federal government began to participate financially in Oregon's Program.

The tool for implementing the classification Program was a Case Planning Schedule, intended to encourage diagnostic thinking on the part of the caseworker, and to enhance planning and service for the client. A copy of the Case Planning Schedule is to be found in the Appendix, page 115. The Schedule included a series of categories covering different aspects of client functioning. The caseworker made an evaluation of client behavior, with a prognosis for future adjustment and need for service.

An intrinsic part of the classification Program was the division of the participating welfare agency into three different categories of service: "Intensive Service," "Environmental Service" and "Regular Service." The caseload for each worker fell into one of these three categories. 
The Intensive Service caseload consisted of no more than thirty-five families and the "level of service is generally defined as being focused upon 'inner problems' or upon the individual's capacity and motivation for change." (See Appendix, Exhibit B, page 19.) The term "families" is defined as both child and non-child family units as well as single individuals.

The Environmental Service caseload consisted of no more than sixty families, and this "level is generally defined as being primarily focused upon 'outer problems' or those environmental factors which, when alleviated, allow the individual to become more successful in dealing with his problems." (See Appendix, Exhibit B, page 19.)

The Regular Service caseload could have an unlimited number of cases, and was "defined as being focused upon the provision of financial aid in the most efficient and helpful manner." (See Appendix, Exhibit B, page 20.) Classification of cases, therefore, using the Case Planning Schedule, resulted in the assignment of each case to one or the other of the three service units. Theoretically then, each case received the kind of service which was most appropriate to its individual needs and its expected treatment potential. This in rough outline was the basic structure of the case classification Program in the state of Oregon, its roots 1ying in a nationwide development of the use of diagnostic categories.

\section{Development of the Research Project}

Because of the vast expenditure of effort and funds in the classification movement, it seemed critically important to begin objectively to examine a classification program and its actual usefulness. If the use of 
case classification was a tool which refined knowledge about human behavior, it was important to know this so that such programs could be further developed. If, however, it did not serve the purpose for which it was intended, it was essential to discover this and to know why the failure had occurred.

It was also useful to know what objective factors influenced the success or failure of such a program. A decision was made, therefore, to look at the recently developed Oregon Program for Case Classification and Planning with the hope that by obtaining some objective data about the Program we would be able to contribute to the pool of information regarding case classification. A number of people in the research group had had practical experience within the Oregon Program, and this gave an added impetus to such a search.

The first counties making full use of the Program were Multnomah and Jackson. It was decided to do a study in Multnomah County for the following reasons: (1) Multnomah County was one of the earliest counties to implement case classification, and therefore had enough experience to provide researchable data; (2) the county offices were located conveniently near the Portland State College School of Social Work; and (3) the administration indicated a willingness to cooperate on the project.

Next, attention was given to which areas of the Program might be feasible for study. It was immediately apparent that it would be impossible to do an exhaustive study of its total current operation. Also, because of its newness and because changes were continually taking 
place, it was not possible to evaluate its success or failure at the time of the study. Therefore, it was necessary to limit the study to selected aspects of the Program's operation and to avoid attempting to make premature evaluations about its effectiveness. Within these limitations the research group's focus was to select suitable areas for study.

\section{Scope of the Study}

In reviewing the different aspects of the Program two areas of concentration were selected. The first area of concern regarded whether or not the use of the Schedule resulted in agreement among workers in classification, and in consistency on prognoses. It was found that it was not possible to measure case movement as a result of use of the Schedule because, even with an adequate movement scale, the Program was still too new for such evaluation. Similarly, it was not possible to examine the Schedule as a training tool because of the difficulty of setting up measurements of the growth of casework skill. Also, since the terms on the Schedule were not defined, the value of respective portions of it could not be determined. Therefore, in examination of the Schedule itself, our scope was limited to considering consistency of classification and prognostication among those using it.

The second area of concern was that of staff attitude toward the Program and use of the Schedule. This was of basic interest as it seemed that negative or positive feelings on the part of the casework staff might influence classification of cases and the services being rendered on the basis of such classification. For instance, it was surmised that a worker liking the Program might do a better job of implementing it than 
one who felt negatively toward it. A related concern was whether staff morale might have bearing on the final outcome of the Program. With these questions in mind, a decision was made to examine the casework staff's attitude toward both Program and Schedule.

The decision to examine these two basic areas of concern, namely, consistency in classifying cases and making prognoses, and, also, attitude of the staff toward both Program and Schedule, resulted in the formulation of a series of questions. These were as follows:

(1) How consistent is classification and prognosis with use of the Case Planning Schedule?

(2) What are some attitudes of caseworkers using the Case Planning Schedule in the Multnomah County Public Welfare Commission?

(3) Does the length of time with the agency or the caseworker's assignment within the agency affect attitudes?

(4) Are there differences in attitudes in the groups of caseworkers in the agency?

(5) Do caseworkers feel that some parts of the Schedule are more helpful than other parts of the Schedule?

(6) What do the caseworkers feel would improve the Program?

After formulation of these questions, group effort was directed toward developing researchable hypotheses which would attempt to answer them. In formulation of these null hypotheses the group took into consideration agency structure, the Program itself, type of data available, the limitations of time for both agency staff and research group and the lack of previous research data. The group attempted to reach the goal of having hypotheses specific enough to be testable and broad enough to cover the hunches of the students. The following were the 
nu11 hypotheses:

I. There are no significant differences in classifying cases with the Case Planning Schedule and without the Case Planning Schedule.

The rationale behind this was that there would be measurable differences in the way in which cases were classified into particular service units depending upon whether or not the Schedule was used. In other words, would it be possible for one to rely more on subjective casework skill and technique in diagnosis rather than bothering to check all of the classification categories? Involved in this question actually was a speculation as to the basic helpfulness of the Schedule in preference to traditional casework method. If the testing of this hypothesis led to the acceptance of the null hypothesis, there would be serious question as to whether the Case Planning Schedule was an efficient tool for assignment of cases. Would a less complex procedure give the same or superior guide for assigning cases? If the null hypothesis was rejected, the agency might be more secure in the use of the Case Planning Schedule as a means of assignment.

II. There are no significant differences in classifying of cases by Intake workers and Unit workers.

The rationale for this hypothesis was that cases that received a preliminary classification at Intake on the basis of one interview may or may not receive the same classification by the Unit worker after the Schedule is fully completed; i.e., after three months' study of the client. If the classification remained the same, it could imply that the plan to assign cases to differential caseloads from Intake had validity. If the findings indicated that there tended to be a change 
in classification and, as a result, a transfer of cases between caseworkers were necessary, the plan would need serious reconsideration. Included in the concerns would be: (1) Would there be an improved method that would decrease the transfer of cases? (2) What does the chance of discrepancy mean to the client in terms of not getting needed service? (3) Are the criteria for classification explicit enough or is the difference in classification by Intake workers and the Unit workers due to inadequate criteria?

Because of difficulties in the testing situation it was not possible to come to definitive conclusions about these questions. However, some of the work done on this hypothesis and some tentative information are to be found in Chapter IV, page 61.

III. There are no differences in attitudes, as measured, of Intake workers, Intensive Service workers, Environmental Service workers and Regular Service workers.

Sub-hypothesis:

There are no differences in attitudes, as measured, of Intensive Service, Environmental Service (maximum service) and Regular Service workers toward the case classification and planning Program.

IV. There are no differences in attitudes, as measured, of Family Service workers and Adult Service workers at all levels.

V. There are no differences in attitudes, as measured, of caseworkers with the agency more than two years and less than five years and caseworkers with the agency less than two years or more than five years.

VI. There are no differences in helpfulness between parts of the Case Planning Schedule according to responses of caseworkers. 
Hypotheses III through VI were designed to elicit attitudes of the casework staff as they related to the classification Program and Schedule. Attitude is defined in this study as "a position or bearing as indicating action, feeling, or mood; hence, the feeling or mood itself." 2

Empirical observation in the months preceding this study indicated that there might be differences in attitudes among the caseworkers. These differences seemed to fall into definable categories of workers. On hypothesis III and Its sub-hypothesis the speculation was that the differential caseload assignments carried an implied status factor. It appeared to be generally accepted within the agency that workers with the highest degree of skill in helping people were assigned to maximum service caseloads. Less experienced workers and less skilled workers seemed to be assigned to the large caseloads. This led to the expectation that the maximum service workers would be more favorable to case classification since they had received benefits in terms of status, lower caseloads, and opportunity for greater work satisfaction than the Regular Service workers.

If the alternate hypothesis were established by this study and if one group were found to be strongly negative and the other positive, the findings could be of great significance for administration. This study did not undertake to establish why the differences would occur. It was hoped that the establishment of the simple fact of significant differences would serve as an impetus to deeper exploration.

Hypotheses IV and V were also formulated because of observations that Indicated a divergence of feelings among caseworkers. The speculation that Family Service workers favored the Program more than the 
Adult Service workers came from casual evaluation of workers' comments. Accusations were made that the Program was biased toward family cases, that the originator of the Schedule had a family service background experience, and that the Family Service Department received preferential treatment. Especially emphasized was that the persons who developed the Schedule had no experience with the aged, infirm or childless families: Further speculation was that the Adult Service workers tended to be more resistive to all new programs. The influence on caseworker attitudes by supervisory and other administrative personnel was considered and it was felt that Family Service supervisors tended to show more enthusiasm for the Program. Determining whether or not there were differences in attitudes between these two departments by means of objective research methods seemed to be an important first step in the direction of resolving these questions.

In hypothesis $\mathrm{V}$ the question was whether the length of service in the agency had an impact on attitudes. Observation led to a tentative evaluation that workers with less than two years' experience were still in an orientation process. They were not yet acquainted with agency procedure, and the onset of a vast new program when they had not formulated concepts of the basic purpose of the agency could be frustrating. It was felt that in this two-year period many workers reached a decision to leave the agency. For these reasons the workers with less than two years' experience were not expected to reflect favorable attitudes to case classification.

The rationale for the prognosis that those workers with the agency for over five years would be negative toward the Program was that these 
workers would tend to have fixed working patterns and would therefore have resistance to changes.

The indication was that the workers with two to five years of experience would be most enthusiastic about the Program. These workers were expected to have aspirations for promotion. They probably would have by this time decided that they wished to stay in public welfare work. The acceptance or rejection of this hypothesis could result in indicating some groups of workers where staff development emphasis should be concentrated, specifically for case classification, but also for the total agency operation.

Hypothesis VI dealt with the component parts of the Case Planning Schedule. It seemed that one way to test the effectiveness of the Schedule was to ask the opinions of the people who were responsible for applying it. If caseworkers found the Schedule an asset in their work with clients, this could in some measure indicate whether the Schedule was fulfilling the function that the designers of the Program intended. Comments and criticisms from the caseworkers led to the speculation that parts of the Schedule gave more concrete help than other parts. It was decided, then, that this hypothesis could test feelings of the workers and possibly lead to some indications of areas of weakness and strength in the Schedule. If, for example, the majority of caseworkers indicated strongly that one part of the Schedule was of negligible help, this might indicate a need to change that part of the Schedule into a form that the workers would find more helpful. On the other hand, such a finding could also indicate that the instructions 
had been vague and the meaningfulness of that part of the Schedule had not been conveyed to the workers. If the latter interpretation held, it would indicate a need for helping the workers understand and increase their skill in the use of that part.

In summation, it can be stated that the research group's work involved a tentative look at a new program representing current trends in public welfare practice. Because of limitations in the research situation and the inherent problems within the Program itself, it was necessary to restrict the scope of the study. The group's goal was to test the hypotheses derived from the two areas of concern, the first being consistency of the Schedule as a casework tool, and the second regarding staff attitudes toward the Program and use of the Schedule. 
Chapter References:

1 "Public Law 87-543, Section 104 (b)," a revision of the Handbook of Public Assistance Administration, No. I-1000, Part I, transmitted by State Letter No. 588 of the Bureau of Family Services, Social Security Administration, United States Department of Health, Education and Welfare. (Washington: September 4, 1962), p. 103.

2Webster's New Collegiate Dictionary (Springfield, Mass.: G. \& C. Merriam Co., 1953), p. 57. 


\section{CHAPTER II}

REVIEW OF STUDIES, PROJECTS AND LITERATURE

Much effort has been expended in recent decades on the nature and incidence of human problems as related to community action to meet problems. An approach receiving increasing emphasis is that related to classifying cases according to various diagnostic and predictive categories in order better to assign and assess community services.

This chapter will describe a series of studies and projects directly related, in history and nature, to the Oregon Program and, hence, to the purposes of our study. Literature related to these studies and projects will be described. Some of the evaluations and critical analyses of diagnostic classification and its relationship to existing theory will be discussed.

In this chapter the term "studies" is used to indicate initial collection and evaluation of data; the term "project" is used to indicate a long-range implementation of the findings of a study.

\section{The St. Paul Study}

The St. Paul study was one of the first in a series of recent studies of human problems and a community's service to alleviate these problems. It was a comprehensive, statistical study of social services rendered during the month of November, 1948, in St. Paul, Minnesota. It was conducted under the joint auspices of the Greater St. Paul Planning 
and Research Council and the Community Research Associates of New York. An interpretation and summary of this study are given in a Public Affairs Pamphlet edited by Eloise Walton. The preliminary findings of the study พ่ere:
During the month of November 1948, forty-one thousand families in St. Paul received help from the one hundred and nine tax-supported and voluntary health and welfare agencies of that area. But six percent or six thousand five hundred of all the city's families accounted for more than half of the cases served by these agencies and cost approximately one-half of the subsidized health and welfare bill. These six percent families were labeled "multi-problem" families. 1

The term "multiproblem" refers to famllies with financial and health problems in addition to unacceptable behavior. ${ }^{2}$

Four years (1948-52) were spent in gathering and evaluating the data of the St. Paul study and the detailed findings are part of a volume by Community Research Associates, Inc. ${ }^{3}$ The research for the book was underwritten by the Grant Foundation. The St. Paul study provided information about:

(1) Number of individuals and families served.

(2) Kinds and amounts of problems presented.

(3) Number of agencies serving them.

(4) Kinds of service provided.

(5) Costs in money and professional manpower.

(6) The concentration of problems and services in multiproblem families and its implications for preventive planning. 4

For instance, there were three areas of need identified among the multiproblem families of St. Paul.

First, economic dependency: seven percent of all the families in 
town were dependent, but in only four percent of these seven thousand families was the problem chiefly one of unemployment. About seventyseven percent of the dependent families were also suffering from 111 health, maladjustment, or both.

Second, the problem of 111 health was examined. Nearly threefourths of the multiproblem families had serious problems of 111 health. In more than one-third of the families, persons were chronically ill; in more than one-fourth, chronically handicapped. Thirty-eight percent of the families with health problems also had dependency or adjustment problems or both.

In the area of maladjustment the study showed that. more than threefourths of the multiproblem families gave evidences of serious maladjustment and forty percent were failing to meet major social responsibilities. Nearly one-third had official records of anti-social behavior on the part of one or more family members. It was found that fifty-eight percent of the "maladjusted" families also had health or dependency problems or both.

An interesting sidelight of this study was that it was shown that the least privileged families used recreation facilities less than other families. Only seven and one-half percent of the multiproblem families were served by recreation agencies in contrast to twenty-one percent of other families in the community. There was also evidence that few of the families were referred by casework, mental or correctional agencies to the recreational agencies. 


\section{St. Paul Project}

Following the publication of the findings described above in 1952, community workshops were held and the Family Centered Project of St. Paul was established. The workshops covered discussions of classification of the families from the 1948 "Six Percent" group into categories that were potentially treatable. A coordinated plan for diagnosis and treatment of these potentially treatable cases was also discussed, as well as the establishment of detection centers for families in the process of becoming "hard-core" cases; 1.e., resistant to treatment.

Public and voluntary social work agencies worked out an agreement whereby each would work with a block of these families on a coordinated basis using family centered treatment concepts. A pilot project was begun in July, 1954, with a group of five private and public agencies carrying cases of one hundred and forty families from the public welfare load. The project was extended to July 1, 1959, at which time more agencies were added to the original five and the number of families expanded to three hundred and fifty. ${ }^{5}$ The Casework Notebook was developed by the St. Paul Project and has been used in the orientation of the staff of other agencies.

\section{Other Studies and Projects}

Community Research Associates further demonstrated that a relatively small proportion of families accounts for much of the community's serious chronic problems in the areas of economic dependency, 111 health, and maladjustment. A series of experimental projects was financed over a five-year period in three communities, each focusing specifically on one 
of the aforementioned problem areas. 6

The communities and their projects were:

(1) Winona, Minnesota - economic dependency

(2) Washington County (Hagerstown), Maryland - 111 health

(3) San Mateo, California - maladjustment in social functioning

A preliminary study begun in Winona in January, 1953, showed a high degree of chronicity among economically dependent families. It was shown, however, that dependent families also had problems of 111 health and maladjustment. The project program was focused on rehabilitation of multiproblem families, accompanied by rehabilitation of the chronically 111 and disabled. A Family Center was established for the purpose of obtaining and securing community responsibility, cooperation and coordination of services. A case register was used to make family diagnoses of the two hundred and thirty multiproblem families identified in the preliminary study. The staff of the Family Center had responsibility for ful1 family casework treatment. ${ }^{7}$

The Washington County, Maryland, preliminary study showed that, in the area of health problems, "indigent disability" was at the core of community health problems. Project focus here was on rehabilitation of those already disabled and on finding and treating persons with potentially disabling conditions. The implementation of this project involved a Family Unit Reporting System whereby all agencies providing services to indigent and disabled families or medical services to disabled persons reported basic information regarding cases on special forms. The project staff, with cooperation of the agencies, did a medical work-up of disabled 
persons and a psychosocial study of approximately four hundred families. These families were classified into five types and a family classification schedule was the primary tool used for diagnosis, treatment, prognosis and evaluation. This project was in operation from January, 1955, to December, $1957 .^{8}$

The San Mateo, California, preliminary study was initiated in January, 1954, and in focusing on the area of maladjustment it was found that serious maladjustment existed in a small percentage of the families, especially those with children under age eighteen. The project implementing this study attempted to discover whether prevention and control in a disturbed area of social functioning could be achieved and by what means (i.e., services) it could be achieved. Community Research Associates suggested that in epidemiological analysis the important factor is to determine what therapeutic service was being rendered with the intention of either intervening to prevent further deterioration or rehabilitating to a higher level of social functioning. 9

The families were classified according to their potential for rehabilitation and also on their degree of deviation from the "normal family." The categories were:

(1) the anxiety-ridden family, (2) the socially ineffective and unstable family, (3) the parentally irresponsible family, and (4) the non-conforming, hostile family. 10

Cases were first diagnosed and a prognosis was then made as to whether the case would "improve," "not change," or "deteriorate." This prognosis was made to indicate the potential for rehabilitation and the levels of casework skills and resources needed for rehabilitation. A schedule was employed as a tool and guide to increase professional skill 
and a periodic evaluation served as a check of the effectiveness of the processes used in this project. ${ }^{11}$ Even so, new tools may be needed if the profession is to answer the question raised by Bradley Buell, Director of Community Research Associates: "Can social welfare prevent, reduce, control problems of persons who fall below the standard our society believes essential to the maintenance of our social and economic way of life?" Continuing, he adds,

The constructive and rehabilitative services of our social service still remains obscure. Moreover, scientific and professional integrity of social welfare is at issue. The evidence that services produce results must be produced both to satisfy the public and to maintain the self-respect of social welfare. 12

Buell stated that differential case classification and assignment:

. . simply means that agencies should classify their caseload by relative potentialities for rehabilitation or prevention and the levels of social service required to meet this goal. Following this, cases should be assigned so that the general professional capacity of the workers and the size of their caseloads correspond, as realistically as possible within the resources of the agency, to the treatment required.13

The next section of this chapter describes other projects which were undertaken in various cities throughout the United States. Although these projects were not conducted by Community Research Associates, the CRA projects may have been a motivating factor in the development of other research. These independent studies and projects were also concerned with defining problem-areas and in giving more effective service to clients with multiple problems.

The Marin County, California, Public Assistance Department in 1956 developed a project to evaluate objectively the effects of employing 
trained caseworkers and reducing caseload size in service to multiproblem families. The project examined statistical and financial trends and the effects on families who were receiving Aid to Needy Children or General Relief when casework services are provided as part of the assistance program. Using a sample of ninety-nine families who were active cases, a caseload of twenty-four multiproblem families was assigned to one worker. The purpose was to concentrate on analysis and solution of the problems of these families and to relieve the rest of the casework staff from the pressures of these families. During the six-month period of study and diagnosis some families responded favorably to the worker's interest and casework service. In summary, some of the implications for family-centered services revealed by the Marin Project are:

(1) Public assistance without services is expensive and for many families is destructive.

(2) Documented material can be used to interpret the real problems of those seeking financial help.

(3) Casework skill is an important and productive tool in the assistance process.

(4) Public welfare administration needs to re-evaluate its processes to better meet the demands made on it by a changed caseload composition. 14

In Michigan, the State Department of Social Welfare and the University of Michigan School of Social Work undertook an experimental project of inservice training for a selected group of workers with Aid to Dependent Children caseloads. Purpose of the project was to assess the effectiveness of training and the effect of reduced caseloads. A secondary objective was to learn more about how to improve services beyond determining eligibility for financial assistance. 15 
The experimental project took place over a three-and-a-half-month period from February, 1957, to May, 1957. There were three groups of caseworkers participating: (1) the Training Group, consisting of eight workers, carrying fifty ADC cases each, meeting four hours per week for in-service training; (2) the Control Group of seven workers, carrying fifty ADC cases each, with no in-service training program; and (3) the "As-Is" Group, consisting of five workers, carrying fifty-three ADC cases, seventy-two 01d Age Assistance cases, five Aid to the Permanently and Totally Disabled cases, two Blind Aid cases and a normal flow of applications. 16

The findings showed that workers with training appropriately took advantage of opportunities to reassure the client; training also seemed to improve the diagnostic acuity of workers. The findings indicated no conclusions regarding the effect of reduced caseloads except the most obvious: reduced caseloads gave workers more time to work with clients. It was concluded that more research was needed since the many variables affecting changes in clients make the evaluation of the effects of in-service training and reduced caseloads more complex than was supposed. 17

A project conducted by the California State Department of Social Welfare was focused on testing method and skill of casework in a selected caseload. Setting for the project was the district office of the Contra Costa County Social Service Department. A sample of twenty-seven cases from the Aid to Needy Children program was selected. In each case there was an incapacitated father; selection was based on the feeling that the father's illness was to some degree emotional in origin. The 
project which lasted for twelve weeks was conceived as an experiment to test whether or not professional social casework method and skill applied to a group of chronic public assistance cases could show apparent results within a limited period of time. The researcher hypothesized that the men were dissatisfied with their situations, wanted to change them, and had the capacity to change if the caseworker had the skill and time to help them. Casework was focused on the meaning of incapacity to each man and on the feeling behind his behavior. The conclusions were that the clients in this project showed a limited restoration to earning power in relation to where each one was at the beginning of the experiment; and that results would have been better if the project had lasted six months instead of three. ${ }^{18}$ Moreover, some implications ware noted for casework service in a public welfare agency. The researcher states that:

. . it is the responsibility of public welfare agencies to utilize social casework skill. Such utilization means sufficient salaries, caseloads selected on the basis of clients' need for casework service, and reduced loads to allow time for casework service to be given. If a better job of evaluating casework can be done in public assistance, better use can be made of personnel. Selected caseloads in which clients are evidencing obvious emotional conflicts should be assigned to professionally trained caseworkers who can be allowed some choice in their selection of cases.19

The Pennsylvania State Rehabilitation Committee had found four major impediments to rendering rehabilitation services to clients:

(1) absence of clearly defined agency objectives or responsibility in this area; (2) work load size; (3) lack of necessary staff consultants, such as physicians and psychiatrists; (4) administrative and supervisory failure to hold caseworkers as accountable...20 
In April, 1957, the Philadelphia County Board of Assistance initiated an experimental project with the purpose of providing improved services to clients and developing principles of working which could be useful to the entire casework staff. Focus of the demonstration project was on the areas of employment, self-care and family relationships. In addition, particular attention was paid to three common problems: physical illness, mental illness and adolescence. Caseload size was set at thirtyfour cases per worker; a unit of four workers and a supervisor was set up to provide intensive service. The first year's operation of this experimental project with a selected group of Aid to Dependent Children families was largely exploratory. Nevertheless, the project experience emphasized (a) the importance of focusing caseworkers' efforts on the total family situation, (b) the necessity for identifying the many and diverse problems of the family, (3) the feasibility of concentrating intensive casework services on family problems, and (d) the importance of community understanding and participation in treatment of family problems in helping families attain self-support, self-care and/or maintain and strengthen family life. ${ }^{21}$

The Arizona public welfare department set up a case classification system in 1961. Case classification systems were described by Virginia L. Tannar who stated:

A case classification system has for its purpose a more effective use of time, staff and skills so that priorities may be directly related to the agency's responsibility for service. Many public welfare agencies are now engaged in developing some such system. Some are working out more complex forms of case classification; others are using a simple coding such as: no significant problems, moderate problems, severe problems. 22 
The Arizona public welfare classifies into the following categories:

Category One contains cases with a serious problem of health, housing or school attendance; clients have a high potential for return to self-support.

Category Two contains cases that require intermittent service because of emergency or changing situations, but for which the worker does not plan to initiate contact for service beyond the requirements for review.

Category Three contains cases that need only minimum service.

The value and usefulness of this plan to the staff is supported by Miss Tannar, who said:

Without a case classification plan and its import for expectations of performance by individual workers it is difficult to convey to the staff what they are supposed to do and to identify what they are to learn in order to do it. 23

\section{Literature}

The St. Paul study and follow-up projects of Community Research Associates mentioned in preceding pages provided the data for the text, Family Casework Diagnosis, in which types of multiproblem families were identified and classified. $^{24}$ Because services to these families were not coordinated, community organizations failed to prevent or control the multiple problems of these families. After the findings of the initial study were published in 1952, a pilot study, using a random sampling of these multiproblem families, was begun to determine whether a clinically useful hypothesis could be developed for family diagnosis. The prelimInary findings were termed "provocative and suggestive."

In 1953 a second project, financed by the Louis W. and Maud Hill Family Foundation of St. Paul, was launched to establish a framework for 
family diagnosis. Data were assembled from seven voluntary family service agencies located in Brooklyn, New York; Cincinnati and Columbus, Ohio; St. Louis, Missouri; Washington, D. C.; Milwaukee, Wisconsin; and St. Paul, Minnesota.

The specific objective of this research was the development of a diagnostic classification system which identified disordered family types. The diagnostic framework included both normal and pathological functioning and made a distinction in disordered behavior which is not of community concern. Family classifications were of four types: (a) the perfectionistic family, (b) the egocentric family, (c) the inadequate family, and (d) the unsocial family.

Casework prognosis is the prediction of the changes expected in the status of classified families: the expectation for "improvement," "deterioration" or "no change." "Levels of social service" is used to denote type of treatment program appropriate to a case:

Level One calls for the most skilled casework staff available, those able to deal with severe problem cases in which prediction for improvement is good.

Level Two calls for supportive method of treatment, such as direct intervention, information, advice and guidance.

Level Three casework service entails mainly financial assistance and problems which either do not affect social functioning or are not amenable to treatment. ${ }^{25}$

To date, the testing of the family classification system has been confined mainly to Community Research Associates projects. Their approaches were first applied in the three public welfare demonstration projects in San Mateo, Winona and Washington County (described earlier in this chapter) on a total of eight hundred and seventy-two families. 
More recently they were applied in a study of the Hartley-Salmon Child Guidance Clinic in Hartford, Connecticut. In each, their use produced results which, according to Voiland, were diagnostically consistent with what was known about the family. The framework for family diagnosis and the classification of psychosocial disorders has been adapted with success in public welfare departments of Pennsylvania and Minnesota and of Omaha and San Francisco. 26

Voiland's book received two notable critical reviews. Henry Maas criticized it for showing a lack of sound knowledge of family functioning, a lack of soundness in research reporting, scant evidence of the purposes of classification, and for what he termed "inconsistent, illogical, poor style." 27 This critic questioned the description of "a healthy family" which makes little allowance for social class differences and none for ethnic differences nor for change in current times. According to Maas,

The assumptions and knowledge basic to this book on family diagnosis remain essentially in the realm of individual psychology. There is little evidence of the author's awareness of family psychological or sociological concepts and insufficient evidence of notable differences between the four family types. 28

An essay review by Nathan Ackerman described Miss Voiland's work as:

Highly controversial; an earnest effort but contradictory evidence was used. Method of gathering data was unsound because it was based on individual interviews, not whole family observations ... The crux of Voiland's problem was faulty conceptualization and method of study. However, it is an important book because it is one of the first attempts to classify family types. 29

In a rebuttal in a later issue of the same journal, Voiland does not agree that to understand family functioning the whole family has to be 
observed together, but she is in agreement about the enormity of the problem of classifying family types. ${ }^{30}$

In a paper presented in 1961 at the National Conference on Social Welfare, Werner Boehm discussed the diagnostic categories in social casework and enumerated five criteria of a classification system.

It should be based on and grow from an explicit statement of the philosophy and theory of social casework. It should embrace all problems with which casework deals and it should be concerned with casework as a whole rather than with any of its phases. It should cover both diagnosis and treatment and in so doing focus on the relationship between worker and client as well as the worker's activities affected as they are by the worker's various roles and obligations. 31

He also states that he feels that the classification of disordered family types proposed by Community Research Associates has a great advantage in that it is problem focused rather than service focused and that focusing is on the family functioning as a unit.

On the other hand, the Community Research Associates classification system is criticized by Lukoff and Mencher who take issue with the theoretical structure and concepts used. For instance, the concept of prevention is used in a limited sense of prevention of further breakdown after the onset of symptoms. According to Lukoff and Mencher, service in a community cannot be organized exclusively on a preventive basis. The concept of a diagnostic system based on grouping families according to the degree of psychological disorientation is a disservice to the client and too difficult a scheme for use by a staff. According to the authors the system "is too family centered." They also state that Community Research Associates makes the assumption that by focusing on "problem families" with community service, the social problems in our 
society can be cured. The identified families are merely the obvious carriers of the social diseases and problems prevalent in society. 32

That diagnostic classifications have many values is discussed in detail by Samuel Finestone in a paper presented in 1960 at the National Conference on Social Welfare. He points out that, besides helping to make social work practice more effective, diagnostic classifications stimulate systematic theory building. However, a case classification system cannot be any better than existing theory. Classification itself is a form of theory building. According to the author, In the process of classification construction, it is necessary to explicate assumptions and to refine and systematize them; it is also necessary to identify gaps and issues in current knowledge and to point the way to further development or reformulation of theory. 33

However, as previously stated, Werner Boehm has suggested that:

The fundamental question in relation to diagnostic categories is: What is the nature of social casework, what are its goals, what are the theoretical and philosophical premises upon which casework rests? ${ }^{34}$

He speculates that it might be best to postpone the development of a classification system until an explicit statement of the concepts of casework and the assumptions about the nature of casework have been developed. However, he accepts the idea that it is unlikely that consenses about theory will ever be achieved and that the development of research and the evolvement of classification systems will continue.

\section{Summary}

The studies, projects and literature which have been reviewed in 
this chapter have dealt with methods or systems which were developed to classify cases or families. The marked similarity of some of the community projects to the initial St. Paul project indicates either some direct influence by the St. Paul project or an unrelated, independent effort by an agency to achieve better diagnosis of problem areas and more strategic use of staff in providing services to clients.

The initial St. Paul study and project and the follow-up projects under the auspices of Community Research Associates were described because of their direct impact on other communities in general, and on the Oregon Program in particular. Interest of the administration of the Oregon Public Welfare Commission in the Community Research Associates projects led to the development of the Case Planning Schedule used in the agency of study, and this Schedule will be described in the next chapter.

Review of the 1iterature included a description of the framework for family casework diagnosis developed from the Community Research projects. Despite criticism by some writers this framework has been accepted by several agencies as a casework tool and is used as a model by which some agencies have developed their own original classification tool.

Divergent viewpoints regarding case classification were found in the 1iterature. Some writers recognized the task of formulating a case classification system as difficult, but the need for a system is widely accepted. There was some speculation in the literature about whether case classification should be postponed until the advent of more adequate theory on which to base the classification system. Critics of the 
Community Research Associates approach have objected to the familycentered approach and the theoretical structure and concepts used, particularly the limited use of the concept of prevention. Classification systems were viewed by writers as being both premature and as a step in theory building.

This chapter has identified some of the existing systems and has described their development. It has been suggested that judgment of these systems should be held in abeyance until it can be determined whether their use results in better casework services to clients, one of the reasons for their development. In the meantime, these systems should be examined and their use studied in order that their effectiveness as a casework tool can be determined. Through such examination it may be possible to refine the systems and contribute knowledge which will help in their implementation.

The Oregon Program, which this study examined, had some similarities and some dissimilarities to the projects which were reviewed. The Oregon Program was considered to be a "systematized approach to providing social services . . The case classification system as instituted in Oregon involved a problem-solving approach and placed emphasis on the family as the basic unit for casework help." 35 Problems were identified through use of the Schedule. But the Oregon Program did not identify or categorize specific family types as did some of the projects which were reviewed. It did classify cases according to level of service needed as was done in the Community Research Associates projects and others. The Oregon Program was similar to Community Research Associates projects in 
its use of a Schedule, but it was dissimilar from the short-range experimental projects under review since it was a long-range program being implemented throughout the Oregon Public Welfare administration.

In Oregon, as was demonstrated in other communities which undertook projects, there was an evolvement of plans and experimental projects growing out of administrative concern about giving increasing casework service to families. Public concern over accountability for public funds paralleled the postwar increase in numbers of welfare clients, especially in the Aid to Dependent Children program. This concern over accountability led to a sharp increase in the number of forms, procedures and instructions necessary to render welfare services and, at the same time, reduced the time which could be spent in giving casework service to clients.

The Oregon Program for Case Classification and Planning was one of the systems designed to assist caseworkers in offering help to families to enable them to live more fully and usefully. Like other social welfare agencies, Oregon Public Welfare was committed to principles and values of the social work profession and the guarantees in the Social Security Act and its amendments. 
Chapter References:

1Walton, Eloise, "Let's Work Together in Community Service," Public Affairs Pamphlet, No. 194 (April, 1953), pp. 1-28.

2 Overton, Alice, and Associates, Casework Notebook, second edition, Family Centered Project, 1959, St. Paul, Minnesota (Community Chest and Councils, Inc.), p. 6 .

3 Buel1, Bradley, and Associates, Community Planning for Human Services (New York: Columbia University Press, 1952).

${ }^{4}$ Walton, 1oc. cit.

SBirt, Charles J., "Family-Centered Project of St. Paul," Social Work, Vo1. 1, No. 4 (October, 1956), pp. 41-47.

6 Bue11, Bradley, "Preventing and Controlling Disordered Behavior A Community Experiment," Mental Hygiene, Vol. 39, No. 3 (July, 1955), pp. 365-375.

7

Community Research Associates, Inc., The Prevention of Dependency in Winona County, Minnesota (New York: Community Research Associates, Inc., July, 1953), pp. 53-56.

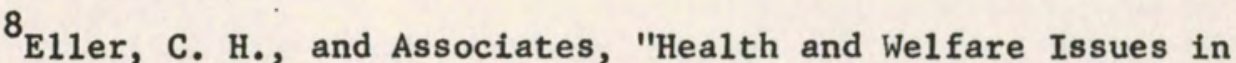
Community Planning for the Problem of Indigent Disability," American Journal of Public Health, Vol. 48, No. 11, Supplement (November, 1958), pp. 1-49.

9 Bue11, Bradley, and Associates, "Reorganizing to Prevent and Control Disordered Behavior," Mental Hygiene, Vo1. 42, No. 2 (April, 1958), pp. 155-194.

${ }^{10}$ Ibid., p. 171.

${ }^{11}$ Ibid., pp. 173-174.

12 Bue11, Bradley, Is Prevention Possible? An address presented at the 86th Annual Forum of the National Conference on Social Welfare, San Francisco, California, May 25, 1959 (published by CRA, Inc., New York, 1959).

13

Ibid., p. 18.

${ }^{14}$ Presley, Betty L., "Marin Project Speech," Welfare News (September, 1958), p. 5. 
${ }^{15}$ Thomas, Edwin J, and McLeod, Donna L., The Effectiveness of InService Training and of Reduced Workloads in Aid to Dependent Children, A Report of an Experiment Conducted in Michigan, U. of Michigan School of Social Work (August, 1957), p. 59.

16 Thomas, Edwin J. and McLeod, Donna L., "A Research Evaluation of In-Service Training and of Reduced Workloads in Aid to Dependent Children," Public Welfare, Vol. 16, No. 2 (Apri1, 1958), pp. 109-112.

${ }^{17}$ Ibid., pp. 132-134.

${ }^{18}$ Wiltse, Kermit T., Social Casework in Public Assistance, State of California Department of Social Welfare (1961), pp. 1-35.

${ }^{19}$ Ibid., p. 34 .

${ }^{20}$ Philadelphia County Board of Assistance, The Philadelphia Rehabilitation Unit (December, 1958), p. 1.

${ }^{21}$ Toward Family Renewal, Annual Report, Philadelphia County Board of Assistance (1958).

22 Tannar, Virginia L., "The Public Welfare Worker in Family Crisis," The Social Welfare Forum, 1962 (New York: Columbia University Press, 1962), pp. 202-214.

23

Ibid., p. 208.

${ }^{24}$ Voiland, Alice and Associates, Family Casework Diagnosis (New YorkLondon: Columbia University Press, 1962), Chap. 11.

25

Ibid.

${ }^{26}$ Ibid., pp. $20-21$.

27 Maas, Henry S., "Family Casework Diagnosis: An Essay Review," Social Service Review, Vol. 36, No. 4 (December, 1962), pp. 444-450.

${ }^{28}$ Ibid., p. 446.

${ }^{29}$ Ackerman, Nathan, "Diagnosing Family Functioning," Children, Vol. 10, No. 3 (May-June, 1963), pp. 116-118.

${ }^{30}$ Bue11, Alice Voiland, "Family Casework Diagnosis - An Interpretation," Children, Vol. 10, No. 4 (July-August, 1963), p. 163.

$31_{\text {Boehm, Werner W., Diagnostic Categories in Social Casework: Problems }}$ and Prospects, a paper presented at the 89 th Annual Forum, National Conference on Social Welfare, New Yorik, May, 1961. 
${ }^{32}$ Lukoff, Irving F., and Mencher, Samuel, "A Critique of the Conceptual Foundation of Community Research Associates," Social Service Review, Vol. 36, No. 4 (December, 1962), pp. 433-443.

${ }^{33}$ Finestone, Samuel, "Issues Involved in Developing Diagnostic Classifications for Casework," Casework Papers, 1960 (New York: National Conference on Social Welfare, 1960).

${ }^{34}$ Boehm, op. cit., p. 9.

${ }^{35}$ Oregon State Public Welfare Commission, The Oregon Program for Case Classification and Planning Handbook (Salem, Oregon, July, 1963), pp. 2-3. 


\section{CHAPTER III}

THE AGENCY AND THE OREGON PROGRAM

This chapter will present relevant information concerning the structure-function of the agency and historical development of the program within which the research study was conducted.

\section{The Community}

The study was conducted within the framework of the Multnomah County Public Welfare Commission. The Multnomah County agency provided public welfare services to an area which was relatively small geographically but was a densely populated urban center. It contained the city of Portland which was Oregon's only large metropolitan area. The 1960 Census revealed a population in Multnomah County of 522,813 of which 372,616 resided within the Portland city limits. ${ }^{1}$ In addition, a significantly large number of persons lived within that part of the metropolitan area outside of the city limits but within Multnomah County. The city was located in the western part of the county and population became more sparse in an easterly direction.

Portland served as the economic center for Oregon. The state's economy was largely based on lumbering and wood products and, to a lesser extent, on agriculture. This was reflected in the city's economy as its ". . manufacturing employment is concentrated in lumber-furniture- 
wood products, food products, other non-durable goods (mainly pulp and paper and primary metals)." 2 The major commercial center of the area was in downtown Portland, while the industrial areas were located inside and just north of the city.

\section{The Agency}

The Multnomah County Public Welfare Commission functioned within the structure of the Oregon State Public Welfare Commission which was an agency of the State of Oregon and a part of the state government operation. The state agency was controlled by a commission which met monthly and was composed of unpaid members appointed by the governor. The operational head of the agency was the state administrator who maintained an administrative and supervisory function. The state office, located in Salem, functioned as a policy-making and supervisory body. Like most public agencies, the State Public Welfare agency was governed in formulation of policy by available funds, as well as by legislative controls and, to some extent, by public opinion.

Operationally, the implementation of policy through dispersal of welfare funds and services was accomplished through sub-units functioning in each county. These were known as County Welfare Commissions and, organizationally, presented the appearance of autonomous operation. Each county agency had its own commission, administrator, professional and clerical staff. In actuality, however, these county agencies were units of the state agency and were under its direct control. All personnel were employed by the state and were covered by the state Civil Service system. The county commissioners made decisions within the framework 
of state policy. Major policy development was accomplished and implemented within the county agency under the control and supervision of the state office through a field representative. The political structure of the locality in which the county agency was located contributed a portion of the welfare funds distributed in that area.

The Multnomah County agency was somewhat unique in the state system. As it served the city of Portland and a good deal of its metropolitan area, the agency was more than three times as large as any other county agency. The agency caseload consisted of about one-third of the total state caseload. ${ }^{3}$

The problems presented by the majority of the agency's clients were those of life in an urban area. That proportion of the agency caseload which consisted of clients living in a rural setting was low. Caseworkers were confronted with urban problems such as inadequate and congested housing, confinement of a minority group to a limited geographical area, a congested "skid row" area with a high incidence of alcoholism and other conditions that tend to exist in large urban areas. Much of the employment available to non-skilled laborers tended to be seasonal. There was little farm work available to take up the slack except for a few brief weeks during harvest, and few persons who might have been expected to avail themselves of this temporary work had adequate experience in crop work to earn sufficient money to meet even basic needs. Competition for available urban non-skilled employment in construction and industry was high. The divorce rate was high and the percentage of single-parent families in the total public welfare caseload was increasing. 
The characteristics of the Multnomah County agency's caseload were somewhat different from other areas of the state which dealt with a greater proportion of rural problems. It was sometimes difficult for state policies to fit the particular situation in Multnomah County.

The structural organization of the agency was similar to most social agencies in that it was a pyramidic structure based on persons at a particular level being supervised by individuals on the level Immediately above. Administrative personnel tended to have a dual function: administration of an area of operation and supervision of the persons next lower to them in the organizational structure. Communication flowed vertically, generally passing through several structural levels before reaching those for whom it was intended. The flow downward tended to be more effective than that which originated on a lower level and proceeded upward.

The agency was administered by the county administrator who held a state Civil Service position. The Multnomah County agency, because of its large size, also had an assistant administrator. At the time of data collection the administrative function of supervision of various functional areas was divided between these two positions. The administrator maintained ultimate responsibility for all areas and had retained direct supervision of the "business services" operation, such as personnel, office management, central filing, clerical services and similar functions. Supervisors of these areas were directly supervised by the administrator. Supervision of the social service areas of operation had been delegated to the assistant administrator. These areas, providing and dispensing 
financial assistance and related casework services, had been divided into various departments dictated in part by the characteristics of the clients with whom they worked.

At the time of the study the Departments of Family Services handled cases of public assistance families with children. There were two of these departments, Family Services A and B, with a departmental supervisor for each. Within each department the organizational structure was divided into supervisory units of several caseworkers under each casework supervisor. Since the implementation of the Program for Case Classification and Planning, these supervisory units were structured in accordance with the classification of cases. Within Family Services "A" there was one Intensive Services unit (five Intensive Service caseloads), one Environmental Services unit (eight E. S. caseloads) and four Regular Services units (eight caseloads each). The student field instruction unit was also in this department for supervisory control. Family Services "B" contained one Intensive, one Environmental and one Regular Services unit. In addition, the public assistance Intake and Reception unit was included in this department. In the channel of supervision between the assistant administrator and the departmental supervisors of Family Services A and B was the program supervisor of ADC and Public Assistance Children's Services. This person served to coordinate the activities of the two departments.

The Department of Adult Services handled public assistance cases consisting of adult families only. It contained four Regular Service supervisory units, one Environmental Service unit and one Intensive 
Service caseload which was assigned to the E. S. unit for supervisory purposes. In this department also was a caseworker who was developing a program of foster care for the aged.

The Department of Special Services contained a variety of separate functions which appeared to have little relationship to each other but were grouped together for purposes of control and supervision. These functions were: The Congregate Care Unit (nursing home caseloads), Homemaker Services, The Abundant Foods Program and Medical Assistance for the Aged Program.

The Children's Department provided child welfare services, including foster care, adoptions and protective services to children. This department had existed as a somewhat separate entity and was somewhat autonomous as it maintained its own intake services and received a certain amount of separate supervision directly from the state office through the child welfare field representative. The separation between the Children's Department and the several public assistance departments extended to the state and federal levels creating a partial barrier to ease of communication between these two Public Welfare functions. The Children's Department and the Department of Special Services were not involved in this research project as cases carried by these parts of the agency had not yet been included in the Oregon Program for Case Classification and Planning.

The caseworkers have the basic responsibility of implementing established agency function through provision of financial assistance and social work services. ${ }^{4}$ These persons were considered by the 
agency and by persons outside the agency as social workers. Less than one percent (in the Multnomah County agency) had professional education in a school of social work. The job requirement, as established by the State Civil Service Commission in consultation with the State Public Welfare Commission personnel, called for a minimum of an underrraduate degree from an accredited college or university. Emphasis was placed on specialization in sociology or psychology, but this had not been considered mandatory and persons were frequently hired with backgrounds in such seemingly non-related fields as chemistry, agriculture and art. Applicants for the position of Caseworker I were expected to pass a Civil Service examination for that position, but this examination had not tended to be a major obstacle to any otherwise qualified person interested in employment as a Public Welfare caseworker. The starting salary was lower than for casework positions in other social agencies and for other professions which initially require an undergraduate degree only.

Newly employed caseworkers were required to attend a course of four week's duration at the Orientation Center, located in Oregon City. This course was conducted by a small staff of professionally educated social workers under the direction of the Staff Development Division of the state office. It consisted of introduction to basic principles of social work and orientation to the policies, procedures and practices of the State Welfare Commission. At that time only a brief orientation to the program was given and new workers were expected to obtain more specific information from the supervisory staff in the county to which they were assigned. 
Positions in the agency above that of caseworker generally required graduate training; however, the agency had been unable to attract sufficiently trained personnel to fill these jobs. There were, therefore, many persons occupying supervisory positions who did not fulfill job specifications. In addition, in the Multnomah County agency several experienced supervisors were on educational leave. Other persons were temporarily filling these positions who had no prior supervisory experience. These replacement supervisors were participating, however, in the Supervisory Trainee Program conducted by the state office in which they were receiving training in supervision, in addition to their onthe-job experience.

During the year preceding the collection of data for the study there were a series of alterations and additions to the structure and functioning of the Multnomah County agency which affected personnel at various levels in the hierarchy.

Prior to September, 1962, the public assistance function of the agency was physically separated into district offices, each serving a geographical area of the county. During September and October, 1962, all separate offices were consolidated into a single building and the structure was reorganized into departments of specialized function (i.e., Family Services, Adult Services, Intake) rather than by geographical location. Many, if not most, caseloads were shifted and reorganized. Also, the normal office routine was disrupted and reformed on a somewhat different basis. For instance, case files which had been readily accessible to caseworkers in the district offices were now filed centrally and had to be requested in advance. The physical surroundings 
were different. Caseworkers often had different supervisors and sat next to other workers whom they did not know. Less space was available for each desk and the lounge area was overcrowded during the lunch hour and coffee breaks. The structure tended to be larger and more impersonal than the smaller district offices had been.

During the first three months of 1963 a statewide review was made of Aid to Dependent Children cases as requested by the federal government. In excess of a hundred $A D C$ cases from Multnomah County were sent to the state office for review and were unavailable to the caseworkers during that time. Many irregularities, some of them minor, were found and workers were required to correct these and report their actions to the state office. This was a major work disruption.

Also involving the ADC program, and, apparently as a result of the above-mentioned review, was a State Commission decision to require a review of financial eligibility of $A D C$ cases every six months when it had previously been required annually. This procedure required additional work at the casework level.

During July, 1963, the State Commission passed a ruling that ADC grants issued to families based on the unemployment of the head of the household would be closed if there was seasonal work available within a fifty-mile radius. This required the immediate closure of about 400 cases in Multnomah County. The result was an added work load on caseworkers carrying these cases and an emotional strain of dealing with the families who found that their income was suddenly stopped. During the 1963 session of the Oregon State Legislature the submitted budget of the State Public Welfare Commission for the succeeding 
biennium was passed with very little change. Included in this budget were the provision for an expansion of the casework staff and appropriation of additional funds for expansion of agency operation. The legislature also passed an increase in state income taxes. This tax increase was submitted to the voting public by referendum petition and was defeated, causing the Welfare Commission to adopt various emergency reductions in fund expenditures in order to comply with reductions ordered by the governor's office. These procedures, and many rumors of additional reductions including possible elimination of staff positions or salary decreases, were a topic of much concern to all levels of agency personnel.

As discussed above, legislative action granted the Welfare Commission a substantial increase in casework staff positions, partly to cover the steadily increasing caseload and partially to accommodate the limited caseloads of the case classification Program. Many of these new staff members were assigned to Multnomah County in one large group at a point in time before the initial reassignment of caseloads following classification of the agency's cases had been accomplished. This also occurred just prior to several casework supervisors leaving the agency on educational 1eave. As a result there was a group of inexperienced caseworkers without established caseload assignments being supervised by inexperienced supervisors. In addition, the arrival of these new workers created further space problems in an already overcrowded building.

A final factor which should be considered was the resignation of the county administrator in November, 1963, and a subsequent period 
during which the identity of his successor was not known to the staff. The former assistant administrator was then appointed as administrator. He was well known to the staff, but the nature and extent of operational and structural change which would arise from this change in administration remained unclear at the time the data were collected.

Thus it was apparent that the Multnomah County agency experienced several conditions which were beyond the normal agency routine in addition to the initial implementation of the case classification Program which itself caused considerable reorientation of staff procedure. It could be assumed that these factors occurring nearly simultaneously could create conditions of continual flux which were conducive to added emotional tension among staff members. It was recognized that the existence of this flux could have a definite effect on the implementation of the case classification Program and staff attitudes toward it. Among other factors, the lack of structural and functional stability could have created or widened an attitudinal split between case classification in theory and in operation. Another possibility was that the staff could have regarded the Program, not as an aid to more effective functioning, but as an additional work requirement imposed upon them by administrative authority.

\section{Development of the Case Classification Program in Oregon 5}

Antecedents of the case classification Program in Oregon were a variety of "demonstration projects" in Douglas, Jackson and Multnomah counties during the past fifteen years. In 1951 a project was conducted in the Peninsula District Office of the Multnomah County agency to 
explore the possibility that reduced caseloads would be more productive and would improve the quality of casework services. This was a demonstration project only, involving caseworkers in one supervisory unit. The results were not definitive, partially due to lack of standardized criteria for selection of cases to be placed in these reduced work loads. None of the various demonstration projects in Oregon became permanent programs, nor apparently did data derived from them have any significant effect on agency policy. They did, however, tend to reflect a new national and state interest in effective provision of casework services to public welfare recipients beyond providing public assistance.

During this same period there were projects and programs in operation in other parts of the United States, including the St. Paul Project involving work with multiproblem families, the Minnesota Project and programs in San Mateo and San Francisco Counties in California. These projects are reviewed in Chapter II in detail. Each of these programs involved a means of standardized diagnosis procedure and classification of cases into categories of the type and amount of service needed for prevention or rehabilitation.

A good deal of professional literature had been forthcoming from the above-mentioned areas which came to the attention of certain of the Multnomah County agency personnel, including Mr. Gordon Gilbertson, then assistant administrator, and Mr. Harold Miller, then the consultant on the Aid to Dependent Children Program and Children's Services.

Mr. Miller instituted an agency survey of Aid to Dependent Children families regarding the caseworkers' opinion of the types of social problems 
in existence and whether or not the family required casework services beyond financial help. At about the same time he began a series of staff development sessions in the Peninsula office on services to ADC families. Case examples were used to illustrate these services.

In March, 1960, Mr. Gerson Goldsmith, a state welfare commissioner, became acquainted with material from San Mateo County and evidenced a desire that the Oregon agency study these projects with the possibility of establishing a similar system in this state. The Commission passed a resolution requiring the state staff to make such a study. Shortly thereafter, the assistant state administrator met with the administration staff of the Multnomah County agency to ask them not to continue with local planning for a special program as there was a need to establish a program for the entire state.

In October, 1960, a regional conference of the American Public Welfare Association met in Portland. It was attended by $\mathrm{Mr}$. Leo Feider of the Minnesota Public Welfare Work Reorientation Project which had been developed with the help of Community Research Associates. He stayed in Oregon to discuss with the state and county staffs the nature of the Minnesota program.

As a result of this conference, the state administrator appointed a committee of four persons to study the results of various state projects. They considered material from San Mateo, California; Lake City, Indiana; Cleveland, Ohio, and other areas, as well as data from local Oregon demonstration projects. The committee recommended to the state administrator that there be no temporary demonstration project 
but that a workable system be developed and adopted on a statewide basis. It also recommended that a staff be appointed on a full-time basis to create and control this program of case classification as a committee would not be effective. These recommendations were accepted. Harold Miller joined the state office staff in February, 1961, to direct the Oregon Program for Case Classification and Planning. He maintained the primary responsibility for developing the Program and guiding its implementation in the various county agencies.

One of the major features of the Program was a Case Planning Schedule, a multi-page form which was to be completed by the caseworker. (See Appendix, page 115.) Development of this Schedule for use in Oregon created problems. The first attempt involved use of material from the Minnesota schedule, but it developed that this material had been protected by copyright issued to the Community Research Associates and could not be used. Because of this a different schedule was developed and was tested in Douglas and Multnomah Counties. It has been revised several times since its original development.

The Program was first implemented in Jackson County and the Peninsula office in Multnomah County in January, 1962. A series of staff training sessions were held concerning the rationale of the Program and the use of the Case Planning Schedule. Following this there was a period in which caseworkers completed a Schedule on active cases and classified them as to level of needed service based on the caseworker's judgment. After completion of scheduling, cases were reassigned to caseloads designed to provide the service needed. The two agencies 
completed the initial work by July, 1962, and the Program was in operation. The rest of the Multnomah County agency became involved from January to June, 1963. In July, 1963, the Program was extended to Lane, Linn, Benton, Clackamas, Washington and Yamhill Counties. The tentative date for completion of the initial phase of the Program on a statewide basis was set for July, 1965. During the 1963 session of the Oregon Legislature the State Public Welfare Commission was granted 130 new casework positions, the majority of which were intended to implement the operation of the case classification Program.

\section{Rationale of the Program}

The Oregon Program for Case Classification and Planning, like similar programs in other states, had been developed to aid the agency staff in providing more effective social services to its clientele. The Case Classification Handbook lists several factors which tend to be peculiar to the public agency:

(1) Public welfare agencies are multi-function agencies dealing with a full range of social problems rather than one or two specialized functions such as family counseling, adoption, child guidance, etc.

(2) Public agencies cannot control their intake of new cases but must "take on" all new clients who are legally eligible for assistance.

(3) Caseloads are large, prohibiting workers from devoting a great amount of time to exploring in depth the problems of each client.

(4) There is always (except in child welfare) the need for determining and reviewing financial eligibility which is an essential factor and must occupy a certain portion of the worker's time with the client. 
(5) Unlike most private agencies, the major proportion of public welfare workers are not trained on a graduate level and frequently have little experience in formulating meaningful diagnosis and treatment plans due to an inexact knowledge of human behavior and social functioning. 6

These factors were considered by the administrative staff of the agency to be inherent in the functioning of the agency and were not likely to be altered materially in the near future. It was felt that caseloads would continue to be large by present professional standards and that the agency would not be able to acquire a large professionally educated casework staff. Due to the disbursement of public funds, there would continue to be a requirement for continuous and time-consuming eligibility review. Thus, any plan for improving social services must take these factors into account.

The case classification Program was based on a standardized procedure for arriving at a diagnosis and plan for treatment of each active case through the use of a multi-page form known as the Case Planning Schedule. Page one served as a case record face sheet and was designed to identify members of the family group. Each of the following pages was intended to cover an area of family functioning (e.g., adult functioning, child functioning, health problems, financial functioning). Each of these pages had been designed so that the caseworker would first identify, by check marks, characteristics of various family members and problems that he had noted in this area. Finally on each page the worker described the goals that he had formulated and his treatment plans for reaching these goals.

The 1ast page of the form functioned as a summary of preceding 
pages. It required a summary statement of the diagnosis of the family situation, the goals of casework activity and plans for treatment. The worker was also asked to predict what changes may take place in the functioning of the family through casework activity.

At the end of the Schedule was an area for classification of the case intended to be the culmination of the diagnostic process. As a result of completing the Schedule on a particular family, the caseworker was expected to have sufficient information at hand to determine the type and intensity of treatment required to obtain significant improvement in the functioning of the family or to prevent further deterioration in functioning.

Cases are classified into one of three groups: Intensive Service, containing those families who manifest impaired functioning in more than one area and who reveal potential for improvement through intensive casework help; Environmental Service, including those whose major difficulty appears to be in adjustment to their surroundings without significant inner problems and for whom help in manipulating their environment would be required; Regular Service, encompassing those families whose social functioning indicates little impairment and, in some cases, families whose socially deviant patterns are so deeply ingrained that it would require a disproportionate amount of staff time and effort to accomplish a minor amount of improvement. 7

In classifying the family into one of these levels of needed service, the worker also indicated whether the situation, if this service was provided, would improve, maintain the present level of social functioning, or deteriorate in spite of the provision of casework services. This prediction covered the period of one year.

New or reopened cases were tentatively classified at the point of intake by the Intake worker who did not complete the entire Schedule, 
only the classification section and certain basic identifying information on the face sheet. The case was then assigned to a Unit worker who was expected to obtain sufficient information within a three-month period to complete the entire Schedule. The classification was changed if the diagnosis revealed that a different level of service would be required to help the family move toward a satisfactory adjustment.

Cases were reviewed periodically to assess movement toward the desired goals through application of the worker's treatment planning. This was done through the use of a one-page form called the Planning Review (See Appendix, Exhibit A, page 8) which tended to condense certain of the information contained in the Case Planning Schedule. The worker was required, through the use of coding, to indicate changes in problems in various areas of family functioning: those which no longer existed, those which continued to exist and new problems which had arisen during the period reviewed. He also indicated the progress of his treatment planning including any changes or alteration of goals and plans necessitated by case movement. This was supplemented with narrative recording in the case record. Intensive Service cases and Environmental Service cases were reviewed every six months and Regular Service annua11y.

The Case Planning Schedule was intended to focus the worker's attention along a specific channel of diagnostic thinking. It was rather general in identification of characteristics and problems and required the worker to write his own observations on strengths and weaknesses as well as his own specific goals and plans for treatment. The designers of the Schedule had indicated an awareness that the individual worker's 
judgment must be relied upon and that personality difference between individual workers was a variable which was only partially controlled by the use of the Schedule.

Organizational planning included the establishment of limited caseloads containing only cases which had been placed into a particular classification. Intensive Service caseloads were not to contain more than thirty-five units, Environmental loads not more than sixty and Regular Service a maximum of one hundred seventy-five. This protected limit tended to be more rigidly enforced for Intensive and Environmental loads. In cases of staff shortage the Regular loads often exceeded the imposed limit, containing cases of all three classifications until vacancies occurred in other loads.

At the time of the introduction of the case classification Program in a county, members of the State Case Classification Unit conducted a series of five weekly training sessions in the county office, each session lasting a half day. These sessions made use of group discussion and practical work to introduce the rationale and operating particulars of the Program to the county staff. Following these sessions the staff completed a Schedule on active cases in the county. This encompassed a period of three months during which time the normal work load continued with only minor alteration. This scheduling period in Multnomah County was reported to have been a time of stress for the casework and supervisory staff. The extent and results of this stress have not been evaluated except to recognize them as factors influencing current attitudes toward the Program. 
After the initial introduction of the Program there was no plan for orientation of new staff members other than that which was received in the previously mentioned Orientation Unit. The supervisory staff was expected to include information in the use of the Case Planning Schedule and other facets of the Program for the new worker.

The State Staff Development Department devised a program of staff training sessions to be offered to various county staffs periodically, covering certain social work concepts and tools, and the Multnomah County agency had participated in this at the time of the collection of data.

\section{$\underline{\text { Summary }}$}

Several factors have been discussed in this chapter which provided a background for the collection and evaluation of the research data. The Oregon Program for Case Classification and Planning was the State Welfare Commission's approach to a concept of formalization and standardization of case diagnosis and planning method becoming widely used by public welfare agencies across the country. The data which were collected involved the functioning of this program in a county welfare agency, one of many such agencies with the state system. It was determined that factors affecting this specific agency and its staff as well as the structure and function of the agency itself should be examined as having influence on the manner in which the case classification Program was implemented.

It has been pointed out that the Multnomah County agency was somewhat unique in the State Public Welfare structure in that it served 
the major metropolitan area and, as such, it was much larger and tended to be more structurally complex than other county agencies. Persons in the county administrative hierarchy tended to regard state policy as not always applicable to the needs of the urban recipient of public assistance. Data collection also revealed that the county agency experienced a series of situations during the preceding year which were outside the normal routine. The initial implementation of case classification itself was one innovation which caused a good deal of reorganization of procedure and could have had a pronounced influence on staff attitudes.

The history of the development of the case classification Program revealed that Multnomah County had been involved in development and testing from the earliest beginnings. The State Director of the Program was a member of the county staff during the early period of development. The feeling of the staff of being pioneers in the Program could have been a factor in acceptance and utilization of the Program.

Finally, the structure of the case classification Program, itself, required understanding and acceptance of the need for formulating a diagnosis and treatment plan for a case. Prior to the initial implementation of the Program the staff was oriented through a series of training sessions. The high rate of staff turnover and the addition of several new staff positions after these orientation sessions were held resulted in the composition of the casework and supervisory staff being somewhat different at the time of administering the questionnaire. Many of these people had not participated in the orientation sessions with resulting incomplete awareness of the intent of the Program and possible effect on their attitudes toward it. 
Chapter References:

${ }^{1}$ United States Bureau of Census, United States Census of Population, 1960, Number of Inhabitants, Oregon. Final Report PC (1)-39A (Washington, D.C.: U. S. Government Printing Office, 1961).

2 Interim Committee on Local Government, Portland Area Study, Staff Research Report No. 1 (July 13, 1956).

3 The publication Public Welfare in Oregon (November, 1963), published by the Oregon State Public Welfare Commission, indicated as of that month the Multnomah County agency was carrying 11,222 public assistance cases of a total state caseload of 29,061. For the same period Multnomah County was providing child welfare services to 2,406 children of a statewide total of 6,956 .

${ }^{4}$ Information obtained from the Personnel Department of the State Public Welfare Commission indicated that as of August, 1963, the Multnomah County agency was allocated a total of 191 casework positions of which 133 were public assistance caseworkers and 58 were child welfare workers. There were 18 public assistance supervisors and 9 child welfare supervisors.

${ }^{5}$ Information concerning the developmental history of the case classification Program in Oregon came primarily from interviews with Mr. Harold Miller, the Director of Case Classification, State Public Welfare Commission, Salem.

${ }^{6}$ Oregon State Public Welfare Commission, The Oregon Program for Case Classification and Planning Handbook (Salem: State Public Welfare Commission, 1963), p. 2 .

${ }^{7}$ Ibid., p. 3. 


\section{CHAPTER IV}

\section{METHODOLOGY}

A vital portion of the evolution of the group project was our communication with individuals and agencies actively involved in the Oregon case classification Program. There were approximately ten contacts with the Director of Case Classification of the Oregon Public Welfare Commission. His major responsibility had been to develop the Case Planning Schedule and establish the Program throughout the state. He helped organize group thought about the Program and assisted in tracing the relevance of the work done by Community Research Associates to the Oregon Program.

Additional meetings were held with the assistant administrator of the Multnomah County Public Welfare Commission. He was the major liaison and helped to utilize the facilities of the agency. He discussed problems that might be encountered in doing research and helped in planning the research group's work within the agency. By staying in close contact, it was hoped that we would be able to design a study which would ultimately be of use to the agency in examining its case classification Program.

Decisions in the group were arrived at as the result of discussions within the group which formed itself into a committee of the whole. The committee system was selected as the means of dividing the labor and 
responsibility in order to make the most efficient use of the individual talents of the group members. Major decisions were made in the committee of the whole and lesser decisions were left to the individual committees.

A system of specialized committee functions became the "modus operandi" to insure the greatest possible efficiency. The committees reported regularly at meetings of the total research group to insure communication and total participation of the group. All of the research students served on a number of different committees; this process enabled the students to become actively involved in different aspects of the project. It was found that despite our system of division of 1 abor much of the actual work involved everyone and represented a part of the educational process necessary for the understanding of the total project.

A pre-test was decided upon as a method of familiarizing the research group with the case classification Schedule, the agency, and to provide the individual student the opportunity to evaluate his own reactions and responses to the Schedule. The total group classified cases in the agency using the Schedule.

An additional purpose of the pre-test was to obtain data for the testing of null hypothesis I:

$\mathrm{H}_{\mathrm{O}}$ I. There are no significant differences in classifying cases with the Case Planning Schedule and without the Case Planning Schedule. Each of the twelve graduate students active in the study in April, 1963, classified four cases with the Case Planning Schedule into level of service; i.e., Intensive Service, Environmental Service, Regular Service. Predictions were also made of Improve, Maintain Level or Deteriorate. The members of the group classified independently using 
the information available in the case records. The cases classified with the Schedule, a total of twenty-four, were selected from Family Service units. As a result of pressures within the agency, the supervisors of two Family units selected twelve cases as they came across their desks, in the normal flow of agency work. The criteria by which these cases were selected were: (1) that they be active cases, (2) that they be Aid to Dependent Children cases with no children in substitute care, and (3) that they had received casework service since the Intake interviews. The cases were randomly assigned to the students.

The second group of cases used in testing this hypothesis was also selected by a staff member at the agency. Forty cases were selected out of the total active Aid to Dependent Children cases requiring reinvestigation in the month of January, 1964. The forty cases were selected using the same criteria as the first group of twenty-four cases. From these forty cases were selected ten cases, the first ten read and validated as fulfilling the criteria.

The ten cases were classified in October, 1963, by ten second-year graduate students of social work as Intensive Service, Environmental Service or Regular Service, and predictions were made of Improve, Maintain Level or Deteriorate without the use of the Case Planning Schedule. The current narrative record was used as the basis for the classification of the cases.

The data were then used to test whether there was a significant difference in the classifications and prognoses between the group that classified with the Case Planning Schedule and the group that classified 
without the Schedule. The results of the classifications of the first twenty-four cases were compared with the classifications of cases in the second group of ten. The statistic used in this instance was the Chi-square at two degrees of freedom and at the .05 level of significance. The results are stated in Chapter V, page 71 .

The second hypothesis conceptualized was:

$H_{0}$ II. There are no significant differences in classifying of cases by Intake workers and Unit workers.

In order to test this hypothesis it was decided to gather data from case records in the Multnomah County Welfare Commission. The plan was to make a comparison between the tentative classification at Intake and the subsequent formal classification by caseworkers in the various departments.

The universe selected included all new cases opened in the Intake Department of the agency in which an application was made for a Social Security grant between March 1, 1963, and July 31, 1963. New cases were chosen for study as a control over information available to the Intake worker. Reopened cases and cases transferred into the agency were excluded as it appeared that the wide range of information avallable in them would bias the classification of cases under study. Cases in which Social Security grants were involved were chosen because they were the only cases in which the Intake worker used the case classification Schedule. March 1, 1963, was selected as a starting point because Intake workers started implementing the Program just prior to this time. The five-month range appeared to cover a long enough span of time to give the students a representative group of cases to study. 
Cases after July 31, 1963, were not considered, as major changes took place in the Intake Department in August, 1963.

From the five hundred and twenty-five cases in the universe a systematic sample was selected. The one hundred and eighty-five cases in the sample were listed by case number and by case name. The cases were then taken from the agency file and inspected by the research group. The classification by the Intake worker into Intensive Service, Environmental Service, or Regular Service, and Improve, Maintain Level or Deteriorate was noted and the case record was inspected for re-evaluation and classification by the caseworkers in the agency outside of the Intake Department (Unit caseworkers).

The form used by the Unit caseworker to record classification was "Page 7." If "Page 7" did not indicate the classification decision of the Unit caseworker, the narrative recording was read for indication of the caseworker's evaluation. Only cases that recorded classification on "Page 7," "Page 8 " or in the narrative recording were considered in this analysis.

It was found that only twelve cases out of the sample of one hundred and eighty-five had been classified by both the Intake worker and the Unit caseworker. Of the twelve, ten retained the same classification and two were changed by the Unit caseworker. There were three major reasons that the cases were not classified by both Intake and Unit caseworkers. A large number of cases were nursing home placements and as an agency policy were not to be classified. Cases closed at Intake or shortly after being assigned to a unit further cut down the number of cases to be reclassified. Of the fifty-one cases that should have been 
classified by the Unit caseworkers, thirty-nine had not been recorded in the case record.

This hypothesis could not be tested because of the limitation of data available.

In the course of this study the tabulations were done as the data were collected. No special committee was formulated as an effort was made to involve all of the group in tabulation and/or verification of tabulations.

The statistics committee members structured the raw data and analyzed the data in relation to the hypotheses. Statistics committee members wrote up their individual findings and submitted them to the chairman of the committee.

The following null hypotheses are related to attitudes of the caseworkers as measured by the questionnaire used in the study.

$\mathrm{H}_{\mathrm{O}}$ III. There are no differences in attitudes, as measured, of

Intake workers, Intensive Service workers, Environmental Service workers and Regular Service workers.

Sub-hypothesis:

There are no differences in attitudes, as measured, of Intensive Service, Environmental Service (maximum service) and Regular Service workers toward the case classification and planning Program.

$\mathrm{H}_{\mathrm{O}}$ IV. There are no differences in attitudes, as measured, of Family Service workers and Adult Service workers at all levels.

$\mathrm{H}_{\mathrm{O}}$ V. There are no differences in attitudes, as measured, of caseworkers with the agency more than two years and less than five years and caseworkers with the agency less than two years or more than five years. 
$\mathrm{H}_{\mathrm{O}}$ VI. There are no differences in helpfulness between parts of the Case Planning Schedule according to responses of caseworkers.

The rationale and implications of the hypotheses have been set forth in the first chapter of the study.

After consideration by the total group, an interviewing schedule was selected as the method of gathering data on attitudes of the caseworkers. The term "questionnaire" has been used instead of interviewing schedule to prevent confusion with the case classification Schedule.

As preliminary drafts of the questionnaire were designed by the questionnaire committee, they were tested on members of the group. A later draft of the questionnaire was pre-tested on seven people outside of the student group and the agency as a means of testing for difficulties not anticipated by the research group. The seven persons taking the pretest were individuals who had had experience in working with the case classification Program but who were no longer employed at Multnomah County Pub1ic Welfare Commission. Revisions resulted from the pre-test both as to content and method of administering. It was also clear that it could not be given to supervisors because the questions were directed to the casework task rather than supervision.

In its final form the questionnaire items 1 through 15 were identification items and were designed as the variables to be used in comparisons and correlations of attitudes as established in the hypotheses. (See Appendix, page 117.) Additional items were included in the identification section beyond those needed for testing the hypotheses for possible exploration or use in future research. 
Questions 16 through 22 were designed to elicit attitudinal responses from caseworkers about different aspects of the Program as follows:

16. Understanding your client

17. Working with client

18. Compatibility with social work theory

19. Casework plan

20. Services to client

21. Full implementation of the Program

22. Effort involved

Response to question 23 was in the form of a matrix designed to reflect a value judgment about the degree of helpfulness to the caseworker of various parts of the Case Planning Schedule in working with clients. Question 24 was an open-ended question in which the caseworkers were asked to make comments about the Program for Case Classification and Planning, especially suggestions for improvement.

At this point it was necessary to decide specifically which caseworkers were to be included in our study. It was necessary to 1 imit the group to those having experience in use of the Case Planning Schedule and who had worked at the agency prior to October 1, 1963. Those workers who regularly utilized the Schedule were those in Adult Services, Family Services and Intake. Because of limited use of the Schedule by Intake workers there was some question as to their inclusion. However, the Intake workers could not be excluded because even their limited use of the Schedule was important in initial case assignment. The research group did, however, eliminate the following caseworkers: (1) three Intake workers who did not use the Schedule and who had specialized functions in hospitals and nursing homes, (2) three workers not assigned to any specific department or classified caseload, and (3) one Adult Services 
worker with a special unclassified load. Having thus limited population, it was then possible to decide to administer the questionnaire to a universe, rather than a sample, of these groups.

The questionnaire was administered to one hundred and eight caseworkers during the month of November, 1963. The universe as defined included thirty-eight men and seventy women ranging in age from twentyone to sixty-six years. All the caseworkers except one had a B.A. or B.S. degree. None of the caseworkers had an M.S.W. degree. There were two with Master's degrees in fields other than social work, however. Fifty-three caseworkers had less than two years' experience in the agency, twenty-one had two to five years' experience, and thirty-four had over five years' experience. When the questionnaire was in final form and the population chosen for interview, decisions were made on methods of administering the questionnaire.

In a training session held for the researchers, instruction sheets as well as suggested introductions were given to each of the seven research interviewers. (See Appendix, pages 118 and 119.) A roleplaying demonstration was given and a discussion of questions and problems was included in the training of the group. The seven interviewers were not well known in the agency. It was thought prior relationships could influence the responses of informants and for this reason each interviewer was assigned to caseworkers whom he had not previously met.

It was found during the pre-tests of the questionnaire that reading the questions aloud with the informant gave the most satisfactory results. Therefore, it was administered individually by members of the group at the offices of the Multnomah County Public Welfare Commission. 
The interviews were held at the caseworkers' desks or at any convenient area in the agency. The purpose of the study questionnaire was explained (as covered in Introduction to Questionnaire, Appendix, page 119) and the meaning it could have to the agency was also explained. The interviews were held at the convenience of the caseworker with it being the responsibility of each student to contact caseworkers assigned to him for appointments. The interviews took approximately twenty to thirty minutes.

The research student and the caseworker read the items together and the student marked the answers in red pencil. Questionnaires were checked for completeness and returned to the student for necessary corrections.

Two meetings were held during the two-week period of interviews to exchange reactions and to clarify problems. A few objections were registered by the caseworkers and were considered; however, it was decided not to make any changes and the interviewing proceeded as planned.

The data from the questionnaire were tallied and tabulated, then given to the statistics committee.

The open-ended question, number 24 , in which the caseworkers commented and made suggestions on the case classification Program, was analyzed by the original questionnaire committee, consisting of four students. Decisions on all comments were made, when the committee did not reach consensus, by a majority vote.

The categories were chosen after experimenting with various categorical plans. One method considered but discarded because it yielded little usable information, was sorting by negative and positive comments. Another sorting 
method was tried in which the comments were sorted by their focus on administrative levels in the agency. This proved unmanageable. In the judgment of the committee these categories used were the most descriptive.

The three hundred and sixty responses to question 24 were transferred to $3 "$ " 5" cards. Each card was coded by worker number and department. The broad categories formulated were as follows:

(1) General comments about the total Program for Case Classification and Planning

(2) Specific comments about the Case Planning Schedule

(3) Comments on implementation of the Program for Case Classification and Planning

(4) Other

(5) Irrelevant

The comments were diverse and complicated but generally could be placed into one of these five categories. The cards were sorted on the basis of a majority opinion of the committee members.

It was found that presenting the information from the open-ended question would be difficult to do in an organized manner. A decision made by the committee and approved by the total research group was to reflect the content in a generalized, descriptive way, giving some weight to quantitative responses and also recognizing the value of single suggestions that appeared to have particular significance. The summary was divided into three major categories of responses relating to the case classification Program, the case classification Schedule and implementation of the case classification Program. The descriptive summary of this question is included in Chapter VI. 


\section{Analysis of Data}

Chi-square was chosen as the basic statistical test for analyzing the data, permitting maximum use of the distribution under conditions found. To assist in analysis a number of appropriate tests of significance were utilized, but except as noted below, will not be reported in the quantitative findings.

When all categories could not be used, because of insufficient theoretical frequencies, cells were combined in the extended median test. On Hypothesis $\mathrm{WI}$ a " $t$ " test seemed appropriate in addition to the extended median test.

Hypothesis IV was tested by a comparison of modal responses and the data from the open-ended question were analyzed by means of a descriptive narrative.

Throughout the study the group noted observations and ideas. The total group recorded and submitted suggestions for the concluding chapter to the individual responsible for writing the chapter. The summary of the findings, suggestions for further study and implications for practice are included in Chapter VII.

This chapter has described the organization of the student research group and the methods used by the group in gathering data for testing of the hypotheses. It included the design and method of administering the questionnaire, a description of the population studied and the methods used in analyses of data in the research project. 


\section{QUANTITATIVE FINDINGS}

Findings from the statistical tests of four major hypotheses, plus one sub-hypothesis are presented in this chapter. The responses of the caseworkers to an additional major hypothesis are presented at the end of the chapter. Hypothesis I pertained to the use of the Case Planning Schedule for classifying cases. Hypothesis II was not testable as was explained in Chapter IV. Hypotheses III through VI dealt with the attitudes of the caseworkers reflected in their responses to items 16 through 22 of the questionnaire. Hypothesis VI was demonstrated by means of modal responses to item 23 of the questionnaire.

The Ch1-square test for independent samples was used to evaluate the discrete data obtained to test hypothesis $I$. The extended median test or the more powerful " $t$ " test was used to evaluate the continuous data obtained to test hypotheses III, IV and V. Hypothesis VI was not tested statistically.

$\mathrm{H}_{\mathrm{O}}$ I. There are no significant differences in classifying cases with the Case Planning Schedule and without the Case Planning Schedule.

The research group made a total of 47 classifications and prognoses on 24 cases using the Case Planning Schedule. These classifications and prognoses were compared to 100 classifications and prognoses on cases that were made by the research group without using the Schedule. No significant difference was found when classifying cases with or without the Schedule. However, the prognosis was significantly affected 
by the worker having completed the Case Planning Schedule.

\section{TABLE A}

RESULTS OF CHI-SQUARE TEST USING .05 LEVEL OF SIGNIFICANCE FOR CLASSIFICATION AND PROGNOSIS WITH AND WITHOUT THE CASE PLANNING SCHEDULE

\begin{tabular}{|c|c|c|c|c|c|c|}
\hline Classification & Res & pons & & df & $\begin{array}{l}\text { Chi- } \\
\text { square }\end{array}$ & $\begin{array}{c}\mathrm{H}_{\mathrm{O}} \mathrm{I} \\
\text { Conclusion }\end{array}$ \\
\hline 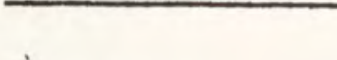 & IS & ES & $\mathrm{RS}^{*}$ & \multirow{3}{*}{2} & \multirow[b]{3}{*}{3.090} & \multirow[b]{3}{*}{ Accept } \\
\hline With Schedule & 21 & 16 & 10 & & & \\
\hline Without Schedule & 33 & 31 & 36 & & & \\
\hline
\end{tabular}

\begin{tabular}{|c|c|c|c|c|c|c|}
\hline \multirow[t]{2}{*}{ Prognoses } & \multicolumn{3}{|c|}{ Responses } & \multirow[t]{2}{*}{ df } & \multirow[t]{2}{*}{$\begin{array}{c}\text { Chi- } \\
\text { square }\end{array}$} & \multirow[t]{2}{*}{$\begin{array}{c}\mathrm{H}_{\mathrm{O}} \mathrm{I} \\
\text { Conclusion }\end{array}$} \\
\hline & IMP & ML & DET & & & \\
\hline With Schedule & 27 & 12 & 8 & \multirow{2}{*}{2} & \multirow{2}{*}{7.121} & \multirow{2}{*}{ Reject } \\
\hline Without Schedule & 46 & 49 & 5 & & & \\
\hline $\begin{array}{l}\text { *The abbreviation } \\
\text { Service, Enviror } \\
\text { workers respect } \\
\text { throughout this } \\
\text { also be used anc }\end{array}$ & apt & $\begin{array}{l}\text { an } \\
\text { r. } \\
\text { re }\end{array}$ & The & $r$ & $\begin{array}{l}\text { er to In } \\
\text { Regular } \\
\text { sed in t } \\
\text { viation } \\
\text { ke worke }\end{array}$ & $\begin{array}{l}\text { nsive } \\
\text { rvice } \\
\text { les } \\
\text { will }\end{array}$ \\
\hline
\end{tabular}

This classification and prognosis with and without the Schedule was designed as a pre-test of what might be expected in the agency setting. In actual practice the Intake worker designated the level of service and predicted the level of the client's future adjustment without completing the Schedule. At some later time the Unit workers, using the Schedule, were expected to reclassify these cases. Hypothesis II was designed to compare classifications made by Intake workers with those made by Unit workers. 


\section{Ho II. There are no significant differences in classifying of} cases by Intake workers and Unit workers.

Hypothesis II could not be tested because too few of a systematically obtained sample of 185 cases previously classified by Intake workers had been reclassified by Unit workers. Although testing this hypothesis was not possible, it would seem that the findings of the pre-test $\left(H_{O} I\right)$ would justify extension of the hypothesis into future studies in the agency.

$\mathrm{H}_{\mathrm{O}}$ III. There are no differences in attitudes, as measured, of

Intake workers, Intensive Service workers, Environmental Service workers and Regular Service workers.

Caseworkers' responses to the following items on the questionnaire were tabulated. Using the extended median test, Chi-squares were computed for each of these items on Hypotheses III through V.

16. How has the Case Planning Schedule affected your understanding of your clients' situations?

17. How do you think the Case Planning Schedule has influenced your effectiveness in working with your clients?

18. How compatible do you think the Program for Case classification and Planning is with social work theory?

19. In completing the Case Planning Schedule on a case, what usually happens to your casework plan?

20. In comparing the Oregon Public Welfare program before and after the Program for Case Classification and Planning, how do you think it has affected services to clients?

21. Assuming that the Program for Case Classification and Planning could be implemented fully and with a minimum of work disruptions, how would you feel about the system? 
22. Do you think the Program for Case Classification and Planning is: well worth the effort or of little worth compared with the effort?

TABLE B

RESULTS OF EXTENDED MEDIAN TEST

USING .05 LEVEL OF SIGNIFICANCE FOR $\mathrm{H}_{\mathrm{O}}$ III

\begin{tabular}{|c|c|c|c|c|c|c|c|}
\hline \multirow[t]{2}{*}{$\begin{array}{l}\text { Question } \\
\text { Number }\end{array}$} & \multicolumn{4}{|c|}{$\begin{array}{l}\text { Percentages of Responses Above } \\
\text { Median For Each Group }\end{array}$} & \multicolumn{2}{|c|}{$\begin{array}{c}\text { Probability } \\
\text { Range }\end{array}$} & \multirow[t]{2}{*}{$\begin{array}{c}\mathrm{H}_{\mathrm{o}} \\
\text { Conclusion }\end{array}$} \\
\hline & $I W$ & IS & ES & $\mathrm{RS}$ & & & \\
\hline 16 & 16 & 75 & 58 & 45 & .05 & .02 & Reject \\
\hline 17 & 0 & 84 & 71 & 43 & .001 & less & Reject \\
\hline 18 & 33 & 84 & 50 & 45 & .80 & .70 & Accept \\
\hline 19 & 16 & 84 & 50 & 48 & .02 & .01 & Reject \\
\hline 20 & 25 & 75 & 63 & 42 & .05 & .02 & Reject \\
\hline 21 & 33 & 67 & 54 & 45 & .50 & .30 & Accept \\
\hline 22 & 42 & 92 & 54 & 40 & .02 & .01 & Reject \\
\hline
\end{tabular}

Table B indicates a variation in attitudes among the groups of caseworkers tested under $\mathrm{H}_{\mathrm{O}}$ III. The over-all degree of most favorableness to least favorableness manifests itself in the following order: Intensive Service workers, Environmental Service workers, Regular Service workers and Intake workers.

A significant difference was found in responses between Intake workers, Intensive Service workers, Environmental Service workers and Regular Service workers on all of the above items except number 18 and number 21. These latter items refer respectively to the compatibility of the Case Classification Program to social work theory, and to implementing the Program with a minimum of work disruption. Social work theory was not defined and the respondents answered as they understood this item. Accepting the null hypothesis on items 18 and 21 does reflect 
agreement by these workers that case classification is compatible with social work theory and that they would favor the Case classification and Planning Program if it could be implemented with a minimum of work disruption. Otherwise, Hypothesis III may be rejected at the 5 percent level for all items tested.

The " $t$ " test was used to determine the extent to which the other groups varied from the Intake workers in their responses to the items considered. Numerical values of 1 through 5 were assigned to the established progression of responses, starting with the most negative ("e") through the most positive (" $a$ ") to allow for the computation of the " $t$ " values. The " $t$ " test values were obtained by comparing the responses of the Intake workers to the other groups considered under Hypothesis III. The Intake workers' responses were also compared to the combined responses of the Unit workers.

The purpose of the comparison was to determine whether there was a significant difference in the attitudes of those first classifying cases and those who subsequently classified these same cases. Further, the extended median test findings required accepting the null hypothesis for two of the items studied under this hypothesis. The " $t$ " test was used to ascertain those groups that reflected the greatest differences in their responses to these items. By accepting the extended median test findings in the absence of the more powerful " $t$ " test a Type II error might have been made with reference to the responses of the Intake workers and the Intensive Service workers on items 18 and 21 . For further information refer to the table of " $t$ " test values in the Appendix, page 120 . 
For Item 16 the " $t$ " test findings also indicated a significant difference between the responses of maximum service workers (IS and ES) and Intake workers regarding the effect completing a Case Planning Schedule had on their understanding of their client's situation. Intake and Regular Service workers were not significantly different in their responses to this item. Therefore, the differences between all the groups studied were attributed to the highly significant difference found in the responses of the Intake and maximum service workers to this item.

Responses to item 17 showed the Intake workers felt the Case Planning Schedule had not "influenced" their effectiveness in working with clients. Using the .05 level, a "t" test showed significant differences between the Unit workers and the Intake group. The Intensive Service workers were more favorable toward the Case Planning Schedule than any group tested.

The Intake workers differed significantly in their responses to item 18 from the Intensive Service workers. This was the only significant difference obtained for this item with the " $t$ " test using the .05 level of significance between the Intake workers and the other Unit workers. Although the Chi-square test of this item did not allow the rejection of $\mathrm{H}_{\mathrm{O}}$ III using the .95 confidence interval, the " $\mathrm{t}$ " test findings demonstrated a significant difference between the two groups mentioned above and thus rejection of this hypothesis is made possible through the " $t$ " test findings. These findings show the Intensive Service workers expressing the attitude that the Program for Case 
Classification and Planning was much more compatible to social work theory than did other groups tested under this hypothesis.

The significant difference obtained with the Chi-square test regarding how the workers felt completing a Case Planning Schedule influenced their casework plan as indicated in item 19 may again be attributed to the highly significant difference in the responses of the Intensive Service workers and Intake workers to this item. Whereas the combined responses of the four groups indicated completing the Case Planning Schedule helped them to develop a "somewhat better plan," the Intake staff taken alone indicated that completing the Schedule did not affect their plan.

On item number 20 no significant difference in responses of Intake workers and Regular Service workers was found regarding how they thought implementing the case classification and planning Program had affected services to clients. Both these groups saw no difference in services to clients since the Program had been started, whereas the maximum service workers expressed the attitude that the Program for Case Classification and Planning had contributed to somewhat better services to clients. Regarding item number 21 , the Chi-square value obtained allowed one to accept Hypothesis III in general regarding the implementation of the Program with a minimum of work disruption, the " $t$ " test reflected a significant difference in the responses of the Intake workers and the Intensive workers on this point. The Intensive Service workers reflected a more positive response toward the Program than was expressed by the other Unit workers or the Intake workers. 
The significant difference obtained in the Chi-square value for item 22 may be attributed to the highly significant difference in the responses of the Intake workers and the Intensive workers. This item pertained to the attitude of the workers toward the effort involved in implementing the system of case classification. The Intensive Service workers tended to see the results obtained in case classification as being more worth the effort than did the other staff members.

The sub-hypothesis was related to the categories of workers created for implementing the case classification Program, but this hypothesis did not include the Intake workers.

$\mathrm{H}_{\mathrm{O}}$. There are no differences in attitudes, as measured, of

Intensive Service, Environmental Service (maximum service) and Regular

Service workers toward the case classification and planning Program.

The median test for " $k$ " samples was used to test this hypothesis. The findings are presented in Table $C$.

TABLE C

RESULTS OF EXTENDED MEDIAN TEST USING .05 LEVEL OF SIGNIFICANCE FOR COROLLARY $\mathrm{H}_{\mathrm{O}}$ III*

\begin{tabular}{|c|c|c|c|c|c|c|}
\hline \multirow{2}{*}{$\begin{array}{l}\text { Question } \\
\text { Number }\end{array}$} & \multirow[t]{2}{*}{$\begin{array}{l}\text { Chi- } \\
\text { square }\end{array}$} & \multicolumn{2}{|c|}{$\begin{array}{c}\text { Probability } \\
\text { Range }\end{array}$} & \multicolumn{2}{|c|}{$\begin{array}{l}\% \text { Above } \\
\text { Median }\end{array}$} & \multirow[t]{2}{*}{$\begin{array}{c}\mathrm{H}_{\mathrm{O}} \\
\text { Conclusion } \\
\end{array}$} \\
\hline & & & & MS & $\mathrm{RS}$ & \\
\hline 16 & 3.404 & .10 & .05 & 61 & 42 & Accept \\
\hline 17 & 5.888 & .01 & .001 & 64 & 38 & Reject \\
\hline 18 & 2.026 & .20 & .10 & 58 & 43 & Accept \\
\hline 19 & 2.026 & .20 & .10 & 58 & 43 & Accept \\
\hline 20 & 5.137 & .05 & .02 & 64 & 40 & Reject \\
\hline 21 & 2.336 & .20 & .10 & 61 & 43 & Accept \\
\hline 22 & 7.290 & .05 & .02 & 67 & 38 & Reject \\
\hline
\end{tabular}

*The more favorable group in each case was maximum service. 
The maximum and Regular Service workers did not differ significantly in their responses regarding the compatibility of the Program with social work theory, with reference to the effect of the classification Schedule on their casework plan, to the effort expended in implementing the Program, and the effect the Schedule had on understanding their clients.

They differed in their responses at the 5 percent level of significance regarding the influence of the Schedule upon their effectiveness in working with their clients, the effect the Program had had upon services to clients, and the worth of the Program in light of the effort that had been required to implement it.

$\mathrm{H}_{\mathrm{O}}$ IV. There are no differences in attitudes, as measured, of

Family Service workers and Adult Service workers at all levels.

These groups of workers existed prior to the implementing of the Program for Case Classification and Planning. The new division of labor; i.e., Intensive, Environmental, and Regular Service, was superimposed upon these two groups.

The median test for " $k$ " samples was used to study the hypothesis with the 5 percent level of significance set as the critical limit. Responses of the two groups to items 16 through 22 on the interview schedule were computed and the results recorded in Table $D$ on the next page. 


\section{TABLE D}

RESULTS OF EXTENDED MEDIAN TEST USING .05 LEVEL OF SIGNIFICANCE FOR $\mathrm{H}_{\mathrm{O}}$ IV*

\begin{tabular}{|c|c|c|c|c|c|c|}
\hline \multirow[t]{2}{*}{$\begin{array}{l}\text { Question } \\
\text { Number }\end{array}$} & \multirow[t]{2}{*}{$\begin{array}{c}\text { Chi- } \\
\text { square }\end{array}$} & \multicolumn{2}{|c|}{$\begin{array}{c}\text { Probability } \\
\text { Range }\end{array}$} & \multicolumn{2}{|c|}{$\begin{array}{l}\% \text { Above } \\
\text { Median }\end{array}$} & \multirow[t]{2}{*}{ Conclusion } \\
\hline & & & & FS & $\overline{\mathrm{AS}}$ & \\
\hline 16 & 11.376 & .001 or & less & 63 & 28 & Reject \\
\hline 17 & 10.354 & .01 & .001 & 62 & 28 & Reject \\
\hline 18 & .472 & .50 & .30 & 52 & 44 & Accept \\
\hline 19 & 5.636 & .02 & .01 & 58 & 33 & Reject \\
\hline 20 & 5.636 & .02 & .01 & 58 & 33 & Reject \\
\hline 21 & 3.812 & .10 & .05 & 57 & 36 & Accept \\
\hline 22 & 12.885 & .001 or & less & 63 & 25 & Reject \\
\hline
\end{tabular}

There was no significant difference in the responses of these two groups to item 18 and item 21. However, they were significantly different in their responses to: (1) question 16, which reflected how they thought the Case Planning Schedule had affected their understanding of their clients; (2) question 17, which asked how the Planning Schedule influenced their effectiveness in working with clients; (3) question 19, which asked what influence they thought completing the Planning Schedule usually had on their casework plan; (4) question 20, which asked them about the influence the Program for Case Classification and Planning had had upon services to clients; and (5) question 22, which asked the worker to indicate if the Program was worth the effort expended in its initial phase of operation. On all points where a significant difference was found to exist, Family Service workers were more positive in their responses toward the classification Program than were Adult workers. 
$\mathrm{H}_{\mathrm{O}} \mathrm{V}$. There are no differences in attitudes, as measured, of caseworkers with the agency more than two years and less than five years and caseworkers with the agency less than two years or more than

\section{five years.}

The median test for " $k$ " samples was used to test this hypothesis. No significant difference was found in the responses of these two groups of workers to items 16 through 22 of the interview schedule. The result of these findings is presented in Table $\mathrm{E}$.

TABLE E

RESULTS OF EXTENDED MEDIAN TEST USING .05 LEVEL OF SIGNIFICANCE FOR $\mathrm{H}_{\mathrm{O}} \mathrm{V*}$

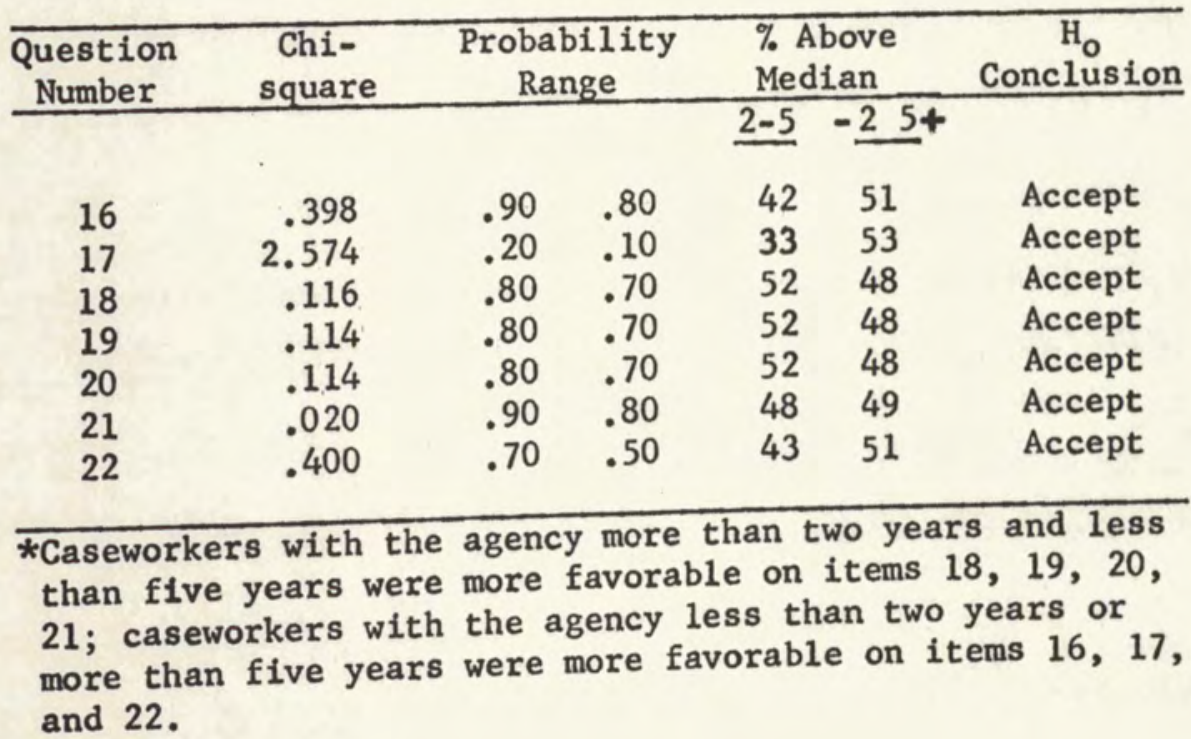

The alternate hypothesis is not substantiated from these findings. However, with a trichotomous Chi-square test, a significant difference in the responses of these groups was found on item 17 and item 22. Item 17 refers to the influence the Case Planning Schedule had on the worker's effectiveness in working with his clients. Item 22 pertained to the effort 
put into implementing the Program of Case Classification and Planning and whether the effort had been worth the obtained results. The results of these Chi-square tests are included in Table $F$.

\section{TABLE F}

RESULTS OF CHI-SQUARE TEST USING .05 LEVEL OF SIGNIFICANCE FOR ITEMS 17 AND 22 UNDER $\mathrm{H}_{\mathrm{O}} \mathrm{V}$

\begin{tabular}{ccccc}
\hline $\begin{array}{c}\text { Question } \\
\text { Number }\end{array}$ & $\begin{array}{c}\text { Chi- } \\
\text { square }\end{array}$ & $\begin{array}{c}\text { Probability } \\
\text { Range }\end{array}$ & $\begin{array}{c}\mathrm{H}_{\mathrm{o}} \\
\text { Conclusion }\end{array}$ \\
\hline 17 & 7.038 & .05 & .02 & Reject \\
22 & 7.526 & .05 & .02 & Reject \\
\hline
\end{tabular}

Of the 108 respondents, 53 had been with the agency less than two years, 21 had worked from two to five years, and 34 had been with the agency for more than five years. The differences reflected in the trichotomous tests were primarily due to the more negative responses made to items 17 and 22 by those workers with the agency more than five years. These findings would tend to support the idea that those with the agency for the longer period of time were less amenable to the implementing of the Program for Case Classification and Planning than those who had been with the agency less than five years.

$\mathrm{H}_{\mathrm{O}}$ VI. There are no differences in helpfulness between parts of the Case Planning Schedule according to responses of caseworkers.

To study this hypothesis, responses to question 23 of the questionnaire were tabulated, and the category containing the modal response of the groups tested was used to ascertain the group attitude toward various parts of the Case Planning Schedule. Caseworkers from three departments; i.e., Intake, Family Service, and Adult Service, were grouped and their 
responses recorded. The results of this tabulation are contained in the Appendix, pages 122 and 123.

The caseworkers in Adult Service and Family Service reflected the attitude that all parts of the Schedule were of more help than hindrance. Intake workers were most often neutral in their responses to all parts of the Schedule. From these results it was inferred that Intake workers found the parts of the Case Planning Schedule less helpful than did workers in Adult and Family Service. The Family Service workers reflected the most positive feelings toward the Schedule. None of the modal responses for any of the three groups fell in the negative response categories. Preferences by all workers to the various parts of the Case Planning Schedule were classified by percentages, as presented in the Appendix, page 123. Five hundred and one of the seven hundred and fifty-six responses to item 23 were positive. That is, approximately two-thirds of the responses obtained expressed that all parts of the Schedule were of more help than hindrance in the execution of their jobs. The preference for particular parts of the Case Planning Schedule was shown by the frequency of responses. These results demonstrated that more workers responded with favor to the "Diagnostic Statement" section of the Schedule than to any other part. The sections entitled "Characteristics" and "Potential Problems" received the least number of favorable responses and were ranked last in order of preference by the workers. However, it was observed that by combining the "very helpful" and the "somewhat helpful" responses, a different ranking of the preferred parts of the Schedule was obtained. From these grouped responses the "Current Problem" section was selected 
as the preferred part of the Case Planning Schedule. The "Diagnostic Statement," formerly the preferred section of the Schedule, dropped to fifth place in rank order. The section dealing with the characteristics of the client remained at the lowest rank. The "Diagnostic Statement" was that part of the Schedule about which the workers had the greatest divergence of opinion.

In addition to the quantitative findings noted in this chapter are the qualitative findings reported in Chapter VI. The conclusions of total findings are in Chapter VII.

\section{Summary}

The first research hypothesis was designed to ascertain the rellability of categorizing cases according to classification and prognostic sections of the case classification Schedule. Because the agency had not completed reclassifications, the hypothesis could not be tested fully. Project group members were able to classify cases with acceptable similarity whether they used the case Schedule or not. There was a significant difference, however, in prognostication.

A set of hypotheses dealt with workers' attitudes toward the case classification Program. All groups of workers showed, on the average, a favorable disposition toward the Program. Significant differences were found in the degree of positiveness among work groups. Workers who had been with the agency less than two years were found to be more favorable than others, but length of service in the agency was not a simple variable.

The final hypothesis referred to utilizing the Schedule. Parts of 
the Schedule relating to "Current Problems" and "Strengths and Weaknesses" of clients were considered the most generally helpful among groups existing in the agency prior to the introduction of the classification Program. Among these established groups there were differences of opinion as to the value of the Schedule as a whole, or of various sections. Much of the difference in attitudes could be attributed to significant differences among new categories of workers created to implement case classification which cut across the old groups. Intensive Service workers, for instance, showed high appreciation of the Schedule's usefulness, and the proportion of this set varied positively in the established groups.

Both in responses toward the Program and in estimations of usefulness, a pattern was discernible. Intake Workers tended toward neutrality; Regular Service workers were more positive, then Environmental Service workers, and, most positive, the Intensive Service group. 
Chapter Reference:

Dixon, Wilfrid J. and Massey, Frank J., Jr., Introduction to Statistical Analysis (second edition; New York-Pennsylvania: McGrawHil1 Books, Inc., 1957), p. 296. 
CHAPTER VI

QUALITATIVE FINDINGS

Question 24 of the questionnaire was included to allow freer expression of attitudes. It was specifically designed to elicit comments and suggestions from the casework staff as to their feelings about the case classification Program in their agency. The question was as follows: "Any comments you would care to add about the Case Planning Schedule or the Program for Case Classification and Planning, including your suggestions for improvement?" It was thought that responses to this type of question would evoke attitudes which might not appear in responses to previous questions. The term "qualitative" as used in this project is defined as: descriptive words rather than numerical size. A detailed account of the methodology connected with administration of this question and the sorting of the responses to it is to be found in Chapter IV. After the 360 responses had been broken down to the final categories of comments about the Program as a whole, comments about the Case Planning Schedule, and comments about implementation of the Program, the research group found that the responses to question 24 corroborated statistical findings in previous questions about staff attitude. Lending particular significance to this development was that the committee responsible for sorting and organizing the responses on this question worked independent of knowledge of the statistical inferences being drawn from the other 
questions. Therefore, two different procedures, one objective and the other somewhat impressionistic and subjective, resulted in consensus about staff attitudes toward the Program. Each finding expanded and strengthened the other.

With this in mind, therefore, the following is a presentation of the responses gleaned from question 24 .

\section{The Case Classification Program}

A total of 14 comments were made which were defined as being positive in nature toward the over-all purposes of case classification. While this number seemed to be only a small proportion of the responses, there was more positive feeling than this number would indicate. Favorable comment about the Program tended to be general, whereas the negative comments tended to be specific and not reflective of a totally negative feeling toward case classification. Typical of the positive comments were that it was a "generally good idea," "Program has good theoretical basis," and it "demands systematic thinking and approach." There was also approval of the idea of specialized caseloads limited in size. In addition to these remarks, there were others which were positive in feeling but which showed that there was dissatisfaction with the way case classification was being implemented. The general feeling was that if there had not been difficulties in implementation the Program would be favorably received by these individuals. There was also the thought that while the use of the Schedule was helpful for the untrained, inexperienced worker, it had limited usefulness for the trained or experienced worker. There were responses questioning the necessity and value of having 
the Program at all. In these particular comments, totaling 11, the respondents did not say why they questioned its worth. A further broad area of criticism involved what might generally be described as fluctuations in the Program, with the feeling that there had been far too many changes in administrative procedures since its inception. Other remarks indicated that the state and county "should have waited until the plan was perfected before implementing." There were comments that it was a disadvantage to move cases so frequently from one worker to another. Related to this were the four comments that case classification was of limited usefulness because of the number and competency of staff.

\section{The Case Planning Schedule}

Eighteen people raised a question about the general applicability of the Schedule itself to different portions of the agency program. For instance, it was suggested that there was "little effectiveness in classifying cases on $\mathrm{OAA}, "$ and that this group was already receiving whatever special services were needed. A similar thought was that the "Schedule seems geared to families rather than single individuals." There was some feeling that a separate Schedule was needed for different departments, as the Case Planning Schedule then in use did not meet the needs of all the different units.

There were 19 cards unreservedly favorable to the Schedule, and these tended to indicate that it was useful in helping to focus on goals and treatment steps and that it was "helpful to have a framework." The fact that it offered the opportunity for a methodical approach to problems was seen as an asset by a number of these people. Other comments were that 
1t was a "good medium for communication between different strata of agency," and that the "Schedule for Intake can be very helpful if it is an ex-applicant and a completed Schedule is in the record."

The largest area of specific criticisms involved the use of, and make-up of the Schedule. These criticisms, numbering 31, were exemplified by the comment, "The mechanical categorization of people gets away from the human element in casework," and expressed the feeling that narrative recording is sufficient. Another repetitive theme was the idea that there were no adequate criteria for classification of cases. There was a feeling that a uniform standard was not applied for classifying cases in Intensive Service, Environmental Service, and Regular Service caseloads. The final classification, therefore, apparently rested upon the personal idiosyncracies and preferences of the worker doing the classification. There were also suggestions indicating that the categories on the Schedule were too general and "not appropriate to family situations."

There were additional specific comments relevant to the use of the Schedule. A recurrent one was that it was too repetitive, and that pages 7a and 8 should be combined. The underlying theme here seemed to be that the Schedule was too long and too burdensome to manage. Five cards represented a negative attitude toward the coding done at the end of the Schedule. Scheduling cases at Intake was questioned because adequate information was lacking. There was also some feeling that more categories were needed to clarify the page on financial functioning as the existing categories did not seem appropriate to the problems involved. Questions were raised about the consideration of goals. One caseworker 
stated, "Sometimes there is an insistence on goals when it is not possible to have goals." Another isolated comment was, "People negatively disposed to scheduling shouldn't schedule cases."

\section{Implementation}

Criticisms also were related to the implementation of the case classification Program in Multnomah County. One, represented by 21 comments, indicated that there was too much paper work involved. It was suggested that this was poor because it took time away from actual casework, and the attitude was that it would have been possible to simplify the amount of work involved. The committee interpreted some ambivalence in comments, such as, "Case classification helps the caseworker to organize his thinking about the client, but use of the Schedule involved too much paper work."

Another area of concern centered about various factors connected with the differential caseloads. One typical comment was, "I do not feel there has been adequate examination of size of controlled caseloads in relation to expected accomplishment." It was indicated that all cases should ideally receive Intensive Service, and that if every worker had a smaller caseload, the same thing could be accomplished without the use of the Case Planning Schedule.

Question was raised about the necessity for the differential caseload. The reaction was that all the caseloads should be mixed in composition, but smaller. It was pointed out that many Intensive Service cases were in Regular Service loads even though they were classified as needing Intensive Service. This caused dissatisfaction because there were cases 
needing Intensive Service which were actually receiving less service than those in Environmental Service. It was stated that these people were actually receiving less service than they had been before classification occurred. Other ideas mentioned were that: (1) Cases were misclassified as Environmental Service instead of Intensive Service to prevent their being lost in Regular Service loads, and (2) Deliberate misclassification took place so that the caseworker could either dispose of or keep a case according to individual preference, regardless of the client's needs as scheduled.

Another problem mentioned on 25 separate cards was the problem of time. Two major themes emerged: (1) When the initial classification was done, there was not sufficient time to do it correctly, and low accuracy and limited value were the results; (2) The purpose of making the workers think in a certain kind of way about their cases was lost because of time pressure.

Comments also focused around the staff's feelings about the help they received in learning about the purposes of the Program and use of the Schedule. This might generally be called staff development. It was expressed that there had been a "lack of orientation before classification Program began." Comments indicated that instructions had been inadequate and confusing. Another thought was that there was a "lack of appreciation for an individual worker's achievement in adapting to policy changes and lack of psychological support of workers." It was also stated that there was a lack of communication between staff members with regard to the Program, and that there needed to be more communication between Intensive 
Service, Environmental Service and Regular Service workers with regard to the respective work assignments. It was the committee's interpretation that all of these criticisms reflected a general discontent with the way in which the classification Program was presented to the staff.

\section{Other}

One additional thought which did not seem to fit any particular frame of reference developed by the questionnaire committee was that the use of the Schedule had created awareness of the lack of social welfare resources in the community. One person felt that case classification "will not solve problems without a strong educational and training program for clients." These two types of responses were then essentially favorable and indicated the Schedule might be helpful in recognizing existing lacks within the community.

\section{Summary}

The committee's impression of staff attitude was that the caseworkers tended to be favorably inclined toward the goals and purposes of case classification, but that the probleme lay within the area of implementation and administrative procedures. A typical attitude seemed to be that it would be a good thing if only it would be operated properly. The specific complaints, therefore, centered more on the way in which it was being administered rather than expressing opposition to the total effort and the purposes behind it. This finding was in direct accord with the quantitative findings demonstrating essentially the same idea. Both quantitative findings and findings described in this chapter indicated that the staff was not opposed to the principles behind case classification and 
related their objections to implementation of the Program.

It also appeared that the statistical finding showing that differences existed between attitudes of staff members in different departments might be related to the open-ended response expressing discontent with classifying all categories of service. If, for instance, classification was of limited usefulness in an 01d Age Assistance case, it would follow that those workers with primary responsibility for such a caseload would be less satisfied with the Schedule. This was indicated by the comment that the "Schedule seems geared to families rather than single individuals." Such a response, therefore, further substantiated the research group's statistical inferences.

Another likely relationship existed between the staff statements that no adequate criteria existed for classifying cases, and the group's quantitative finding that there were no differences in classifying cases with or without the Schedule. Since adequate criteria seemed to be lacking, it appeared that the use of the Schedule would not result in reliable or valid classification.

These were just a few of the responses which related to the group's statistical findings, and each approach lent support to the other. An open-ended question, therefore, provided interpretation of the quantified results of the study. 
CHAPTER VII

\section{CONCLUSIONS}

The study represents the first known attempt to investigate factors pertaining to the implementation of a system of case classification in a specific public welfare agency. Because of the limitations imposed by time, the availability of data and the complexity of many interrelated factors imposed by the provisions of the Program and of the functioning of the agency, the focus of the study became limited to two specific areas. These were: (1) the use of the Case Planning Schedule in the classification of cases into one of three categories designated by the Program, and (2) the attitudes of the caseworkers in various departments of the agency toward the case classification Program and the Case Planning Schedule.

Hypothesis I concerned the use of the Case Planning Schedule in classifying cases into Intensive Service, Environmental Service or Regular Service. Investigation through the activity of the research group showed that there was no significant difference in classifying cases by level of service, but there was a significant difference between the two methods in making a prognostic statement, with more agreement present when the Case Planning Schedule was used. Further research into this area through study of agency records in testing Hypothesis II was not possible as sufficient data were not available. The question implied by this exploration, however, continued to be of significant importance 
since cases were tentatively classified at the point of intake into the agency by Intake workers who did this without completing a Schedule. When the case was assigned to a field worker, the Schedule was subsequently completed and the earlier classification either confirmed or changed. The research group found, however, that for the period examined there were very few cases which indicated that the field worker had completed a Schedule within the required three-month period. The conclusion was that this group of cases was assigned a classification without use of the Schedule and remained in that classification without further evaluation. The research group's own investigation revealed a difference in prognostic statements with and without the Schedule. If it could be accepted that implementation of the Program depended upon arriving at a classification as a result of completion of the Schedule, It might be concluded that some cases within the group examined may not have been correctly classified. The extent to which this had continued to be true in cases opened during more recent months was not explored. The question arose that, if this pattern had continued, was the use of the Case Planning Schedule, an integral part of the Program, being implemented?

Hypotheses III, IV, V, and VI concerned an examination of the attitudes of the caseworkers. The research group found, in general, that worker attitudes toward the Program were favorable, although varying degrees of favorableness were encountered in comparing questionnaire responses of workers by categories of caseload assignment, departmental assignment and length of service. 
In comparing maximum service workers (those with Intensive Service and Environmental Service caseloads) to Regular Service workers, it was found that although there was a significant difference in response both groups indicated a tendency toward being favorable to the Program. Maximum service workers were, as a group, more strongly favorable as had been predicted. This group had smaller caseloads which were rigidly controlled in size and had apparently attained a greater status in the agency. This increase in status was not unexpected since the agency considered itself a social agency and had gradually been placing increased emphasis on casework services beyond the provision of financial assistance only. The maximum service workers were expected to provide a greater proportion of such services to their clients, and therefore were more nearly able to meet the expressed goals of the agency. Thus, they had acquired a higher status and could be expected to regard favorably the Program which made this possible.

The attitudes of the Regular Service workers, as a group, were only relatively less favorable than those of the maximum service workers. This was not expected by the research group. More of their answers tended to indicate a moderate favorableness, but, as with the other group, there were few responses in the moderately or strongly unfavorable categories. The reasons for this were not clear since the Regular Service workers did not actually represent a homogeneous group but were located in various departments and represented varying degrees of experience. In the Family Service Departments many of the workers with Regular Service caseloads were new to the agency and were not present during the initial case 
classification orientation sessions. In Adult Services, on the other hand, the majority of the workers had Regular Service caseloads as the initial classification of non-child families seemed to reveal little need for more intensive service to most recipients. Many of these workers had several years of Public Welfare experience.

The Regular Service caseloads were large and caseworkers were expected to provide only financial assistance. This in itself was a considerable undertaking when some caseloads contained as many as one hundred and seventy-five families. Thus, reasons for the attitudes favoring the Program were not entirely clear. One possibility was that many of the families which were more difficult to deal with had been removed from the Regular Service loads, allowing the workers to establish a routine which was more free from unexpected emergencies. In a setting which embodied a good deal of paper work this could have been quite desirable to a caseworker who valued systematic organization. Another factor was the large number of new caseworkers, the majority of whom were young. It was possible that many of these persons, having arrived after the initial implementation of the case classification Program, tended to accept the existence of it as an integral part of agency functioning to a greater extent than the older workers. It may have been that many of these persons aspired to sufficient competence to warrant assignment to a maximum service caseload in the future.

A comparison was made between caseworker attitudes in Family Services and Adult Services. There was a significant difference in attitudes between these two groups with Family Services generally more positive. The Adult Services caseworkers responded more often in the 
moderately favorable to neutral area. Again, the reasons for this were unclear, but they might be conjectured to lie in the area of status. In social work theory and practice there is a good deal more attention paid to the problems of children and families with children than to the difficulties of the elderly and the physically incapacitated. Adult Services were composed primarily of the latter while Family Services dealt with the former. It seemed possible that greater status would accrue to the group which dealt with more generally recognized social problems and such a group would be more favorable to a program emphasizing service and which increased the visibility of persons providing services to the recognized problems. As a corollary to the above, a comment was noted by various members of the research group that the Schedule appeared to have been designed for families with children and was more appropriate for use with this type of family. These comments were not investigated as part of this study and were a matter which could be taken up in future research.

A comparison was made between workers divided into three groups by length of service in the agency. It was expected that workers who had been on the job from two to five years would have the most favorable attitudes toward the program. It was found, however, that there was no significant difference between the zero to two and the two to five-year groups. The difference between these groups and the group which had been with the agency more than five years was significant, with the latter group being noticeably less favorable in most areas. This group indicated more responses in the neutral categories. 
For several years prior to the research study, Public Welfare in Oregon had been in a state of considerable flux, with the introduction of new programs, policies and procedures being presented to the casework staff at a rapid rate. For this reason it was possible that the older staff members, in point of service, tended to reserve their acceptance of any new program until it had proven its helpfulness. This would help to explain their frequent neutral answers. There was also a consideration that certain of the older staff, not being professionally trained and thus denied professional identification, had become identified with certain aspects of bureaucratic functioning, placing major emphasis on specific limits of job specification and role expectation. These persons might not have easily accepted a program designed around concepts which were unfamiliar to them and which appeared to require skills which they did not feel they possessed.

The unexpected favorable attitude by the workers who had been with the agency less than two years has been discussed previously. It may have involved acceptance of the Program as a part of agency function and desire to gain status within the boundaries of the Program through increased competence in providing casework services.

In assessing responses from the entire casework staff concerning their attitudes toward the Case Planning Schedule it appeared that the staff was generally favorable. Approximately two-thirds of the responses indicated that all parts of the Schedule were of more help than hindrance in casework planning. There appeared, however, to be some disagreement concerning the usefulness of various parts of the Schedule. The "Diagnostic 
Statement" offered the most controversy. The use of this form had not yet become an integral part of agency routine and the variety of opinion concerning usefulness of its various parts tended to reveal that the staff was not yet fully comfortable in its completion and application. It was noted that Intake workers tended to be somewhat neutral in attitudes toward the Schedule and its various parts, which might be expected since they did not use the form in their daily activities except to complete the face sheet and to indicate a tentative classification.

Responses of the casework staff to two questions tended to create speculation concerning the theory of the case classification Program versus its implementation in the agency. Question 18 concerned the Program's compatibility with social work theory and question 21 asked for attitudes concerning the Program if operated at full implementation with a minimum of work disruption. Responses from the staff to these two questions contained a higher proportion in the strongly favorable category than responses to any other question. It appeared that the agency casework staff as a whole had a high regard for the Program in theory but was somewhat less favorable to the manner in which it had been implemented. Responses to question 24, which provided for comments, tended to corroborate this attitude. Comments construed as favorable were frequently directed toward the Program in general, whereas unfavorable comments were often specifically critical of implementation by the agency.

Chapter III discussed the state of flux in which the agency had functioned during the year preceding the research investigation. The attitudes of the staff appeared to reflect this and indicated a somewhat 
negative reaction to the lack of stability in the work routine. The implementation of the case classification Program added to the frequently shifting situation with its reorganization of caseloads into the three previously described categories of service and the shift of emphasis to standardized diagnosis and planning through use of the Case Planning Schedule. Caseworkers formerly were held accountable only for establishing and reviewing financial eligibility but were now also accountable for identifying and treating the family's psycho-social problems. The above caused a good deal of work reorientation, as former routines were no longer functional under the demands of the new program. Concerning staff attitudes, an area which was not explored was a possible relationship between caseworker attitudes and the attitudes of the supervisory and administrative staff. It would seem likely that there would be a causative relationship involved, as what persons in positions of authority felt about the Program was undoubtedly communicated in some form to the casework staff. This was suggested as a possibility for future research.

A major consideration which was not investigated was the effectiveness of the Program on improvement in the functioning of the agency's recipients, which was the primary reason for the existence of the Program. The research group had considered exploring this, but it was determined that effective investigation would require the development and utilization of an instrument for objectively assessing case movement. It was felt that the Program was still too new to apply such an instrument. It appears, however, that research into this area is vitally needed to investigate the effectiveness of the Program in improving client functioning. 
As a result of the study, implications arose concerning the effect and importance of a case classification system to the agency and to the profession of social work. A major question which might be of concern to the agency, both state and county, was the effect of such a program on the existing agency structure which did not appear to have been materially changed to accomodate it. Other agency procedures which pre-existed continued to exist in essentially the same form. Narrative recording, for example, did not appear to have been redesigned to reflect use of the Case Planning Schedule. The requirement of periodic financial review of each case had not been changed in content or procedure. Except for reorganization of caseloads and supervisory units in terms of categorical classification, there appeared to have been little change in organizational structure. Was the Program designed to fit into the existing structural system? If it did not fit, what changes in the Program could have been made to cause it to function more effectively within the prevailing system? On the other hand, if it could be assumed that the case classification Program held a high priority, what changes might have been made in the existing structure to more easily accommodate the Program?

A number of responses to the open-ended question (number 24) in the attitude questionnaire appeared to reveal inadequate knowledge of the provisions of the case classification Program. An implication arose concerning the adequacy of staff training. Many caseworkers joined the staff subsequent to the series of orientation sessions given by state personnel and may not have had sufficient knowledge of the Program. Staff turnover continued to bring new staff members to the agency. The frequent 
addition of new persons implied a need for some form of continuous staff training program for new personnel. Could such a program be maintained by a county agency or should state office personnel be involved? Where should efforts be concentrated? Would learning through small group discussions be useful? Would new workers learn best through participation in group discussion with more experienced workers? Should agency efforts be concentrated in training supervisors to be teachers and group discussion leaders? Would participation by experienced workers in the training process increase their own motivation?

If continual reinforcement of the theory and practice of the case classification Program was not carried out, at least until it became firmly established in the agency routine, there existed the possibility that it would become dysfunctional. The agency, both county and state, indicated that this Program had a high priority. Did it, in fact, have such a priority? Had other agency functions become subordinate or had they been continually stressed as strongly as before, forcing the case classification Program into a lower priority status than was verbally stated? What could be done to assure that the Program maintained its ascribed importance? Was it sufficient to verbally stress the importance of such a program if, in fact, caseworkers were faced with other activities which must be accomplished first?

The design of the case classification Program, apart from its implementation by any specific agency, was an important consideration in its potential effectiveness. Although certain core concepts were retained, there were frequent changes in the operational design and there was no evidence that the ultimate design had yet been achieved. The Case Planning 
Schedule was the central device around which the Program functioned and this form had undergone a number of revisions. The designers of the Schedule saw it as a tool to standardize the diagnostic and treatment planning procedures. Did the form do what it purported to do? Did it fulfill its function as effectively and easily as other methods, such as a detailed recording guide? Or, did it tend to be so lengthy and demanding that it was often not fully completed, thus defeating its purpose? Could the Schedule be shortened without reducing its effectiveness as a diagnostic and planning device?

The core concept which was the ultimate result of completing a Case Planning Schedule on any case was the classification of that case into a category of service. Did the Program present adequate criteria for classification into the categories? Were the differences between the categories consistent? It appeared that Intensive Service implied a quality of service; Environmental Service, a type of service; and Regular Service, a rather ambiguous lack of specific service. If criteria for choosing a categorical classification were inadequate, did such classification then rest with the subjective determination of the caseworker, thus working against the stated goal of objective analysis? Did a vagueness in criteria allow caseworkers to classify to meet their own needs; to keep or get rid of cases.

As society becomes more industrialized, urbanized and complex, the number and complexity of social problems increases. More people become unable to function without some form of help. It appears that the public agency, with its capacity for dealing with large numbers of people, is growing in importance. Public agencies are generally characterized by 
large individual caseloads carried by untrained caseworkers. Following World War II, public agencies have been attempting to devise means of coping with the ever-increasing number of persons seeking help. It has become apparent, that methods of operation employed by the smaller, specialized and highly professionalized private social agencies of intensive individual attention to each applicant cannot always be successfully applied to the large public agency. The concept that is growing in use by public agencies is that of case classification with its provisions for standardized diagnostic and planning procedures, objectively controlled evaluation of data and selection of persons or families who will receive a concentration of agency efforts.

This approach offers a departure, in some areas, from traditional social work concepts and practices. Does the practice of concentration of effort toward a portion of the total caseload imply segregation based on severity or type of need? Does the eligible applicant have a right to public assistance? If so, does he have a right to corollary casework services? Is discrimination being practiced by providing services to some and not to others? On the other hand, what if the client refuses the service or objects to the classification in which he has been placed? Must a client accept casework service if he is to receive public assistance? In regard to current social work concepts, does case classification imply that some needs can be ignored in favor of others? What influence will case classification have on the public image of social work? The profession has sought to identify itself with a model similar to the entrepreneurial professions, such as medicine, which do not deny help to anyone who is in need and asks for help. Is case classification 
causing the profession of social work to veer away from the traditional model of individual help and toward a concept of help for the larger group, the community, in which help for individuals is based on community needs? Does this imply the necessity for accurate and reliable assessment of community problems as a basis for determination of what individual needs will be met?

What implications does this shift in emphasis hold for social work education? Should greater emphasis be placed on systematic gathering and assessing of data; on tests of reliability and validity? Should concentration be shifted from individual needs to community needs? Should emphasis be placed on accumulating data rather than distributing it into individual case records? Can we systematize, rather than individualize, our approach?

As previously stated, this research study was limited to certain specific areas and could not expect to deal adequately with the complex of factors involved in the implementation of a major change in the functioning of a public welfare agency. The data which were obtained, however, did provide information concerning the effects of the Program on the casework staff, information which should be of assistance to administrative personnel in coping with staff morale and motivational changes which have resulted. Introduction of a major new factor into a complex system is certain to affect the members of the system. It appears important that the nature and intensity of these effects be assessed in the light of alterations required to regain systemic stability. Analysis of the data obtained revealed influences which either were not or could not be controlled during implementation of the Program. The 
degree to which these influences favorably or unfavorably affected the casework staff's attitudes toward the case classification Program was not assessed, but it did appear that staff reaction had been generally favorable. Certain additional alterations may have been necessary in agency structure and functioning following the study to aid in the effectiveness of the Program, and it was felt that additional research, either by the agency or an outside group, would be helpful in determining the nature and degree of change required. In addition, since it has been found that the use of systems of case classification is increasing throughout the country, additional research into the effectiveness and desirability of utilization of such systems is becoming an ever-increasing necessity. 
BIBLIOGRAPHY 


\section{BIBLIOGRAPHY}

Ackerman, Nathan. "Diagnosing Family Functioning," Children, Vol. 10, No. 3, May-June, 1963, pp. 116-118.

Arizona State Department of Public Welfare. Study of Arizona Rehabilitation Program, 1959, pp. 1-19.

Beisser, Paul T. "Maladjustment," Modern Philanthropy and Human Welfare. New York: The Grant Foundation, 1952.

Birt, Charles J. "Family-Centered Project of St. Paul," Social Work, Vol. 1, No. 4, October, 1956, pp. 41-47.

Boehm, Werner W. Diagnostic Categories in Social Casework: Problems and Prospects. Paper presented at National Conference on Social Welfare, New York, 1961.

Bue11, Alice Voiland. "Family Casework Diagnosis - An Interpretation," Children, Vol. 10, No. 4, July-August, 1963, p. 163.

Bue11, Bradley. Is Prevention Possible? New York: Community Research Associates, Inc., 1959.

Bue11, Bradley. "Know What the What Is," The Survey Midmonthly, Vol. 84, No. 10, October, 1948, pp. 299-302.

Bue11, Bradley. "Preventing and Controlling Disordered Behavior," Mental Hygiene, Vol. 39, No. 3, July, 1955, pp. 365-375.

Bue11, Bradley. "We Know Better than We Do," The Survey Midmonthly, Vol. 87, No. 12, December, 1951, pp. 533-535.

Bue11, Bradley, and Associates. Community Planning for Human Services. New York: Columbia University Press, 1952.

Bue11, Bradley, and Associates. "Reorganizing to Prevent and Control Disordered Behavior," Mental Hygiene, Vo1. 42, No. 2, April, 1958, pp. 155-194.

Community Research Associates. The Prevention of Dependency in Winona County, Minnesota. New York: Community Research Associates, Inc., July, 1953.

Dixon, Wilfrid J. and Massey, Frank J., Jr. Introduction to Statistical Analysis. Second edition. New York-Pennsylvania: McGraw-Hill Books, Inc., 1957, p. 296. 
Edwards, Allen L. Techniques of Attitude Scale Construction. New York: Appleton-Century-Crofts, Inc., 1957.

E1ler, C. H., and Associates. "Health and Welfare Issues in Community Planning and the Problem of Indigent Disability," American Journal of Public Health, Vol. 48, No. 11, Supplement, November, 1958, pp. 1-49.

Fanshe1, David. "A Study of Caseworkers' Perceptions of their Clients," Social Casework, Vo1. 39, No. 10, December, 1958, pp. 543-551.

Feider, Leo J. "Casework in Rehabilitation," Public Welfare, Vol. 17, No. 4, October, 1959, pp. 145-150, 172.

Finestone, Samue1. "Issues Involved in Developing Diagnostic Classification for Casework," Casework Papers, 1960. New York: National Conference on Social Welfare, 1960.

Gay, Eleanor. "Collecting Data by Case Recording," Social Work, Vol. 3 No. 1, January, 1958, pp. 76-80.

Geismar, L. L. Measuring Family Functioning. St. Paul Family Centered Project. (Mimeographed)

Geismar, L. L. "The Multi-Problem Family: Significance of Research Findings," The Social Welfare Forum, 1960. New York: Columbia University Press, pp. 166-179.

Geismar, L. L. and Ayres, Beverly. "A Method for Evaluating the Social Functioning of Families under Treatment," Social Work, Vol. 4, No. 1, January, 1959, pp. 102-108.

Geismar, L. L. and Ayres, Beverly. Families in Trouble, An Analysis of Basic Social Characteristics of One Hundred Families Served by the Family Centered Project of St. Paul. St. Paul: Family Centered Project, January, 1958.

Geismar, L. L. and Ayres, Beverly. Patterns of Change in Problem Families. St. Paul Family Centered Project - Greater St. Paul Community Chest and Councils, Inc., July, 1959.

Glabe, Donald B., and Associates. "Reorientation for Treatment and Control. An Experiment in Public Welfare Administration," Special Supplement, Public Welfare, Vol. 16, No. 2, April, 1958, pp. I-XXIII.

Greving, Frank T. "Basis and Plan for More Effective Use of Community Resources for Mental Health," Mental Hygiene, Vol. 42, No. 4, October, 1958, pp. 570-577. 
Heyman, Margaret M. "Criteria for the Allocation of Cases According to Levels of Staff Skil1," Social Casework, Vo1. 42, No. 2, July, 1961, pp. 325-331.

Interim Committee on Local Government. Portland Area Study, Staff Research Report No. 1, July 13, 1956.

Kadushin, Alfred. "Testing Diagnostic Competence: A Problem for Social Work Research," Social Casework, Vol. 44, No. 7, July, 1963, pp. 397404.

Kogan, Leonard S., and Associates. A Follow-up Study of the Results of Social Casework. New York: Family Service Association of America, 1953.

Lefson, Leon. "Critical Decisions in Public Welfare Programs," Social Service Review, Vol. 36, No. 1, March, 1962, pp. 32-43.

Lukoff, Irving F. and Mencher, Samuel. "A Critique of the Conceptual Foundation of Community Research Associates," Social Service Review, Vo1. 36, No. 4, December, 1962, pp. 433-443.

Lurie, Harry L. "Community Planning for Human Services: A Review," Child Welfare, Vol. 32, No. 1, February, 1953, pp. 11-14.

Maas, Henry S. "Family Casework Diagnosis: An Essay Review," Social Service Review, Vol. 36, No. 4, December, 1962, pp. 444-450.

Mencher, Samuel. "Principles of Social Work Organization," Social Casework, Vo1. 44, No. 5, May, 1963, pp. 262-266.

Meyer, Carol H. "Individualizing the Multi-Problem Family," Social Casework, Vol. 44, No. 5, May, 1963, pp. 267-272.

Oregon State Public Welfare Commission. The Oregon Program for Case Classification and Planning Handbook. Salem: State Public Welfare Commission, 1963.

0'Reilly, Charles T. and Kellum, Constance E. Factors Underlying Caseweighting in Public Assistance: A Research Report. The School of Social Work, Loyola University, Chicago, 1962.

Overton, Alice. "Casework as a Partnership," Children, Vol. 3, No. 5, September-October, 1956, pp. 181-186.

Overton, Alice, and Associates. Casework Notebook. Second edition.

St. Paul: Family Centered Project, March, 1959.

Page, Harry 0. "Case Classification: Administrative Tool for Effective Service," Public Welfare, Vol. 20, No. 1, January 20, 1962, pp. 44. 
Page, Harry 0. A New Direction for Public Welfare. A speech at Biennial Round Table. Conference of the American Public Welfare Association, 1961. New York: Community Research Associates, Inc.

Philadelphia County Board of Assistance. The Philadelphia Rehabilitation Unit. December, 1958.

Philadelphia County Board of Assistance. Toward Family Renewal. Annual Report, Philadelphia County Board of Assistance, 1958.

Pollack, Otto. "Design of a Model of Healthy Family Relationships as a Basis for Evaluative Research," Social Service Review, Vol. 31, No. 4, December, 1957, pp. 369-376.

Presley, Betty L. "Marin Project Speech," Welfare News. Chicago: September, 1958.

"Public Law 87-543, Section 104(b)," a revision of the Handbook of Public Assistance Administration, No. I-1000, Part I, transmitted by State Letter No. 588 of the Bureau of Family Services, Social Security Administration, United States Department of Health, Education and We1fare. Washington: September 4, 1962, p. 103.

Public Welfare in Oregon, Vol. 28, No. 11. Salem: State Public Welfare Commission, November, 1963.

"Recent Developments in Public Assistance," Social Service Review, Vol. 37, No. 1, March, 1963, p. 93.

Ripple, Lillian, and Alexander, Ernestina. "Motivation, Capacity, and Opportunity as Related to the Use of Casework Service: Nature of Client's Problem," Social Service Review, Vol. 30, No. 1, March, 1956, pp. 38-54.

Robinson, Marion 0. "Community-wide Planning for Family, Health and Welfare," Marriage and Family Living, Vol. 19, No. 2, May, 1957, pp. $198-203$.

Selby, Lola. "Typologies for Caseworkers - Some Considerations and Problems," Social Service Review, Vol. 32, No. 4, December, 1958, pp. 341-349.

Social Research Service, State Charities Aid Association. MultiProblem Families - A New Name or a New Problem? New York: May, 1960.

Tannar, Virginia L. "The Public Welfare Worker in Family Crisis," The Social Welfare Forum, 1962. New York: Columbia University Press, 1962, pp. 202-214. 
Thomas, Edwin J. and McLeod, Donna L. "A Research Evaluation of InService Training and of Reduced Workloads in Aid to Dependent Children," Public Welfare, Vol. 16, No. 2, April, 1958, pp. 109112, $132-134$.

Thomas, Edwin J. and McLeod, Donna L. The Effectiveness of In-Service Training and of Reduced Workloads in Aid to Dependent Children. A Report of an Experiment Conducted in Michigan. School of Social Work, University of Michigan: August, 1957.

Thorndike, Robert L. "The Problem of Prediction," Social Welfare Forum, 1957. New York: Columbia University Press, 1957, pp. 26-41.

United States Bureau of Census. United States Census of Population, 1960 , Number of Inhabitants, Oregon. Final Report PC (1)-39A. Washington, D.C.: U. S. Government Printing Office, 1961.

Voiland, Alice, and Associates. Family Casework Diagnosis. New YorkLondon: Columbia University Press, 1962, Chap. II.

Volland, Alice N., and Buell, Bradley. "A Classification of Disordered Family Types," Social Work, Vol. 6, No. 4, October, 1961, pp. 3-11.

Walton, Eloise. "Let's Work Together in Community Service," Public Affairs Pamphlet, No. 194, April, 1953, pp. 1-28.

Webster's New Collegiate Dictionary. Springfield, Mass.: G. \& C. Merriam Co., 1953, p. 57 .

Wiltse, Kermit T. "New Approaches to the Administration of ADC Programs," Casework Papers. New York: Family Service Association, 1959, pp. 20-30.

Wiltse, Kermit T. Social Casework in Public Assistance. State of California Department of Social Welfare, 1951, pp. 1-35.

Wiltse, Kermit T. and Fikel, Justine. "A Study of the Administration of the ADC Program," ADC: Problems and Promise. Chicago: American Public Welfare Association, 1959. 
APPENDIXES 
115

EXHIBIT A

CASE PLANNING SCHEDULE 
Case Name:

Rel to

Date of change:

ame

Head Birthdate

Birthplace Educ. 
Adult self-image

Usually feels able to cope with responsibilities

b. Sometimes " " " " "

Seldom " " " " " " " " " " " " "

d. Usually comfortable in role of adult -- as parent, spouse

e. Sometimes " " " " " " " " " " " " " "

$f$ Seldom " " " " " " " " " " " " " " " "

Relationships to family, others

a. Usually warm, responsive

b. Sometimes " "

Seldom " "

Gemerally emotionally independent

Sometimes " "

Seldom " "

8. Usually successful in marital adjustment

h. Sometimes " " " " " " " "

i. Seldom " " " "

Relationship to community

a. Usually participates in community activities (e.g., church, clubs, PTA)

b. Sometimes " " " " " " " "

c. Seldom participates " " " " " " "

d. Usually accepts commuinity standards

Sometimes " " "

Seldom accepts " "

g. Community usually accepts the adult (behavior, race, standard of living)

h. Community sometimes " " " " " " " " " " " " " " " " " "

i. Community seldom accepts " " "

arrent Adult Problems

" "

" "

A. Chronic feeling of inadequacy

B. Unsatisfactory relationships with family, relatives

C. Adult unable to cope with marital problems

D. Unsatisfactory interaction with community

E. Adult rejects community moral standards

F. Adult in conflict with: (1) school (2) the law (3) agency (encircle)

G. No apparent problem

H. Other - explain

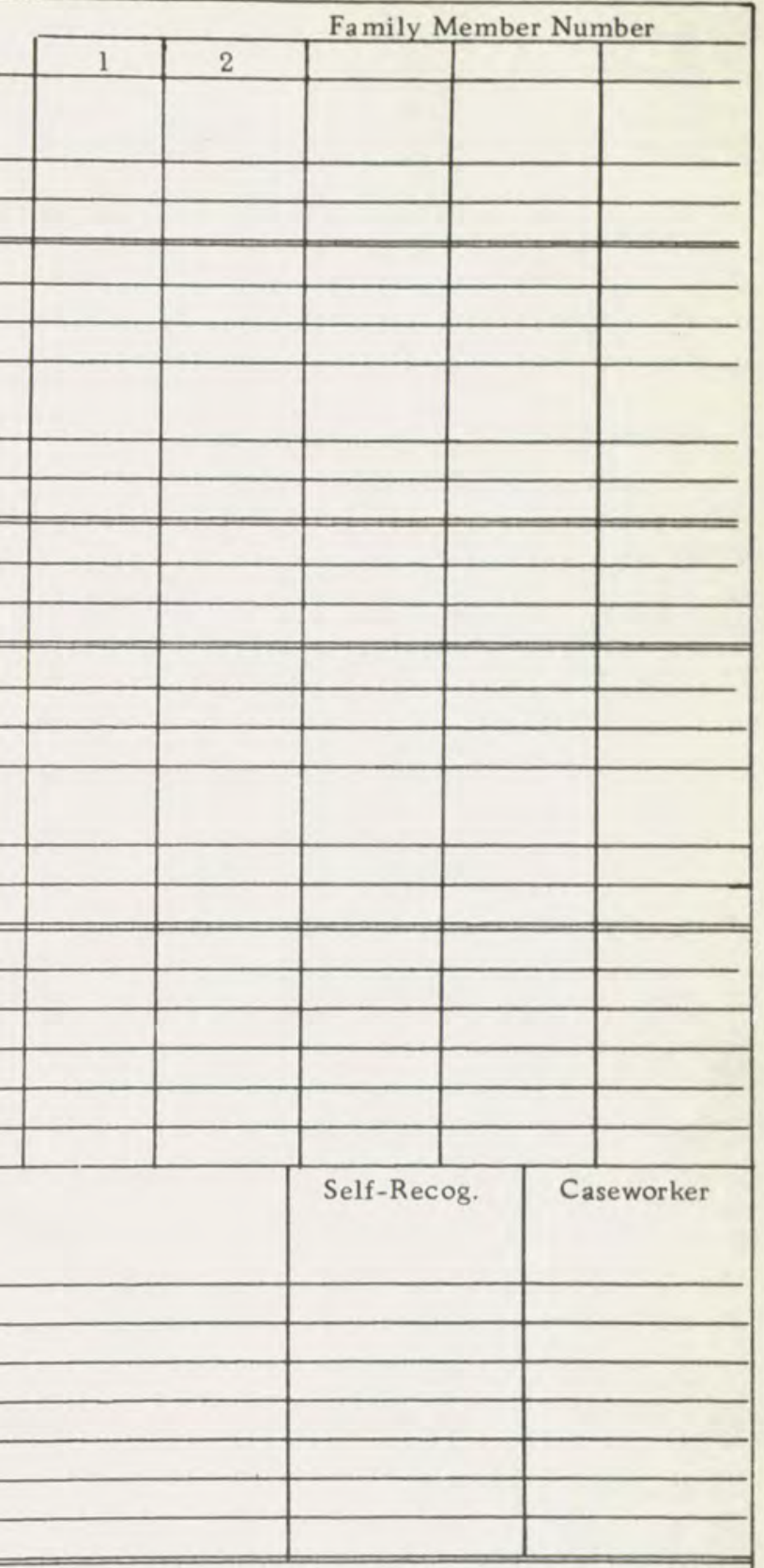


aluate These Characteristics

Parent care and supervision

3. Basic needs usually met (food, sleep, housing, medical care)

Basic needs sometimes met " " " "

Basic needs seldom met " " " "

Usually meets emotional needs of children

Sometimes meets " " " "

Seldom " " " "

Usually encourages participation of other parent

Sometimes " " " "

Seldom encourages " " " "

Parent - child relationship

a. Usually warm, responsive

Sometimes warm "

Seldom " "

Usually allows child to develop at own pace (not over-protective, over demanding)

Sometimes allows "

Seldom allows " " " " " " " " " "

Usually praises accomplishments

Sometimes " "

Seldom " "

Usually sets good example for children

Sometimes sets good " " "

Seldom sets good

Usually encourages responsibility for home tasks, habit training

Sometimes " " " " " "

Seldom " " " " " "

\section{Child Rearing Problems}

A. Parent does not plan appropriate substitute care when absent

B. Parent neglects basic need for food, housing, medical care

C. Parent continues harmful housekeeping standards

D. Parent abuses or exploits children

E. Chronic parent-child conflict

F. Parent sets poor example for children

G. One parent family with lack of substitute for absent parent role

H. Emotional neglect

I. No apparent problem

J. Other - explain

Problems (enter code letter)

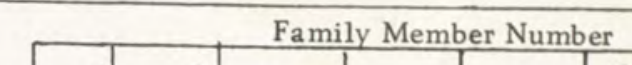

\begin{tabular}{|l|l|l|l|l|l|l|}
\hline & 2 & & & & Child \\
\hline & & & & & \\
\hline & & & & & \\
\hline & & & & & \\
\hline & & & & & \\
\hline & & & & & \\
\hline & & & & & \\
\hline
\end{tabular}

(2)

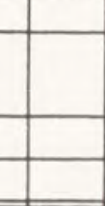

\begin{tabular}{|l|l|l|l|l|}
\hline & & & & \\
\hline & & & & \\
\hline & & & & \\
\hline
\end{tabular}

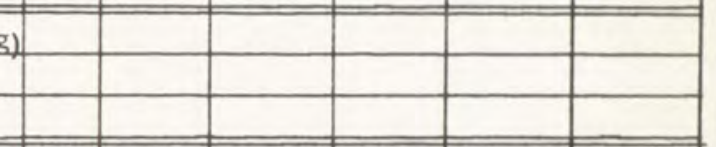


These Characteristics

\section{Relationship to family}

a.

b.

c. $\frac{s-1}{2}$

d. Usually has positive interaction with siblings

e. Sometimes has " " "

f. Scldom has " " " "

g. Usually shows appropriate degree of independence

Development of the child

a. Usually successful in social adjustment

b. Sometimes

c. Seldom

d. Development usually appropriate to age level (phy sical, motor, mental)

e. Development sometimes

f. Development seldom approrial

Relationships outside of home

a. School performance usually at grade level and age

b. School performance sometimes at grade level and age

c. School performance seldom at

d. Usually attends school regularly

e. Sometimes attends "

f. Seldom attends school regularly

8. Peer relationships usually successful

h. Peer relationships sometimes successful

i. Peer relationships seldome successful

j. Usually follows acceptable moral stancards

k. Sometimes "

hild Problems

roblem in family relationship

etarded development: (1)physical(2)emotional(3)mental(encircle

Unacceptable behavior symptom:(1)withdrawn(2)aggressive(3)sexual(encircle)

Child has school adjustment problem

Problem in peer relationship

Child in conflict with the law

No apparent problem

H. Other - explain

otential Problems (enter code letter)

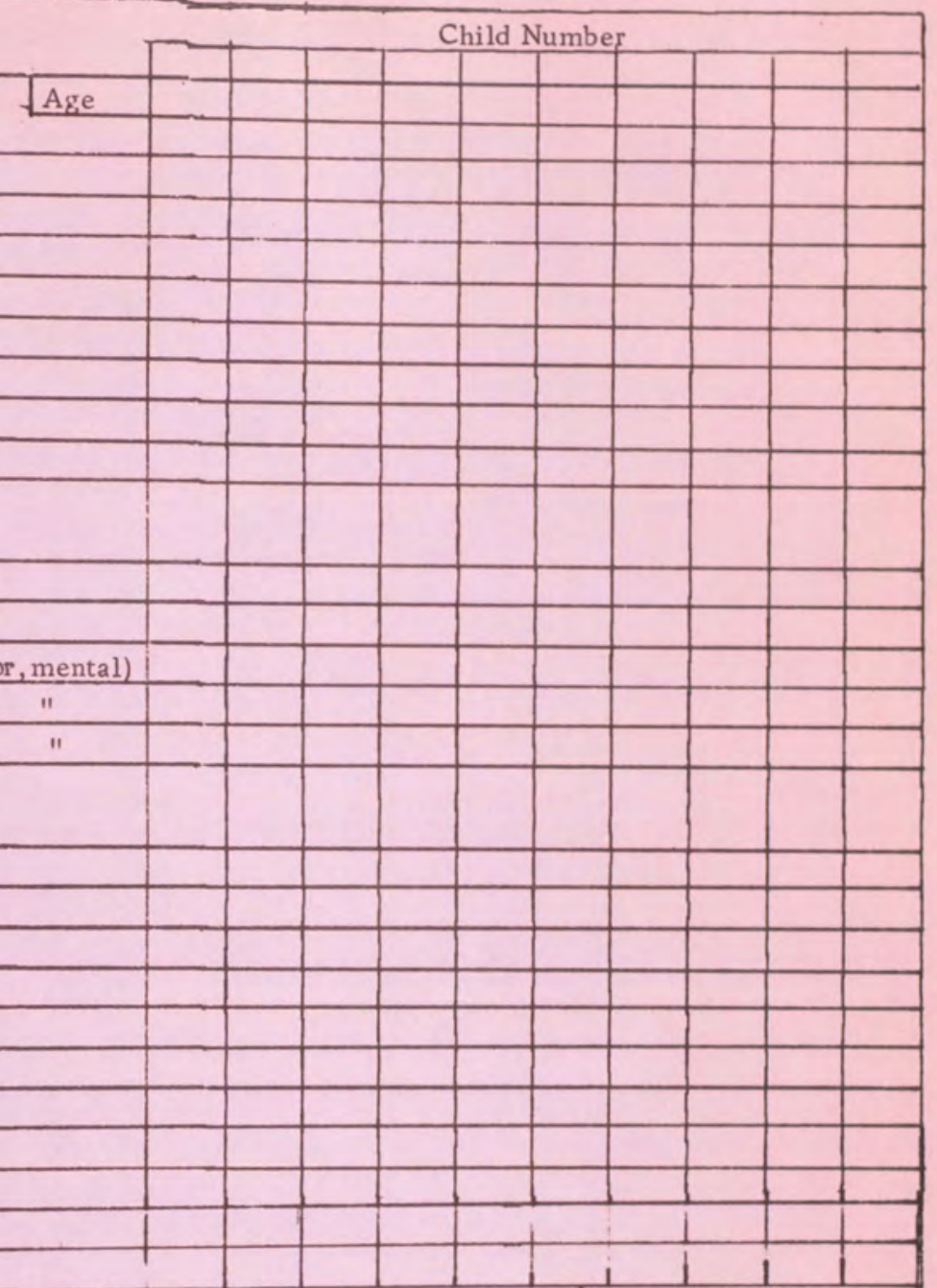

Self-Recog.

Caseworker

Prognosis - IMP

ML

DET 
These Characteristics

\begin{tabular}{|l|l|l|l|l|l|}
\cline { 2 - 5 } & \multicolumn{5}{|c|}{ Family Member Number } \\
\hline
\end{tabular}

Pential for self-support

Strong potential for rehabilitation

Questionable potential for rehabilitation

Poor potential for rehabilitation

Usually develops and uses financial resources

Sometimes develops and uses financial resources

Seldom develops and uses financial resources

Potential for self-support not applicable for evaluation

$k$ experience

Usually motivated toward self-support

Sometimes motivated toward self-support

Seldom motivated toward self-support

Usually is realistic about use of work skills, reso urces

Sometimes is realistic about use of work skills, resources

Seldom is realistic about use of work skills, resources

Lacks marketable work skills

handling and use of money

Income usually used to meet basic needs(housing, food, clothing)

Income sometimes used to meet basic needs

Income seldom used to meet basic needs

Usually wants to improve unsuitable living conditions

Sometimes wants to improve unsuitable living donditions

Seldom wants to improve unsuitable living conditions

Living conditions do not create a problem

port payments by parent or spouse

Usually contributes ac cording to agreement

Sometimes contributes according to agreement

Seldo $m$ contributes according to agreement

Pattern of contributions not applicable for evaluation

Financial Problems

Family has capacity for employment but is limited by: (1) education, (2) skills,

(3)age, (4) disability, (5) lack of marketable experience, (6) lack of substitute

child care, (7) employment not good social plan, (8) work not available (encircle

appropriate numbers)

Family does not seem motivated toward employment

Chronic mismanagement of funds

Chronic financial dependency

Family needs help in improving sub-standard housing or in obtaining household aids

such as washing machine, etc.

Non-support by parent or spouse

No apparent problem

Other - explain

reared in assistance family

Yes

No

Unknown

Problems (enter code letters)

Weaknesses

Treatment Steps 
valuate These Characteristics

- Physical Health

a. Usually in good health

b. Sometimes in good health

c. Seldom in good health

d. Physician diagnosed problem

e. Suspected health problems (undiaznosed)

Mental/emotional health

a. Usually in good mental/emotional health

b. Sometimes in good mental/emotional health

c. Seldom in good mental/emotional health

d. Physician's diagnosed mental/emotional health probelm

spected mental/emotional health problem (undiagnosed)

Reaction to health problems

a. Usua)ly able to care for self with health limitations

b. Sometimes able to care for self with health limitations

c. Seldom able to care for self with health limitations

d. Usually follows medical regime

e. Sometimes follows medical regime

f. Seldom follows medical regime

g. Usually realistic about health problems

h. Sometimes realistic about health problems

ldom realistic about health problems

ealth Problems

A. $\mathrm{P}$

ysical health problems needing: (1) diagnosis (2) treatment (3) spec. plnng. (encircle

B. Mental/emotional problems needing: (1)diagnosis(2)treatment(3)spec. plnng. (encircle)

C. Problem of patient's adjustment to health limitations

D. Family unable to accept member with illness

E. No apparent problem

F. Other - explain

tential Problems (enter code letter)

Family Member Number

\begin{tabular}{l|l|l}
\hline & & \\
\hline & & \\
\hline & & \\
\hline
\end{tabular}


iagnostic summary: Review all statements about strengths, weaknesses, all prognostications, and give brief description of ient-worker relationships:

Goals: Summarize from diagnostic work-up (pages 2-6). Use (f) to indicate stated goals of the family:

featment steps: Summarize from diagnostic work-up (jages 2-6) and foliow Public Welfare Service Guide P 7a, or P 7b:

ancial and other resources:

lanned for use

Not available

Non-existent

Velfare $\mathrm{C}_{\text {asework Plan for the year (encircle) }}$

Return home or to relatives 4. Adoption

Indefinite foster care

5. Self-support

nstitutional care $\#$

interview

6. No plan formulated

inte

pe per

Classification by level of needed serv
Improvement - within a year
Maintain level - within a year
Deteriorating - within a year

Schedule completed by:

\begin{tabular}{|l|l|l|}
\hline IS level & ES level & RS level \\
\hline & & \\
\hline & & \\
\hline
\end{tabular}

Date:

reviews due (page 8)

ment

Service

ental Service

Service
Date 
thild Families

wices for child families in need of assistance

Provide interpretation of needs as defined by agency standards and policies

Help obtain, develop, and use financial resources

Plan for correct determination of need

Maintain current and accurate eligibility determination

Help in sound income management

avices to unmarried parents and their children

Help to obtain living arrangements

Hclp obtain medical care (pre-natal, confinement, post-natal)

Hclp mother in planning for future self and child

Reier to Adoptive Services if mother plans to release child

Help to clarify legal status of unmarried parents

Provide counseling in preparation for marriage

Help to establish paternity

Help obtain financial support

Help mother in plans for substitute care

Hclp mother with more appropriate social planning

Obtain and help use specialized services (child welfare services, psychiatric,

psychological, legal, planned parenthood, Well Baby Clinic)

vices for families disrupted by desertion, separation, divorce, death or

pending breakup

Obtain support from absent parent

Provide marital counseling to maintain marriage or to reconcile parents

Help for the overburdened parent with dual role (money management,

child discipline)

Help handle emotional reactions to disrupted marriage

Obtain specialized services (marital counseling, psychiatric, psychological)

ivices for parents with potential for self-support

Obtain employment evaluation of skill, capacity, opportunity

Help obtain job training (DVR, Vocation Ed, Adult Ed, Comm. College)

Obtain and help use medical care for restoration or rehabilitation of capacity

Help to secure and maintain employment

Help to plan substitute care

Help obtain work necessities (clothing, transportation, etc.)

Help obtain and use specialized services (alcoholic rehab., AA, psychiatric)

vices for children in need of protection

Obtain and interpret facts of neglect and help parent assume responsibility

Help to improve homemaking and child-care practice

Obtain and help use specialized services (day care, training in homemaking or

child care, child welfare services, psychiatric, psychological)

Help plan for voluntary substitute care

Obtain court protection for the neglected child

ices for children with special needs

Obtain and help use medical services for the handicapped child (clinical

psychiatric, psychological)

Help with child behavior problems

Help to secure and continue special educational plans for children

Help older teenagers plan for or obtain employment

Date completed:

Check where appropriate:

\begin{tabular}{|l|l|l|l|l}
\hline Providing & $\begin{array}{l}\text { Plan to } \\
\text { Provide }\end{array}$ & $\begin{array}{l}\text { Unable to } \\
\text { Provide }\end{array}$ & Completed & NA \\
\hline
\end{tabular}

\begin{tabular}{ll|l|l|l}
\hline & & & & \\
\hline
\end{tabular}

\begin{tabular}{|l|l|l|l|l}
\hline & & & & \\
\hline & & & & \\
\hline
\end{tabular}


Non-Child Families

evices for non-child families in need of assistance

Provide interpretation of needs as defined by agency standards and policies Hclp obtain, develop, and use financial resources Plan for correct determination of need

Maintain current and accurate eligibility determination Help in sound income management

ervices for adults in need of protection

Obtain and help use medical services

Enlist help of relatives, friends for needed protection

Help secure and maintain healthy living conditions

Help arrange for specialized services (foster care, group care, institutional care, friendly visitor, volunteer service)

Help obtain and use recreational, religious facilities

Help to secure legal protection (property rights, guardianship)

vices for adults who need to remain in or return to their own homes

Secure and help use medical services

Help manage in own home

Help obtain house keeper, homemaker

Enlist help of relatives, friends, and other resources

Help in plans for return to own home or community

ivices for adults with potential for self-support

Obtain employment evaluation of skills, capacity, opportunity

Obtain and help use medical care for restoration or rehabilitation of capacity

Obtain and help use training for employment (DVR, VA, Blind Commission,

Adult Education, Community College)

Help secure and maintain employment

Help obtain work necessities (clothing, transportation, etc.)

Help obtain and use specialized services (Alcoholic Rehab., AA, Senior

Craftsmen of Oregon)

Date completed:

Check where appropriate :

\begin{tabular}{l|l|l|l|l}
\hline Providing & $\begin{array}{l}\text { Plan to } \\
\text { Provide }\end{array}$ & $\begin{array}{l}\text { Unable to } \\
\text { Provide }\end{array}$ & Completed & NA \\
\hline
\end{tabular}


ction to separation from parents

Usually accepts separation

Sometimes accepts separation

Seldom accepts separation

Family relationships severed

lationship to substitute parental figures

Usually warm affectional relationships

Sometimes warm relationships

Seldom warm relationships

Usually accepts parental authority and direction

Sometimes accepts

Seldom accepts

lationship to other children in same home

Usually has positive interaction with siblings

\begin{tabular}{lllll} 
Sometimes has " & " & " \\
\hline Seldom has & " & "
\end{tabular}

Usually has positive interaction with non-siblings

Sometimes has positive interaction with non-siblings

Sellom has positive interaction " " "

No other children in same home

Problems of Child in Substitute Care

Unable to accept separation

Child does not understand reason for separation

No contact with own: (1) family (2) siblings (3) relatives (encircle)

Unable to relate positively to substitute parents

Unable to relate positively to other children in the same home

Child's total adjustment in substitute care unsatisfactory

No apparent problem

Other - Explain

al Problems (enter code letters)

\begin{tabular}{|l|l|l|l|l|l|l|l|l|}
4 & 5 & 6 & 7 & 8 & 9 & 10 & 11 & 12 \\
\hline
\end{tabular}

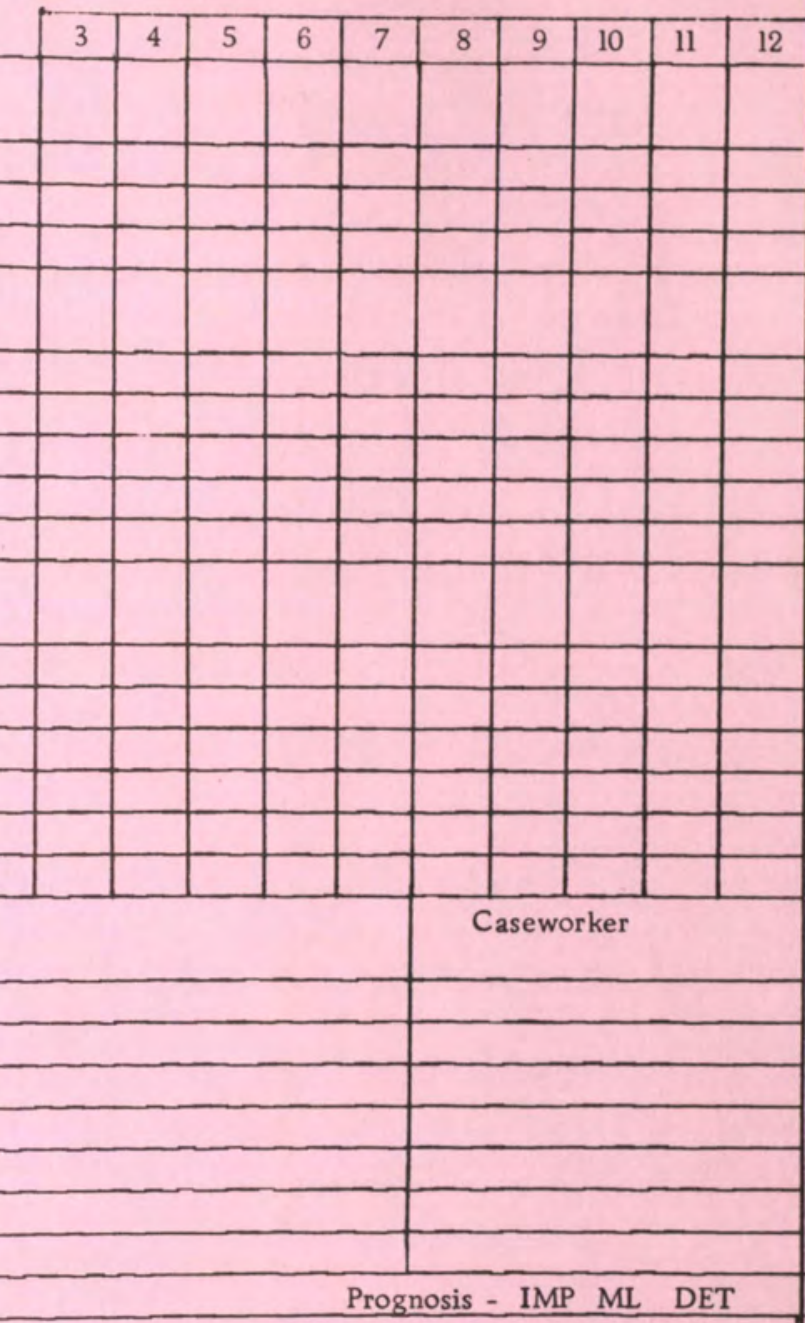


Prog. \& Case No.

These Characteristics

Relationship to child

Usually warm affectional relationship

Sometimes warm affectional relationship

Seldom warm

Usually contacts child

Sometimes contacts child

Seldom contacts child

of agency planning

Usually cooperates in plan for visits

Sometimes cooperates in plan for visits

Seldom cooperates in plan for visits

Usually aids adjustment in placement

Sometimes aids adjustment in placement

Seldom aids adjustment in placement

ancial support

Voluntary agreement

Court ordered agreement

Unable to support because of illness, no income or other reasons

Usually contributes according to agreement

Sometimes contributes according to agreement

Seldom contributes according to agreement

ental support indirectly through

OASDI

Veterans Benefits

Indian Benefits

Other inheritance

Other: explain

Problems in Parental Functioning

Parent disrupts child adjustment in substitute care

Parent neglectful or indifferent in parental responsibility

Parent opposes or ignores planning for child

Parent has abandoned child

Parent fails to support in line with ability

No apparent problem

Other - explain

al Problems (enter code letters)

\begin{tabular}{|l|l|l|l|l|l|l|l|l|l|}
\hline 3 & 4 & 5 & 6 & 7 & 8 & 9 & 10 & 11 & 12 \\
\hline & & & & & & & & & \\
\hline & & & & & & & & & \\
\hline & & & & & & & & & \\
\hline & & & & & & & & & \\
\hline & & & & & & & & & \\
\hline & & & & & & & & & \\
\hline & & & & & & & & & \\
\hline & & & & & & & & & \\
\hline
\end{tabular}


These Characteristics

fult self-image

Usually accepts and understands decreased physical ability Sometimes " " " " " Seldom " " " " " " " " " " "

Usually accepts and understands decreased mental ability ometimes " " $4001 "$ " eldom " " " " " " " "

Isually has hobbies or interests which are satisfying ometimes has " " " " " Seldom " " " " " " "

lationship to family, others

Usually adjusts to changing role (loss of spouse, not being provider, etc.) \begin{tabular}{llllllllll}
\hline Sometimes " " " & " & " & " & " & " & " & "
\end{tabular} Usually has close supportive contacts with family Sometimes has" " " " " Seldom has " " " " " Usually has contact with friends

Sometimes has " " "

Seldom " " "

ustment to placement

Usually forms satisfying relationship to group

Sometimes " " " "

Seldom " " " " "

Usually adjusts to routine of facility

$\begin{array}{llllll}\text { ometimes " } & \text { " } & \text { " } & \text { n } & \\ \text { eldom } " & \text { " } & \text { " } & \text { " }\end{array}$

Usually has satisfying relationships with facility staff Sometimes has " Seldom " " " " " " " "

roblems of Adult in Substitute Care

Adult does not accept physical or mental limitations

ult does not accept substitue care planning

contact with: (1) family (2) friends (encircle)

ult has difficulty in relating to the group

ult has not cultivated or maintained satisfying hobbies or interests

dult's total adjustment in substitue care unsatisfactory

apparent problem

her - explain

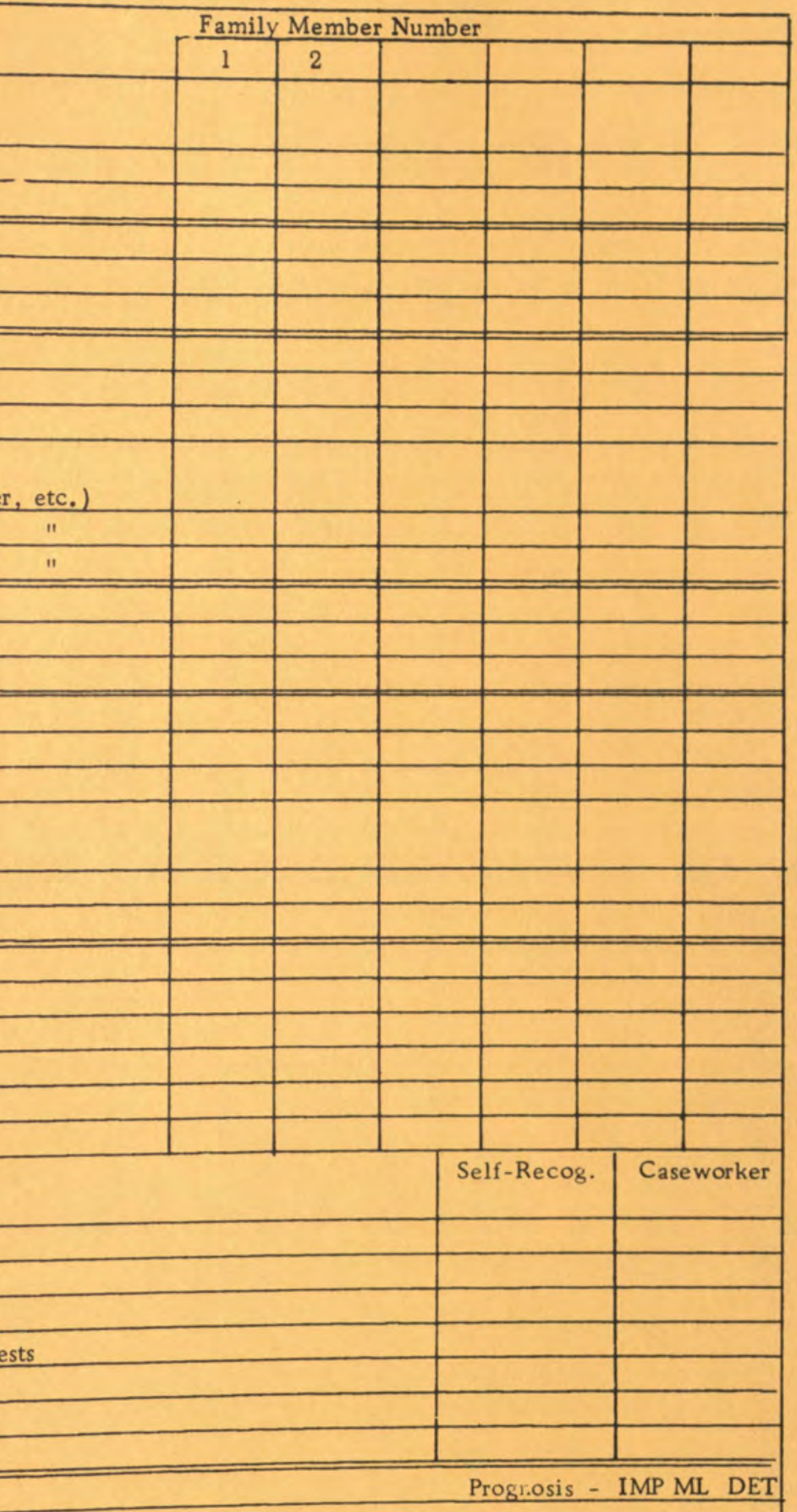

Weaknesses

Treatment Steps 
f Worker

Date

Number of Contacts

Name

Covered

to

Case Number

ent Diagnostic Summary:

Over-All Status: IMP ML DET

\begin{tabular}{|l|l|l|}
\hline & Current & Current Goals \\
\hline Sub. Care & & \\
\hline Rearing & & \\
\hline Sub. Care & & \\
\hline Sub. Care & & \\
\hline cial & & \\
\hline
\end{tabular}

nt Treatment Plan (including resources in use or to be used). Follow Public Welfare Services Guide Page 7a or 7b:

res not available:

non-existent:

at start of review period $\$$

sed because of services:

ened earnings

loyment; training

sehold equipment

sekeeping services

d Care services ther

\begin{tabular}{|l|l|l|l|}
\hline Classification & IS & ES & RS \\
\hline vement & & & \\
\hline an Level & & & \\
\hline oration & & & \\
\hline
\end{tabular}

Change due to service:

Increase \$

Decrease \$

Decreased because of services:

Increase in self-support

Increased support of parent

Increase in contribution or

other benefits (OASDI, VA)

Resources available for use

Case Closed

Other

Prior

Rate of interviews

per

Date next review due

Assignment

Changed to

Initials of Supervisor 
EXHIBIT B

INSTRUCTIONS FOR THE COMPLETION OF

THE CASE PLANNING SCHEDULE (SPW 444) 


\section{Instructions for the Completion of the Case Planning Schedule}

(SPW 444 )

The Case Planning Schedule is the most important case planning tool in the Program for Case Classification and Planning as it becomes the primary vehicle through which each family unit is analyzed and classified. Completion of the CPS according to the instructions will increase the validity of the information upon which the agency can base its planning. The CPS is organized in four sections: Section I, the Face Sheet, Page 1 and the Diagnostic Work-up, Pages 2-6; Section II, Treatment PIanning, Page 7; Section III, The Public-Welfare Services Guide, Pages $7 \mathrm{a}$ and $7 \mathrm{~b}$; Section IV, The Planning Review, Page 8. All of the instructions for these sections are included in this one set of instructions. It is intended that the schedule be completed as accurately as possible with written entries being brief and to the point. Entries are to be made in pencil or ink. Questions about specific entries or the interpretation of certain items should be cleared with the Director of the Program for Case Classification and Planning or with the Field Representative.

\section{The Face Sheet CPS Page I Section I}

The CPS Face Sheet is designed to enable the caseworker to focus upon the unit of persons who will comprise the casework unit. This is the unit toward which the caseworker will direct casework planning and treatment. This face sheet is a modification of the PA 403 Face Sheet of 11-59. The instructions for this new Face Sheet are included in the instructions for the Case Planning Schedule and will not be found on the vack of the Face Sheet.

\section{The Family Unit Concept}

Any individual acquires a set of social values primarily from the family into which he is born and in which he is reared. Whatever the characteristics of a particular society, the family is a collection of individuals who must function as a group. The family has a group identity resulting from the interaction between the individual members in relation to the social functions which they must perform. Knowledge of each person's role in the family and the way in which the family group functions is an obvious necessity in diagnostic understanding.

Analysis of social functioning and plans for improving this functioning obviously cannot include all members of the broad biological family group. Some members may be separated physically and the assessment of their social functioning may be a separate analysis. For example, an aged couple may be living with a married son and his family. However, the evaluation of their functioning cannot be made through one CPS. Financial functioning, adult relationships, or child rearing may involve one set of facts for the aged couple, and another for the son and his family. 
In assessing the social functioning of the individual, he or she must be seen in the context of the family group, not seen as an isolated individual, as be or she influences and is influenced by the group. Bven when the home is broken by divorce, desertion or the temporary separation of one of the parents or children, the remaining group is the basis for assessing individual and family social functioning.

\section{Basic Family Units}

There are both child family and non-child family units. A family consists of two or more persons related by birth, marriage, or adoption, who usually reside together in a common household. Family members physically absent from the home, but legally still a part of the family are considered as part of the basic family unit. Former family members legally separated from the family, are no longer considered a part of the original case unit, and if they continue to receive services, are considered as a separate family unit.

Examples of the constellation of persons who would be considered as part of the same family unit, analyzed on the same CPS:

Non-child Family

1. Adult married couples, living with adult self-maintaining children who have no children of their own.

2. Adult married couples, one or both of whom are living in substitute care such as a nursing home, home for the aged, institution or foster care.

3. Single adults living alone or single adult siblings living together.

4. A single adult or a married couple with an adult child who is dependent on the parent or parents for physical care and support.

\section{Child Family}

5. A single adult and a minor child or children.

6. A married couple and thesir minor children.

7. Persons in penal or mental institutions and their families, as long as they are legally still part of the family.

8. Children in foster care and their original families as long as parental rights have not been permanently terminated.

9. A minor unwed mother (under 21) and her child who is residing with her parents.

Examples of more than one family unit requiring separate Case Planning Schedules:

1. An adult unwed mother and her child residing with her parents. 
2. An aged couple residing with their children who have children of their own.

3. Divorced or legally separated family heads would be two family units if both parties were receiving agency services.

4. Families with children where parental rights have been terminated -- the parents and children would be separate units if services were being given to each unit.

\section{Other Influential Persons}

Although the basic family unit must be carefully defined for purposes of analysis and planning, there are often other persons whose functioning must be analyzed in relation to members of the family unit, either to help determine financial eligibility or as part of the treatment planning. Such persons must be distinguished from the family unit but their functioning may be analyzed in relationship to the role they plan in connection with the social functioning of the family unit.

Such persons might include: divorced or deserted spouses who maintain some contact with the family; children who no longer are a part of the family unit; other relatives; guardians; foster parents; close friends.

\section{Instructions for the Face Sheet Page I}

Identifying Information - As in the past, the heading should be completed by recording the program and case number and by identifying the county. The family surname should be entered as well as the date of the completion of the face sheet. The date of change should be entered whenever significant changes are made in the family unit or in social characteristics about the individual members of the unit. If the family was known to the agency in the past under another name, enter the previous name (or number) under cross reference at the bottom of the face sheet.

Family Unit Compositon - Line 1-12 are reserved for members of the basic family unit. Line \#I is reserved for the male head (MH) of the unit if he is the legal spouse of the female head (FH). He may be the natural father or the step-father of the children. No other persons should be listed on this line.

Line \#2 is reserved for the female head (FH) of the unit. She may be the mother or step-mother of the children listed. No other persons should be listed on this line.

Please note - Divorced or legally separated spouses should not be listed on line \#I or 2 but, rather, under Other Iegal Parents, lines \#13 and $I_{4}$ (If additional space is required lines \#15 and 16 may also be used.) Unwed parents (usually the father) also should not be listed on lines \#I or 2 but in Other Legal Parents if paternity has been legally determined or in Other Significant Persons if no legal action has occurred. This 
would be true whether this unwed parent were living in the same household as the family unit or elsewhere. A deceased parent woulbe be listed in the Marital History of $\mathrm{MH}, \mathrm{FH}$.

Substitute parents such as uncles, aunts, grandparents or foster parents are not listed on lines \#I or \#2 although they may be providing the care and supervision of the children. All substitute parents are to be shown on line \#19 for the male substitute parent and line \#20 for the female substitute parent. Foster parents are not shown on the face sheet but are listed on the Child's Foster Care Placement Record.

Deserting fathers are to be listed on line \#I (MH) although there may not be current contact and his whereabouts may be totally unknown. Deserting mothers are to be listed on line \#2 (FH). Deserting parents would be listed in this way until there is a change in their legal status, i.e., divorce, legal separation or death of the parent.

In the situation of a mon-child family in which there are parents and an adult child, who continues to be dependent upon the parents for physical care and support, living in the same household this adult dependent child should be listed on line \#3 following the adult male and Pemale heads on line 1 and 2 .

In those cases where two adult siblings are living together, planning cannot be carried out for one in isolation from the other, therefore list one sibling on line \#1 if a male or line \#2 if a female and the other sibling on line \#3.

It is intended that whenever a caseworker analyzes the functioning of a family unit or when formulating treatment planning for a family unit, the parent must be included in such an analysis. When the parent is physically absent it is important not to forget the significant influence of that parent upon the family planning, even though there may be no recent contact.

Lines 3-12 are reserved for the minor children and adult dependent children in the family unit. Iines 13-18 are reserved for Other Iegal Parents and for Other Significant Persons. It is important to identify the relationship between those listed on lines 3-20 to the head of the family unit. $\frac{\text { Basic Social Information - Additional information is to be entered for }}{\text { each individual included in the family unit (lines 1-12) and Other Legal }}$ Parents (lines 13 and 14 ). The needed information must be added when available. When such information is not available at the time of the case analysis, leave the item blank. The needed information must be added when available.

Rel. to Head - Enter relationshio to the head of the family unit. 
Birthdate - Self-Explanatory.

Birthplace - Self-Explanatory.

Education - Enter completed grade number as of date of case analysis for both adults and children。

Race - This space is intended for listing the individual's race, using the definition currently in use by the U. S. Bureau of Census, the Children's Bureau and others. This is: White (W), including Mexican; Negro $(\mathrm{N})$; Indian (I); Other (O). A determination of what race a person may belong to may vary according to the situation. In some cases, the worker may indicate the person's race in accordance with general community standards as the way in which the community sees the person will have an eifect on his functioning and on casework planning. In other situations, race may be indicated in relation to a possible resource, such as Indian benefits.

Religion - Enter the appropriate abbreviation for the person's religious denomination。

The spaces for race and religion allow for only an indication of these two items, yet the meaning of race or religion to the individual and to his family may have considerable significance beyond what can be shown on the face sheet. It may be necessary, therefore, to give these matters much consideration when describing various areas of family functioning on subsequent pages of the CPS.

Whereabouts - For those persons not residing with the family unit, enter the amount of information which would establish their residence elsewhere. This might include a child temporarily living with a relative (e.g., an aunt), an adult who is in the hospital (e.g., in OSH) or a parent who is not legally separated (e.g., city or state). This entry does not replace the address sheat or other records which might require more specific addresses.

Legal Custody with whom - This column asks for information about the legal custody of the child when there has been a change in parental custody by court action. The name and relationship of the person should. be entered or the name of the institution should be entered. For adults, the guardianship status as established by court order should be entered on the appropriate line showing the name of the guardian.

Date of action - Enter here the date of the court order affecting the legal custody or the guardianship. Do not enter the date of the referral to the court.

Other Legal Parents - In this section are listed parents who are no longer functioning as head of the family unit due to legal action such 
as divorce or legal separation. Also listed in this section would be an unmarried parent, whether or not this unmarried parent is living with the head of the family unit, if paternity has been established and is legally recognized.

Other Significant Persons - This section is to be used for listing of other persons who are not members of the family unit but whose interaction with it or any of its members is of such significance that their functioning as it relates to the family should be analyzed in relationship to eligibility determination or treatment planning. Such persons might include divorced or deserting spouses, children who are no longer a part of the family unit, other relatives, guardians or close friends. Substitute parents, except foster parents, should be listed on lines 19 and 20 of this section.

Marital History of $\mathrm{MH}, \mathrm{FH}$ - Enter the information about the marital history of the $\mathrm{NH}$ and $\mathrm{FH}_{0}$ urrent status refers to the status of the head of the unit at the time of completion of the face sheet. If the parent is unmarried enter the word "unwed". If the unit head has never married enter the word "single". Do not enter the word "desertion" here since it does not describe the legal marital status. The Date of Current Marriage and the Date of Current Divorce or Legal Separation blanks must always be completed. If there is confusion or lack of knowledge about these dates, leave the item blank until the factual information is obtained.

The rest of the items about previous marriages are self-explanatory. The number of children still responsible for is to be completed by showing the number of children for whom the unit head might still be carrying some responsibility other than the children who are members of the present family unit and who are listed on lines 3-12. An entry might be for the present male head: 3 with mother in California.

Social Security Number - Enter the Social Security Number (sometimes referred to as OASDI No. or S.S.A.N.) opposite the family number listed in the column to the left.

Other claim numbers, cross references, other active agencies, etc. This space is provided for previous case numbers and other information

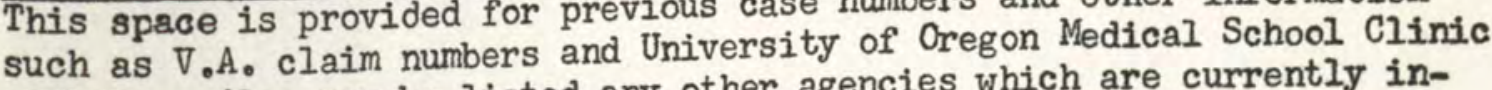
numbers. Also may be listed any other agencies which are currently involved in planning with the family unit or any of it's members.

\section{The Diagnostic Workup CPS Pages $2-6$ Section I}

These pages are designed as a tool to help the caseworker evaluate the characteristics, social problems, adjustment, strengths, weaknesses, and to make predictions about the behavior of the members of the family unit. This part of the Case Planning Schedule will help guide the 
analysis of those who are identified as being included in the basic work unit or theraputic unit toward whick casework planning will be directed. A similar format or design is used for each of these pages. Note that each page is entitled by an area of social functioning. These broad areas of social functioning have each been given a separate page to facilitate the partialization of social characteristics and problems in each of these areas, however, it must be remembered that the family's functioning in any area is interdependent on, and interrelated with, the other areas.

All entries made on these pages should be carefully done and should be based upon the best judgment of the caseworker according to the evidence available through the case narrative and through direct experience with the family unit. These entries will not be evaluated according to the accuracy of completion but will be evaluated according to the logical relationship between the characteristics and the evaluative statements as have been entered on the CPS。 For example, if the item "Usually successful in marital adjustment" is checked for an adult on page 2, the current problem would not be "Chronic marital conflict" and the worker would not be identifying this characteristic as a weakness under the evaluative statements。

The classification of the family unit is based upon the Diagnostic Workup, in which social behavior is evaluated, problems are identified and treatment planning becomes goal directed. A classification system provides a means of relating social data to each other in a systematic way. The whole process becomes more explicit and therefore strengthens the scientific basis of casework practice. According to Werner Boehn, University of Minnesota Graduate School of Social Work,: "A classification system in casework can be defined as a set of diagnostic categories and a parallel set of treatment categories. The diagnostic categories help the caseworker to organize and order the phenomena he observes in a specific case and thereby facilitate his conclusions about the nature of the problems, the factors associated with its existence, and by implication, suggest a strategy of intervention. Treatment categories make explicit the goals of change and spell out the means of intervention implied in the diagnostic scheme. Treatment categories help the caseworker to identify the specific steps, resources and conditions which need to be marshalled to bring about the desired "goal"。

To help the caseworker systematize the diagnostic process, pages 2-6 are identified according to areas of social functioning. In evaluating behavior it becomes more helpful when the caseworker can evaluate according havior it becomes more helpful, when, child rearing, financial, and health.
to broad areas such as adult, child,
In focusing thinking about a specific area in an orderly way, it must be kept in mind that human behavior cannot be partialized when it comes to treatment planning。 Behavior in one area has an effect upon behavior in other areas. The dosign of the Case Planning Schedule helps to direct attention to a smaller and nore manageable dimonsion。 The CPS then leads 
the intellectual process from the more specific back to the general or to the summarization of the analysis and its meaning to the family unit. This in turn facilitates more adequate treatment planning.

The following format has been used on each page, 2 through 6 , including those pages designed for the evaluation of the adult in substitute care (Page 2a) and for the child in substitute care (Pages $4 \mathrm{a}$ and $4 \mathrm{~b}$ ).

\section{Characteristics}

In developing a social diagnosis, details of behavior or conditions must be reviewed and observed. These details which explain the nature and cause of social problems are generally referred tc as symptoms. For each area of social functioning the caseworker is to observe and identify the social relationships and role performance of members of the family unit. Indicate by use of a check mark ( $/ f)$ those characteristics which seem to more nearly describe the situation. If the list of characteristics does not seem to be complete or the wording does not seem to fit the situation as observed by the caseworker, star (*) the section and make a notation under strengths or weaknesses.

Note: Each item has been scaled by use of the words usually, sometimes, seldom. This scale is not intended to provide the complete range of possibilities but does eliminate the arbitrariness of a yes-no answer. Because of the variables involved, the caseworker could not know with absolute certainity, the frequency with which a behavioral pattern is repeated. The caseworker is able to observe and racord only a small part of the behavior of the family members. As a guide in using these terms, the dictionary definition is given for each: usually - ordimarily or customarily; sometimes - occasionally, now and then; seldom rarely, not often.

Do not try to make an entry in each area for each family member merely to indicate that it has been reviewed. If the caseworker does not have the information or does not know, please indicate by writing in the word "unknown" on the appropriate line. This will help the caseworker in future use of the CPS as a planning tool. Keep in mind that this analysis is based upon the judgment of the caseworker.

\section{Social Problems}

To redirect our efforts towards family rehabilitation and to strengthen family life, increase self care and improve self-support, it is necessary to identify those problems which might impede or at least which influence our ability to help the family or individual improve their social functioning. For each area of functioning a number of social problems have been listed. The goal in casework services is to help
resolve or ameliorate these social problems, some of which cannot be totally resolved without community action and planning. The fact that 
these problems will be identified does not imply that this agency can take full responsibility for the treatment necessary to remove them. On the other hand, to ignore the existence of these problems is sheer folly since the functioning of the family unit is directly related to their social problems. Future planning of the agency will mean more involvement in community planning as the agency moves forward from the mere identification of social problems towards the resolution of these problems.

The listing of problems is not intended to be all inclusive but does represent those problems which seem to be most significant to casework with family units. Please note that each list of problems provides for the identification of "other" problems if the list does not seem adequate. Experience has shown, however, that most social problems are listed in the Case Planning Schedule. Again, the identification of these problems depends upon the judgment of the caseworker.

These problems are to be identified when they represent the current situation at the time of the Diagnostic Work-up. The family unit will be reacting to these particular problems. Some of these problems may be fairly recent and some may have been influencing their social

functioning for many years. If a problem had occurred in the past, but has been resolved satisfactorily, do not identify it as being current. An example might be the fact that three years ago the male head of the unit was arrested for burglary. He was released after one year in jail and since that time has had no additional trouble with the authorities and seems to have altered his attitude toward law enforcement. In this situation the caseworker would not identify "Adult in Conflict with the Law" (CPS, Page 2) as being a current problem. Since problems do not exist in a vacuum, the caseworker must always judge the existence of a problem in relation to its effect on social functioning of the adult or family. When the caseworker has identified current social problems, the case recording and other social data must be available to support such judgments.

For each set of problems on Page 2 through 6 there are two or more columns. The column headed "Self-Recog." (Self-recognized) is intended for use in identifying problems of which the adult, parent or family has indicated an awareness. The column headed "Caseworker" is for use when it is a problem that the worker identifies. The caseworker's judgment will prevail as to whether or not an individual's actions, attitudes or limitations constitute a problem in a particular area. These columns will be marked with the family member number, or numbers, to indicate to which member, or members, of the family unit the problems belong. An example would be: The female head frequently becomes intoxicated in the home, setting a poor example for her adolescent daughter. She has told the caseworker of her fears that her behavior will influence her daughter's actions. On the CPS, Page 3 under Current Child Rearing Problems, the worker would identify "F, Parent sets poor example for the 


\section{$-10-$}

children" by marking "2" in the column headed Caseworker to indicate that this is a problem concerning the female head of the family unit. He would also mark a "2" in the Self-Recog. column to indicate that the FH has recognized the problem.

It is difficult to clearly establish the degree of seriousness of social problems, in all instances. By checking the problem as being current, the caseworker is not making a distinction on a value scale. If there is any real indication that the problems exist, the caseworker should check it. Under the sections labeled Strengths and Weaknesses the caseworker ebould write in statements which will establish the degree of the effect of social problems upon the member of the family unit.

\section{Potential Problems}

In reviewing social problems and determining whether or not they exist currently, the caseworker will also be thinking about the future functioning of the family unit. There may be indication that certain problems will develop in the near future which will affect the course of planning with the family unit. If this appears likely the caseworker should identify by problem letter according to the list of current social problems. Identification of potential problems is extremely important in helping to focus upon preventive casework activity. Potential problems to be identified might include those which would develop even with appropriate services being given, as well as those which might occur without services. Identification of potential problems is extremely important in helping to focus upon preventive casework activity. The classification of the family unit and the resultant administrative planning for services will be related to the potential problems and to the existing social problems.

\section{Prognosis}

A prognosis is essentially a prediction about the future course of social functioning and is based upon the identified current social problems, the evaluation of strengths, and the evaluation of weaknesses. The caseworker must predict what is likely to happen in an area of social functioning and should confine the prediction to the next 12-month period. The prognosis will influence the diagnostic summary and the treatment planning and will have a direct influence upon the administrative assignment according to the level of service. The prognosis is to be recorded by encircling one of the abbreviations, IMP, ML or DET. The prognosis is to be made with the assumption that appropriate services will be given in relation to the problems.

\section{Strengths, Weaknesses}

The fact of the existence of social problems does not, in itself, provide much direction to treatment planning unless the family's ability to cope 
with problems is carefully evaluated. Because the Case Classification System is problem oriented, it may appear to have a negative connotation but in the design of the Case Planning Schedule, Pages 2-6, space is provided for written evaluative comments which elaborate upon the strong points as well as the weak points in the area of social functioning. It requires an equal amount of skill and thought to identify the strengths in the family. The design of the CPS helps to give more direction to this identification. In the large boxes provided on each page of the Diagnostic Work-up, the written statements are to be brief and concise: If particular reference is made to a certain member of the family unit, the written entry should be identified by the appropriate family member number as first identified on the face sheet Page 1. These comments also need to be supported by the case narrative material whenever possible. The caseworker will also find that the review and identification of characteristics and problems will be concretized by these narrative statements. It is the beginning outline on the whole diagnostic and treatment plan. When necessary, the caseworker may write on the back of the page if not enough space is available. Note that the comments about Strengths and Weaknesses are related to an area of functioning and therefore is somewhat partialized. At the end of the Case Planning Schedule these comments will be summarized.

\section{Goals}

At the bottom of each page 2-6 covering each area of functioning, there is a space provided for a brief statement of goals. This should represent a concrete and concise statement about the future direction of casework activity in relation to existing and potential problems. Both long range and short range goals are to be included. The statement of goals represents the caseworkers plan and not necessarily the gools of the family unit. If their goals differ, this should be noted under the previous sections "Strengths", "Weaknesses". Please note that the statement of goals is related to each specific area and that these statements are later summarized and interrelated in Section II, Treatment Planning Page 7.

\section{Treatment Steps}

The caseworker is to list the specific steps to be followed in order to treat the situation and must be related to the goals. These steps are to be ranked by order of priority, in a logical series or sequence. Again, short concise statements are to be entered. Note that these statements about treatment steps will also be summarized and transposed to page 7 uf the Case Planning Schedule.

\section{Adult Functioning Page 2}

To supplement the previous instructions, some additional directions are given here as related to the adult area of functioning. The adult 
characteristics are listed to enable a review of what the adult thinks of himself, the adult's relationship to the family unit and his relationship to the community. The caseworker must evaluate each adult in the family unit. Extra columns are provided for adults who might be listed under Other Legal Parents or Other Significant Persons on the Face Sheet. This might include: relatives who are providing the care and supervision of the children; an adult son; or a guardian.

Problems can be identified by the caseworker for both the parent and the substitute parent by marking the appropriate family member number in the column headed "Caseworker". This column is also used for identifying problems of adults in non-child families. For any problem identified as being current, the worker should also encircle the code letter, e.g., (F) for adult in conflict. For those problems which contain several subparts the caseworker is to encircle the number of the appropriate subpart as well. For example if the adult is in conflict with the law, the number 2 would be encircled. This will facilitate later completion of the Planning Review, Page 8, CPS。

This page is designed for the evaluation of all adults whether or not they are aged, disabled or parents of small children. Although a more refined distinction could be made about special problems of the aged, this part of the schedule has been designed for more general use. The description of the meaning of the problem to the adult will be stated under Strengths and Weaknesses, thus allowing for greater clarification of problems peculiar to the aged or to a specific kind of disability.

\section{Adult Functioning in Substitute Care Page 2a}

This page is designed to supplement Page 2, CPS and is to be used to evaluate the functioning of an adult or adults in a nursing home, home for the aged, or other substitute care. Page $2 a$ is supplemental only and must be used in conjunction with Page 2, not as a substitute. Health problems will be indicated on Page 6 .

\section{Child Rearing Function Page 3}

The general instructions already given would also be followed for the completion of this page. Page 3 would not be completed if there were no minor children in the family unit. If the caseworker has any question abolt the child rearing practices, consult with the supervisor and review section 2507 Volume II of the Staff Manual Minimum Standards uf Care and Health for Children.

The several columns are intended to be checked in evaluating the way in which the parent or substitute parent carries out their role of rearing children. The final column entitled child is to be used whenever the child rearing practice affects a child in a different way from the majority of the children in the family. Parents sometimes reject a 
specific child while providing adequately for the other children. When this is noticed, the caseworker should note that observation and should elaborate through written comments in the large boxes at the bottom of the page. Write in the word "all" if the child rearing practice applies equally to each child in the family.

In order to complete this page properly, the caseworker will need to rely upon the way the parent talks about the child and upon his own personal observations of the relationship between the parent and the children, A review of the case narrative will also be helpful. If the caseworker has no knowledge about the child rearing practice the item should be identified by writing in the word unknown. In such an instance, the caseworker will be implementing future planning to fill in such gaps when they might exist.

\section{Child Functioning Page 4}

As a very important part of the Program for Case Classification and Planning, specific knowledge will be necessary for each child in the family. In the past, public assistance caseworkers have not been able to give proper attention to the children of public assistance families. This' becomes more necessary as the agency expands its services to families, in particular, the strengthening of family life. Hopefully, many families can be helped to the extent that these children will be less likely to repeat the patterns of their parents in the future.

The primary source of information about children is the parent. Whenever possible, the caseworker should observe and meet the children. Additional information might be found in the case narrative.

New emphasis is being given to school performance and school adjustment by the design of this page. Again the parent is the first source of information and when appropriate the school can be contacted to obtain additional information when it appears likely that there might be a problem in this area.

For each family with children attending school, the caseworker will need to discuss the children's sohool performance and adjustment with the parent. If the performance is poor or the child does not seem to have made a satisfactory adjustment to school, the worker should determine if there are factcrs in the family unit which might contribute, such as lack of adequate home study space, lack of warm, clean clothing for the child which is not greatly different in style and condition than that of his classmates or failure of the parent to encourage good study habits by providing privacy or quiet when necessary. If there are lacks in these areas the goals and treatment steps should reflect the need for planning to correct such problems. 
Child Functioning in Substitute Care Page $4 a$

This page and the one which follows are designed to be used whenever children are being cared for by adults who are not the parents of the children. This will include all children who are living with grandparents, uncles, aunts, older siblings, unrelated foster parents, etc. Children who are separated from their parents need additional consideration by the caseworker, even though they may be residing with relatives. The caseworker is not to take for granted the placement of a child with a relative, without evaluating the kind of home being provided and the kind care and supervision which might be given. The caseworker also needs to be aware of the child's feelings about being separated from the parent.

Page $4 \mathrm{a}$ is designed to help the caseworker evaluate the way in which a child relates to his substitute parents. This page supplements page 4 Child Functioning which covers more general information. Page $4 a$ is intended to provide a deeper analysis of children in substitute care.

The instructions for completing the various parts of this page are already given. Remember to write in the word "unknown" if the information is not available. Treatment planning will reflect the need to obtain more information.

\section{Parental Functioning with Child in Substitute Care Page $4 \mathrm{~b}$}

This page has been developed to be used along with page 4 a for children living in substitute care. Page $4 \mathrm{~b}$ has been designed to enable the caseworker to evaluate the way in which the natural or legal parent relates to the child and to the substitute home. Included is a review of use of agency planning, which implies that the caseworker helps to work out visiting between the natural parent and the child and which implies that the caseworker takes more responsibility for planning for the child than would be the case if the child were living in his own home. The caseworker should plan to encourage contact between the natural or legal parent and the child and should plan for the return of the child to his own home as soon as this is feasible.

The functioning of any or all children of a particular family who are in substitute care should be evelnated on one set of pages $4 \mathrm{a}$ and $4 \mathrm{~b}$ as part of the CPS evaluating the functioning of the family unit. The appropriate child number column will be marked for each child as he or she is listed on the face sheet. The completed CPS, including pages $4 \mathrm{a}$ and $4 \mathrm{~b}$ will be filed in the family file. Duplicate copies can be made if needed.

\section{Financial Functioning Page 5}

In reviewing this area of social functioning it is important to think 
about potential rehabilitation of the individual or family whenever there is any slight possibility of considering this as a plan to reduce financial dependercy. Jenerally, finsncial functioning includes a review of the kind of past work experience and the degree and type of skills and resources available to the client. Because money is so crucial to the adjustment of a member of our society, it is very important that the caseworker knows the way in which the family unit handles money and the way they react to the lack of financial security.

Under the current financial problems, further clarification is necessary in relation to those persons who have been displaced by the machine age or by automation and who are not among those to be considered for retraining because of age or limited capacity to learn new skills. When this appears to be a current problem in the area of financial functioning it is suggested that the problem be identified by encircling A, and \#5.

To help in interpreting the item, Chronic Financial Dependency the following information is provided. Chronic financial dependency usually means that a person has been primarily dependent upon the public agency or upon others for a long period of time. The definition of when this problem exists will vary because of economics, environmental, mental and physical health and psychological factors which influence the individual's motivation to become or to remain independent. Usually an attempt has been made to motivate the individual to a degree of self-support and after reasonable effort by the caseworker there has been no apparent change. The problem should be identified whenever a plan has been used for a year by the caseworker without apparent success. The caseworker is reminded that this problem can be identified as a Potential Problem when the worker believes that an attempt should be made to increase motivation toward self-support. It is assumed that self-support might be a reasonable goal for those who are identified as "chronic financial dependency". Those persons who are extremely poor employment risks because of age, disability and other factors would not necessarily be considered as chronically dependent.

This page is designed to allow the caseworker to identify the financial problems of both the parent or adult and the substitute parents. The problems listed on this page are to be identified only when it exists currently. For example, the caseworker should not check the problem of non-support if it is not a current problem but did exist in the past.

Parents reared in an assistance family is to be completed by checking yes, no, or unknown。 Check yes only if the parents received assistance for a sufficient length of time to have had a significant effect on the person, whether or not such effect is readily discernible. It is sometimes very significant to know that the family unit has such a history, as there frequently is a relationship between such a background and financial dependency. In thinking about this area, it might be helpful to comment about the fact that siblings of your client may also be receiving assistance. 
Because a great deal of material is being covered on the page Financial Functioning, not much space has been provided for written statements about strengths and weaknesses. Please feel free to use the back of the page when necessary.

\section{Health Problems Page 6}

This page is designed for the evaluation of health problems in the family unit. Evaluated would be the adults and children as well as the substitute parents. It is very important to determine the individual reaction and adjustment to illness. The degree of mental and physical health has an important affect upon the potential for rehabilitation.

Note that the caseworker must make a distinction between health problems which have been diagnosed by a physician, peychologist, or a psychiatrist and those problems which the caseworker thinks might be present but not yet diagnosed. All suspected health problems should be diagnosed and the treatment planning should reflect this goal. When a health problem has been diagnosed, this diagnosis should be entered in the large box Weaknesses, and should also be identified by family member number.

\section{Treatment Planning Page ? Section II}

This section provides for the summarization and integration of the knowledge about areas of social functioning, the problems which have been identified, the evaluation of the capacity of the family unit to handle their problems and the prognosis or future of the adjustment of the family unit. This section becomes most important as it provides the basis for the classification of the case which, in turn, enables the administration to make the necessary plans.

It will be necessary to summarize all comments about strength and weakness and integrate this material into a diagnostic summary for the family unit. At this point the caseworker will no longer be partializing the unit as was done with the examination by area of social functioning. The caseworker will be able to relate one area to the other then determine the way in which the family meets all their problems and the capacity the family might have for future improvement. A brief description is to be added to describe the kind of client-caseworker relationship which will influence the direction and the success of future goal-oriented planning. The worker will also use this section to elaborate and explain where necessary, the basis for prognostications made in the various areas of social functioning.

Goals will be summarized and restated in simple concise language, from those listed on page 2-6 of the Diagnostic Work-up. Open-end kinds of statements are to be avoided. Goals should be described as an expression of what the agency intends to do about current social problems as well as the prevention of future problems. As the caseworker records a goal on 
this page under $\underline{B}$, it should be identified by area of functioning such as Health, etc. In many instances, goals will be listed which have been stated or strongly implied by the family. These will be prefixed with an (f).

Treatment steps - Entries in this section should be numbered to indicate the sequence of actions and should indicate the time limit within which these steps are to be taken. The entries should be very specific and concise and should describe the actions of the caseworker and the family unit, which will help in reaching the stated goels. Treatment steps are to be summarized and integrated from those listed on pages 2-6 of the Diagnostic Work-up. This statement of Treatment steps and of Goals form the basis of casework activity or planning with the family unit, and should be coordinated with the Public Welfare Services Guide, Pages 7a and $7 \mathrm{~b}$, Section III CPS.

Resources - Identify those resources which are organized and those which are more informal. Include consideration of relatives, social groups, clubs, churches, as well as organized social agencies in the community. The identification of resources which might be needed for a family unit requires a great deal of careful thought and imagination. The creative use of resources and the searching out of resources, frequently leads to rehabilitation of the family. Please complete each part of this section very carefully. The more accurate and thorough the caseworker can be in this area, the more effective can be the administration which needs this kind of information for future planning.

Resources planned for use would be those already available to the client and would be those which the caseworker plans to use. Resources not available includes those which exist in the community but which are not available to the family because of lack of funds or because of a waiting list. Resources non-existent would be those which do not exist in the community or within this agency.

Child Welfare Casework Plan for the Year - This section is provided for use of child welfare staff only. In determining the priority of service for an individual child or children within a given caseload the casework plan should be in accordance with the Statement of Priorities for Child Welfare Services. For example, a child for whom adoption is planned would be a priority service.

Since all children in foster care are the second basic priority according to the Statement of Priorities the following guides are suggested in determining what priority service is needed:

a. The child in foster care on whom the evaluation is incomplete should receive priority service until such time as the diagnosis and treatment plan is formulated.

b. The child for whom indefinite foster care is planned whose cur- 
rent adjustment in foster care evidences serious disturbance, for whom either the kind of foster care, or the particular foster home may need re-evaluation in terms of the degree to which it is or is not meeting the child's needs.

c. The child currently in foster family care for whom the plan is placement in a residential treatment center.

d. The child for whom return home or to relatives is the plan, and preparation of the child, family and foster parents has not begun.

e. The child for whom self-support is the plan when the diagnostic summary indicates that the child will need major casework services to move into independence of the agency.

Conversely, the following factors suggest that the child be given regular service:

a. The child for whom indefinite foster care is planned, whose adjustment in his foster home is such that it is best for him to continue there, and there are no known problems within the foster family which necessitate change.

b. The child settled in foster family care, but for whom institutional care is planned, but the agency has no control over when the child can be admitted. Children awaiting placement in Fairview are an example.

c. The child for whom return home or to relatives is the plan and preparation has been completed with the child, family and foster parents, but the plan is not to be put into effect immediately. For example, a child needs to complete his grade in school before the change is made.

d. The child for whom self-support is the plan and who is settled in the means by which he will reach his independence. For example, marriage, armed services, has work arrangements all settled, etc.

Where the casework plan for the year differs from one child to another in the family, encircle the appropriate item and place the child's family member number thusby: (1) Return home or to relatives \#4; (4) Adoption \#6.

In addition the family member numbers of those children for whom it has been determined that priority service is required will be listed following Priority and those who receive regular service will be listed following Regular.

For children assigned a priority service rating, whether or not the child is to receive it a review should be made at least every six months. For children determined to need regular services, reviews should be conducted at least annually. However, when there is a significant change in the child's situation or circumstances, there should be a review with 
treatment goals and planning related to case movement and direction.

\section{Classification}

The point at which the analysis of the case and the treatment planning is brought to usable form for the agency, is the identification of the family unit in terms of a level of services. The case classification is a somewhat arbitrary administrative device which helps to determine priority of services as well as factoring out those family units who need little or no casework service. Planning with families and individuals who have social problems require different levels of service from the agency. Three broad areas have been established - Intensive Service, Environmental Service, and Regular Service. In deciding upon which level is more appropriate it is helpful to think about services as a continuing spectrum with no clear break or demarcation between each level. The following factos influence the classification of the family unit: The number and complexity of the social problems, (2) the degree of seriousness of the social problems, (3) the number of potential problems requiring preventative action, (4) the capacity of the family or individual to adjust or to resolve their problems, and (5) the location of the cause of the problem, within the individual or within his environment.

Intensive Services (IS) - This level of service is generally defined as being focused upon "inner problems" or upon the individual's capac1ty and motivation for change. A more intensive client-caseworker relation. ship is necessary to facilitate movement toward improved social function- ing. The caseworker will be required to plan for frequent interviews. An example of this level of service might be the mother who is overwhelmed by fears and anxieties about her capacity of an adult or as a mother and who, because of these anxieties, cannot function as well in providing for the children. Another example might be the feeling of worthlessness expressed by a father who because of past experiences, is extremely fearful of obtaining employment.

Environmental Service (ES) - This level is generally defined as being primarily focused upon "outer problems" or those environmental factors which, when alleviated, allow the individual to become more successful in dealing with his problems. The focus of the casework activity is to help the client identify, locate and use resources. Please note that those cases in which one goal is employment would not necessarily be classified as E.S. Employment is not always the primary goal as there may be other problems which need to be resolved before moving toward employment. In some cases there may need to be many contacts with the family before full use can be made of the resources so that the distinction between the Intensive level and the Environmetal level cannot be based on the frequency of interviews. An example of Lnvironmental Service might be the mother who is seeking employment but who has no particular skills and who could be referred to a practical nurse training program if funds could be located by contact with community groups or relatives. 
Regular Service (RS) - This level of service is generally defined as being focused upon the provision of financial aid in the most efficient and helpful manner. If there are any problems in the family unit, the family seems able to cope with them without outside help. A minimum amount of service is necessary. The focus of casework activity is upon meeting financial need. An example might be the family or individual who needs financial aid and for whom no planning for employment seems appropriate as would be generally true of a 75 year old man who is in relatively good health and who is able to take care of himself within the limits of his age and health.

Beyond determining the appropriate level of services, the caseworker will need to decide what might happen in the family unit within a period of a year, with services being provided as needed. If the caseworker believes that there will be Improvement within a year, the appropriate box should be checked under the service level. If the level of adjustment will remain the same with service, then Maintain level should be checked. If the caseworker expects the situation to worsen, in spite of services, the item Deteriorating should be checked under the appropriate level of service.

In determining the most appropriate level of service which might be needed in order to alleviate or resolve social problems of the family, the ability of the county to provide casework services should not decide the classification of the family unit, as the quantity and quality of the agency's services is related to experience, time and ability. Do not pre-judge the services level even though it may appear to the worker that the agency cannot provide the service.

Rate of Interview should be completed in order to show the number of contacts within a month or year which will be necessary in order to carry out the treatment steps and goals within the classified level of service. This rate of interview is an estimate to be used by the casework and the supervisor in c aseload management.

Date Planning Reviews due refer to the Planning Review Page 8. Instructions for the completion of this review will be found on the following pages. The due date is determined by the classification of the case: IS every 3 months, ES every 6 months, RS annually.

Assignment - This item is to be completed by the supervisor who will make the assignment according to the material (Page 2) which describes the Program for Case Classification and Planning. The term Maximum Services refers to the county's plan for providing services to family units which have been classified as IS or ES and which have the protective ceilings. The term Regular Service refers to the family units which have been classified as RS and implies that the casework will provide the service at a minimum level.

The entire Case Planning Schedule, in effect, replaces the former Face 
Sheet, PA 403 of $11-59$ and should be filed in the case record folder in the position formerly occupied by the earlier face sheet.

\section{Public Welfare Services Guide, Page $7 a$ and $7 b$, Section III}

Following the analysis of the family unit and the diagnostic conclusions, treatment planning is outlined according to the social diagnosis. Treatment planning involves a concept of the different types of services which might need to be provided by the caseworker in order to achieve the goal toward which the family and caseworkers are working. A list of services most appropriately provided to those families and individuals known to public welfare has been designed. This list has been titled Public Welfare Services Guide - Child Families, Page $7 a$ and Non-Child Families, Page 7b. It is intended that these pages be used jointly whenever it seems appropriate to the caseworker. Page $7 \mathrm{~b}$ for non-child families will usually be sufficient for those family units not involving children, i.eo, single adults, married adult couples. The caseworker who is attempting to delineate the services for a child family by using page $7 \mathrm{a}$ may sometimes find it necessary to use page $7 \mathrm{~b}$ also, particularly when there is an aged grandparent in the family or when an adult has need for substitute care.

Use of the Public Welfare Services Guide - The list of services has been designed to be used as a guide for the caseworkers in arriving at treatment planning (page 7) and in completing the Planning Review (page 8). This list is not meant to be all-inclusive, but does include those services which this agency believes to be most important and most appropriate. The use of this guide should provide more clarity to the agency in describing activities of the agency. The guide will also provide a review for the caseworker when the caseworker is attempting to outline the treatment goals and planning and should help the caseworker think about services which may not be immediately obvious for a particular family unit. This guide will also help the caseworker define the services now being provided and those services which the agency is unable to provide.

Completion of Page 7a, 7b - The Public Welfare Services Guide is to be completed for all cases which have been classified and assigned to public assistance staff. All public assistance families assigned to child welfare staff should also have the page $7 \mathrm{a}, 7 \mathrm{~b}$ completed. The form is to be completed by use of a check mark in the appropriate column for each service on the list at the time of the original completion of SFW 444. Page $7 \mathrm{a}, 7 \mathrm{~b}$ is to be completed and filed along with the Case Planning Schedule in the case file. (Refer also to Executive Bulletin 63-51 on Services and any subsequent revisions of that Bulletin.)

\section{Planning Review Page 8, Section IV}

The purpose of the Planning Review is to focus the case planning upon the reevaluation and rethinking about the family unit problems and progress 
during a period of service time, following the initial analysis and classification of the family unit. After the study and diagnosis by the caseworker has produced treatment plans, the most crucial part of the Program for Case Classification and Planning, begins with the implementation of these plans. A number of questions need to be reviewed and answered such as: Were the diagnosis, the treatment goals and oteps correctly assessed? Were the plans really effective in the resolution or treatment of social problems? Was there new diagnostic information which came to light and which affected the identification of problems, treatment planning and the classification of the case?

Because the original scheduling of the case frequently is done under less than ideal conditions, some errors could have been made in that first analysis. After a period of time has passed, the original diagnosis and planning has been tested by experience and there has been some time for reflection and for the assessment of newly obtained knowledge about the family unit. The Planning Review is the means by which the case classification system is reviewed and thus puts "life" into the use of the system in an orderly way. Experience has shown that it requires an equal amount of time and thought to complete the Planning Review as was required for the Case Planning Schedule.

In reviewing casework services for a family unit who receives financial aid it is necessary to review financial costs in relation to these casework services. Our experience has shown us that there is a direct relationship between overall financial costs and the caseworker activity in such areas as employment, parental support payments, household equipment for improving living conditions and child care payments. Reporting on the changes in financial aid because of agency services will be extremely helpful in public interpretation and acceptance of the agency.

Use of the Planning Review

For each family unit which has been classified, a Planning Review is required. The frequency of the review is related to the classification by level of service. A review is required every six months for IS, every six months for ES and annually for RS or at the time of the eligibility review. If the caseworker wishes to complete a review at any other time, he may do so since this review form can be used as a planning tool as is true for the rest of the CPS. When the caseworker has completed the review, it is discussed with the supervisor so that there is a mutual understanding of the family situation and the treatment plan. The supervisor will also review the rate of interviews with the worker. There must be an entry in each section so that proper tabulation can be made for the Statistical Report SFW 464.

Completion of the Planning Review Page 8

Heading - The name of the caseworker who completes the review should be 
entered along with the date of the review and the case name as identified in the county filing system. The Period Covered is the month and year from the time of the original SFW 444 or the last Planning Review. The Number of Contacts should be completed as accurately as possible from caseworker notes and from the narrative recording.

Current Diagnostic Summary - At each review, the caseworker should rethink and rewrite the diagnostic summary, covering the period of time being reviewed. Entries should be brief and concise yet descriptive enough to illustrate the level of adjustment. As part of this summary, the caseworker must encircle the appropriate abbreviation indicating the Over-all Status. Supportive evidence to support this judgment must be recorded in the case file.

Problem Areas - In the review of the case planning, examine each area of functioning and re-identify the current social problems, Enter the problem letter as found on the Code Sheet 442 , which is a part of the Handbook. In addition, restate the current goals by which the problems will be resolved or modified. Potential problems may also be identified and entered in this section by encircling the problem letter.

Current Treatment Plan - In this section, restate the current plan by outlining the specific steps which are to be followed. Indicate the resources which are to be used and relate current treatment planning to the Public Welfare Services Guide, Page $7 \mathrm{a}$ or $7 \mathrm{~b}$. Re-identify the Resources not available or non-existent.

Grant at start of review period - In order to complete this section, the caseworker should project grant changes which are expected to go on for a period of time, excluding fluctuations such as special payments or onetime grants. Nursing Home vendor payments should be reported, along with categorical grants. Medical costs such as hospital drugs, physicians' fees and transportation would be excluded. The first blank must always be completed by recording the amount of that grant at the beginning of the review period. If there has been a change in the grant during the review period, because of casework services, the blanks should be completed by inserting the monthly amount as it has increased or decreased. If the grant change is not a result of services or if the grant has not changed, write in zero after Increase or Decrease. For cases that are closed or suspended show the amount of the monthly grant at the start of the review period and write on the same line the word Closed or Suspended.

The explanation for the grant changes recorded as an increase or decrease, should be completed whenever the change is related to caseworker services. Add to the list of reasons for change, any other reason not already listed. The blanks are to be completed by a check mark.

If the case is closed for assistance and services, a Planning Review should be completed. The case planning should be briefly summarized for 
the period of time since the last review. The caseworker should note the reason for the closing of the case.

Present classification and other blanks on the bottom of the page are self-explanatory. The Assignment section is to be completed by the supervisor when a change is indicated.

\section{Routing of the Planning Review}

After the review is completed and initialed by the supervisor, the form will be routed to the control clerk for notation of review dates and for tabulation of information for the purpose of statistical reporting. The Planning Review can then be filed in the case file behind the Case Planning Schedule.

\section{Use of Planning Reviews for Reopened Cases}

On a reopened case a Page 8 is used by the intake worker to identify the preliminary classification. The field worker will complete the Page 8 if no significant changes have taken place in the family composition or in the problem solving ability of the family. If there are significant changes the CPS should be completed. The use of the Planning Review will reactivate the office controls by identifying the case classification and assignment. The use of the Planning Review will also enable case assignment under the county plan for services under the Program for Case Classification and Planning.

If a new case is closed during the initial three-month period, the Case Planning Schedule should be completed, if possible, along with the Planning Review. In the event that there has been insufficient contact with the family prior to the closing, it may not be possible to complete the CPS, however, the Planning Review could be completed at the time of closing for all cases. These forms will provide information which would explain the nature of the social problems and the kind of case planning which was applied. The information obtained should be helpful to the agency in analyzing experience in short-term contacts as well as the preventative effects of services for a family unit new to the agency. 


\section{Oregon Program for Case Classification and Planning}

\section{Supplemental Instructions for Scheduling Adults in Substitute Care}

(To be inserted in Program for Case Classification and Planning Handbook following Page 24 of the "Instructions for the Schedule".)

Purpose of Scheduling - These cases will be scheduled along with other kinds of cases being served by the agency in order to achieve the same objectives which will lead to improved social services. Each case will be individualized through the process of the social study, the diagnosis and the outlining of treatment goals and steps. The systematic scheduling of cases should help staff in the continuous task of improving the level of services.

Goals - The following set of goals are those subscribed to by this agency in relation to adults who reside in substitute care, i.e., nursing homes and homes for the aged.

1. To provide financial security by supplementing available sources of income.

2. To provide adequate medical care within the funds of the agency.

3. To restore or improve the physical health conditions in order to increase the ability for self care and/or self support.

4. To enable the client to return to his own home when this is within the capacity of the client.

5. To improve or maintain adjustment to substitute care.

6. To improve or maintain relationship with relatives.

Treatment Planning - In each case the caseworker is asked to think about the planning for that individual and is asked to describe the problems, strengths and weaknesses in each case. Although some services might be self-evident and the provision of some services might be assumed, nevertheless such services must be described. Only in this way can administration become more knowledgeable about the needs of the clients. A brief and complete description of the planning for these services should lead to an administrative classification of the case. 
Classification by levels of service - The classification of adults in substitute care will roughly approximate the classification levels as defined in the Handbook on Case Classification. Using this as a guide, the caseworker is asked to apply the following definitions which have more direct application to adults in substitute care.

Regular Services - For these cases, the term "regular" is used to describe those activities which are considered to be usually necessa., in providing for the needs of these clients. This would include the annual review for eligibility and the periodic re-evaluation for the purpose of determining the rate of care in the facility. Such ratings require a review with the nurse or operator of the facility and some contact with the patient. Regular Services will usually be used to describe those clients who have a relative or friend who is actively involved in maintaining an interest and a contact with the client. Such a client may also be ambulatory and able to participate in recreational activities within the facility and in the commuity. Health problems usually associated with advanced age are being stabilized. Another type of client might be one who is no longer able to communicate with others because of advanced senility which, therefore, limits service planning.

Environmental Services - For adults in substitute care, Environmental Services will be defined as a service which requires more time and activity by the caseworker and which is primarily focused upon the manipulation of the environment. These clients can be described as being out of adjustment to their surroundings. In order to help them, the caseworker will need to work with the operator, the doctor, the nurse and the relatives or friends to secure their support and cooperation by interpreting the needs of the client. The caseworker will also help the client use recreational resources or will help develop such resources. Usually these clients are able to understand and accept the limitations of their physical condition and show a desire to improve their adjustments.

Intensive Services - This level of service will also require more than the regular time and attention of the caseworker in which the primary focus is upon feelings and attitudes. The client who needs this type of service has adjustment problems which grow out of internal attitudes and feelings about the placement in substitute care, about the loss of independence in self care, and about the loss of normal physical emotional functioning in society. The caseworker will need to focus primarily upon the client and will work directly with him.

Note: It is understood that the above definitions are intended to be used as a guide in determining the primary focus of casework activity. Many cases will have a degree of each level of service at any point in time so that any distinction being made is necessarily transitory in nature. Classification by service levels should be used as a guide, keeping in mind that behavior and physical health conditions may change a great deal. 
Use of Classification - The analysis or scheduling of adults in substitute care will give staff a classification by level of service. However, the policy of assignment of caseworkers to given substitute care facilities remains unchanged. Therefore, the classification will be used as a caseload management device. A weighting system will be used to help determine the amount of time and effort necessary for the caseworker to provide the needed service. Regular Service will have the weight of one point per family unit; Environmental Service, 2 points; and Intensive Service, 3 points. The total number of points should add up to no more than 120 points. The standard of 120 points is based upon the supposition that there will be enough staff available to provide the services to adults in substitute care. 

Supplementary Instructions for Families with Children in
Substitute Care

(To be inserted in PCCP Handbook following Page 24 of the "Instructions for the Schedule".)

The following instructions are to supplement those directions given in the Handbook on Case Classification, Pages 3 and 4 .

1. In a child family unit where both parents are deceased, leave line 1 and line 2 blank and enter the deceased parent's name and other social data on lines 13, 14 under "Other legal parents". Write in word "deceased" under "Whereabouts".

2. In a child family unit where the legal parents were divorced and the mother remarried, there is both a legal father and a stepfather involved. If the mother is deceased, enter the name of the legal father on line 1 instread of the name of the stepfather. The mother's name would be entered on line 13 or 14 . The word "deceased" should be entered under the column "Whereabouts".

3. If both legal parents have remarried and the children are in substitute care, determine which parent holds or last held legal custody and enter that parent on line 1 or 2 along with the spouse of that legal parent. If neither legal parent was given custody in a divorce action, the caseworkers should use their own judgment sbout which legal parent might be more involved in case planning.

4. In the child family unit where there are several marriages by the legal parents, line 13 and 14 are to be used to indicate the names of these other legal parents. The caseworker may add other lines in that section and may number additional legal parents as $13 a$ and $14 a$. If there is still not enough space available, the worker should show other legal parents under the section marital history and show the relationship to their children who are included in the basic family unit, $e_{\bullet} g .$, John Doe $(\# 5,6)$. 
EXHIBIT C

QUESTIONNAIRE 
QUESTIONNAIRE

1. Name

4. Department: a) Intake 2. Age 3. Sex

5. Present Assignment: a) Intake mental Service d) Regular Service

b) Intensive Service c) Adult Service

6. How long on present assignment? Years _ Months

7. Employment in Multnomah County Public Welfare Commission? Years Months

8. Employment in other Public Welfare Agencies? Years Months

9. Employment in other social agencies? Years Months

10. Number of years of colle ge

11. Undergraduate Major

12. Since finishing college, how many courses for credit have you taken which relate to social work?

13. Current membership in Social Work professional groups: a) A.P.W.A. b) Child Welfare League c) Oregon Social Welfare Ass'n

d) N.A.S.W. e) other (Specify)

**On questions 14 through 22 check $[-7$ one answer only**

14. Under Program for Case Classification and Planning as now implemented, what type of service would be your first choice as a work assignment?
a. Intensive service
b. Environmental service
c. Regular service
d. Intake
e.__No preference

15. If Program for Case Classification and Planning were fully implemented so that all cases were assigned according to classification, what type of Intensive service
b. Environmental service
Negular service
N._Intake service would you prefer as a work assignment?

16. How has the Case Planning Schedule affected your understanding of your clients' situations? a. Much better understanding

b. Somewhat better understanding

c. No difference

d. Somewhat poorer understanding

e.__ Much poorer understanding 
17. How do you think the Case Planning Schedule has influenced your effectiveness in working with your clients? a. Much more effective

b. Somewhat more effective

c. No effect

d. - Somewhat less ef fective

e. Much less effective

18. How compatible do you think the Program for Case Classification and Planning is with social work theory?
a. Highly compatible
b. More compatible
c. Balance of compatible and incompatible
d. More incompatible
e. Highly incompatible

19. In completing the Case Planning Schedule on a case, what usually happens to your casework plan? a. Much better plan

b. Somewhat better plan

c. Does not affect plan

d. Somewhat less appropriate plan

e. Much less appropriate plan

20. In comparing the Oregon Public Welfare Frogram before and after Program for Case Classification and Planning, how do you think it has affected services to clients?

a. Much better services

b. Somewhat better services

c. No difference

d. Somewhat worse service

e. Much worse service
21. Assuming that the Program for Case Classification and $\mathrm{Pl}$ anning could be implemented fully and with a minimum of work disruptions, how would you feel about the system? a. Strongly favorable

b. Somewhat favorable

c. Neutral

d. Somewhat unfavorable

e._Strongly unfavorable
22. Do you think the Program for Case Classification and $\mathrm{Pl}$ anning is: a. Well worth the effort

b. - Of more worth than bother

c. About balanced between effort and results

d. More effort than worthwhile

e. Of little worth compared with the effort 
23. How do the following parts of the Case Planning Schedule influence your work with your client? (Check [ $]$ one box for each part.)

\begin{tabular}{l|c|c|c|c|c}
\multicolumn{1}{c|}{ Parts } & $\begin{array}{c}\text { (a) } \\
\text { Very } \\
\text { helpful }\end{array}$ & $\begin{array}{c}\text { (b) } \\
\text { Somewhat } \\
\text { helpful }\end{array}$ & $\begin{array}{c}\text { (c) } \\
\text { Neither help } \\
\text { nor hinder }\end{array}$ & $\begin{array}{c}\text { (d) } \\
\text { Hinder } \\
\text { somewhat }\end{array}$ & $\begin{array}{c}\text { (e) } \\
\text { Hinder } \\
\text { much }\end{array}$ \\
\hline A. Characteristics & & & & & \\
\hline B. Current problems & & & & & \\
\hline C. Potential problems & & & & & \\
\hline D. Strengths \& Weaknesses & & & & & \\
\hline E. Diagnostic statement & & & & & \\
\hline F. Goals & & & & & \\
\hline G. Treatment steps & & & & & \\
\hline
\end{tabular}

24. Any comments you would care to add about, the Case Planning Schedule or the Program for Case Classification and Planning, including your suggestions for improvement?

$a_{0}$

b.

d。

e. 
1. Bveryone is free to use his own style of speaking in making the introduction, but the general outline of the introduction must be adhered to. You may not add any points that are not already in the introduction, but at discretion you may occasionelly leave out points if you do not feel they are applicable. Please answer any questions arising from the introw duetion us briefly as possible without divslglng the chinling behind the scudy.

2. 2lease keep notes about any significant cosments made by respondent during the course of the interview. In this way, these coments will not be lost or sorgotten. These can be noted briefly in the margin of the questionnairs.

3. If no answers exactily fic the Seelings of the individual, check an answer closese to the feeling. In other words, force respondent to make some kind of a choice.

4. Questions h12: For the few who have advanced degrees, sti.11 try to put answex on the basis of number of courses takeno

5. Between question $\$ 13$ and Question 14 , say something sbout reading the questions and looking at then together. ('so be discussed at the meeting.)

6. Question si3: Add in anything they think of for "other" category。 We will sort then out batex.

7. Questions \#18: If they indicate they know little or nothing about soclal work theory, explain to thein that they have to have sone theoretical base for what they are doing. We want them to answer on the basis of theis understanding, whatever this is. Again, wake their answer this one.

8. Question 24 : Please note that there is rook for five suggestions. Do not go over Elve, but if they do not want to contribute this wany, that is acceptable in this qquestion. This is, incidentaliy, the acost difEicult question to deal with, and a high degree of care will be needed to keep discussion to subjece at hand and elfminate your cra personal bias. 
12y name is , and $I$ am a second year student at the School of Social Work. One of the requirements for ray Master's Degree Involves an independent research study, which some of us are working on together as a group. We plan to write a report on the results of the study. Oux work here savolves the case classlfication Program in Mulenosah County, as we have decided to try to look at the Program and see some of the ways in which it is working well, and some of the ways in which it may not be working we11. Even though we can't study the entire Progran, we hope that it will be at least a beginning in finding out what is actually going on, as very lifele research has been done in case classlzicacion in general. We hope that eventually our study will be of some help in improving the opezation of the agency, and that in this way we will be helping both ourselves and you as mell.

Befoze starting on the questions, however, I would like to tell you that any answer you give Ls strietly confidential and will be shared anly with our actisor and with the research group. Your name wil.2 also be disassociated from your answers very early in the project, and so it will be impossible sos anyone in the ageney to know the answers you personally have given. We are doing this beesuse it is essential that we have a true pickure of your real feelings. Otherwise, we will not be able to find what we are looking for. We very wuch appreciate the time you are giving us hare, as we know how busy you are. As we go along, please feel free to ask about. those questions which are not eleax to you, and if you have any thing you want to ask about what has already been said, please asit now, The way in which $I$ an going to do this is to allow you to see the questionnaire as I zead ic off to you. I. will first ask the question, and then read off the five possible answers, and then you may select the anøuer which comes closest to your way of thiniking. All zight? Shall we begia? 
STATISTICAL TABLE 1

RESULTS OF " $t$ " TEST USING .05 LEVEL OF

SIGNIFICANCE FOR INTAKE WORKERS COMPARED TO

R. S., I. S., E. S., AND TOTAL OF F. S.* WORKERS

\begin{tabular}{|c|c|c|c|c|c|}
\hline \multirow{2}{*}{$\frac{\text { Items }}{16}$} & \multirow{2}{*}{$\frac{\text { Groups }}{\text { IW vs. RS }}$} & \multirow{2}{*}{$\frac{. t "}{.759}$} & \multicolumn{2}{|c|}{$\begin{array}{c}\text { Probability } \\
\text { Range }\end{array}$} & \multirow{2}{*}{ 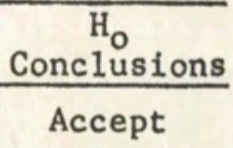 } \\
\hline & & & .50 & .40 & \\
\hline & IW vs. IS & 5.358 & .001 & & Reject \\
\hline & IW vs. ES & 5.833 & .001 & & Reject \\
\hline$\dot{1}$ & IW vs. FS & 2.500 & .02 & .01 & Reject \\
\hline \multirow{4}{*}{$\overline{17}$} & IW vs, RS & 2.777 & .01 & .005 & Reject \\
\hline & IW vs. IS & 6.684 & .001 & & Reject \\
\hline & IW vs. ES & 4.909 & .001 & & Reject \\
\hline & IW vs. FS & 1.464 & .20 & .10 & Accept \\
\hline \multirow[t]{4}{*}{$\overline{18}$} & IW vs. RS & .757 & .50 & .40 & Accept \\
\hline & IW vs. IS & 2.820 & .02 & .01 & Reject \\
\hline & IW vs. ES & .543 & .60 & .50 & Accept \\
\hline & IW vs. FS & 1.137 & .30 & .25 & Accept \\
\hline \multirow[t]{4}{*}{19} & IW vs. RS & 1.500 & .20 & .10 & Accept \\
\hline & IW vs. IS & 5.470 & .001 & & Reject \\
\hline & IW vs. ES & 1.870 & .10 & .05 & Accept \\
\hline & IW vs. FS & 3.515 & .001 & & Reject \\
\hline \multirow[t]{4}{*}{20} & IW vs, RS & .766 & .50 & .40 & Accept \\
\hline & IW vs. IS & 3.906 & .001 & & Reject \\
\hline & IW vs. ES & 2.190 & .05 & .025 & Reject \\
\hline & IW vs. FS & 1.853 & .10 & .05 & Accept \\
\hline \multirow[t]{4}{*}{$\overline{21}$} & IW vs. RS & .237 & .90 & .80 & Accept \\
\hline & IW vs. IS & 3.013 & .01 & .005 & Reject \\
\hline & IW vs. ES & 1.013 & .40 & .30 & Accept \\
\hline & IW vs. FS & .526 & .60 & .50 & Accept \\
\hline \multirow[t]{4}{*}{22} & IW vs. RS & .583 & .60 & .50 & Accept \\
\hline & IW vs. IS & 2.950 & .01 & .005 & Reject \\
\hline & IW vs. ES & .611 & .60 & .50 & Accept \\
\hline & IW vs. FS & .446 & .70 & .60 & Accept \\
\hline
\end{tabular}

*F. S. is an abbreviation for Field Staff. 
STATISTICAL TABLE la

ADDITIONAL INFORMATION OF " $t$ " TEST

FOR INTAKE WORKERS COMPARED TO OTHER GROUPS

OF WORKERS UNDER $\mathrm{H}_{\mathrm{O}}$ III

\begin{tabular}{|c|c|c|c|c|}
\hline Items & $\begin{array}{c}\text { Groups } \\
\text { Compared }\end{array}$ & $\mathrm{N}$ & $\bar{x}$ & SD \\
\hline \multirow[t]{5}{*}{16} & IW & 12 & 3.33 & .653 \\
\hline & IW vs. RS & 60 & 3.56 & 1.775 \\
\hline & IW vs. IS & 12 & 4.42 & .251 \\
\hline & IW vs. ES & 24 & 3.96 & .255 \\
\hline & IW vs. FS* & 96 & 3.80 & .262 \\
\hline \multirow[t]{5}{*}{17} & $\mathrm{IW}$ & 12 & 3.00 & .000 \\
\hline & IW vs. RS & 60 & 3.30 & .830 \\
\hline & IW vs. IS & 12 & 4.25 & .195 \\
\hline & IW vs. ES & 24 & 4.08 & 1.060 \\
\hline & IW vs. FS & 96 & 3.61 & .984 \\
\hline \multirow[t]{5}{*}{18} & IW & 12 & 3.90 & .790 \\
\hline & IW vs. RS & 60 & 4.10 & .850 \\
\hline & IW vs. IS & 12 & 4.75 & .620 \\
\hline & IW vs. ES & 24 & 4.08 & 1.100 \\
\hline & IW vs. FS & 96 & 4.19 & .913 \\
\hline \multirow[t]{5}{*}{19} & IW & 12 & 3.30 & .495 \\
\hline & IW vs. RS & 60 & 3.78 & .710 \\
\hline & IW vs. IS & 12 & 4.50 & .519 \\
\hline & IW vs. ES & 24 & 3.79 & 1.040 \\
\hline & IW vs. FS & 96 & 3.88 & .729 \\
\hline \multirow[t]{5}{*}{$\overline{20}$} & IW & 12 & 3.00 & .848 \\
\hline & IW vs. RS & 60 & 3.23 & 1.153 \\
\hline & IW vs. IS & 12 & 4.25 & .620 \\
\hline & IW vs. ES & 24 & 3.70 & 1.000 \\
\hline & IW vs. FS & 96 & 3.48 & 1.110 \\
\hline \multirow[t]{5}{*}{$\overline{21}$} & IW & 12 & 4.25 & .729 \\
\hline & IW vs. RS & 60 & 4.31 & .983 \\
\hline & IW vs. IS & 12 & 4.91 & .028 \\
\hline & IW vs. ES & 24 & 4.54 & .833 \\
\hline & IW vs. FS & 96 & 4.45 & .903 \\
\hline \multirow[t]{5}{*}{22} & IW & 12 & 3.58 & 1.279 \\
\hline & IW vs. RS & 60 & 3.33 & 1.445 \\
\hline & IW vs. IS & 12 & 4.83 & .577 \\
\hline & IW vs. ES & 24 & 3.87 & 1.328 \\
\hline & IW ys, FS & 96 & 3.67 & .510 \\
\hline
\end{tabular}

*FS is an abbreviation for Field Staff. 
STATISTICAL TABLE 2

MODAL RESPONSES OF ADULT, FAMILY, AND INTAKE SERVICES, AND THE COMBINED MODAL RESPONSES OF THESE SERVICES TO THE PARTS OF C.P.S. FOR $\mathrm{H}_{\mathrm{O}}$ VI

\begin{tabular}{|c|c|c|c|c|}
\hline $\begin{array}{l}\text { Sections of } \\
\text { Schedule }\end{array}$ & $\begin{array}{c}\text { Adult } \\
\text { Service } \\
\end{array}$ & $\begin{array}{l}\text { Family } \\
\text { Service }\end{array}$ & $\begin{array}{l}\text { Intake } \\
\text { Service } \\
\end{array}$ & $\begin{array}{c}\text { A11 } \\
\text { Caseworkers } \\
\end{array}$ \\
\hline Characteristics & c & b & c & c \\
\hline $\begin{array}{l}\text { Current } \\
\text { Problems }\end{array}$ & b & a & c & b \\
\hline $\begin{array}{l}\text { Potential } \\
\text { Problems }\end{array}$ & b & b & c & b \\
\hline $\begin{array}{l}\text { Strengths and } \\
\text { Weaknesses }\end{array}$ & b & b & c & b \\
\hline $\begin{array}{l}\text { Diagnostic } \\
\text { Statement }\end{array}$ & b & a & c & a \\
\hline Goals & b & a & c & b \\
\hline $\begin{array}{l}\text { Treatment } \\
\text { Steps }\end{array}$ & b & a & c & b \\
\hline
\end{tabular}

a - Very Helpful

b - Somewhat Helpfu1

c - Neither Helps Nor Hinders 
STATISTICAL TABLE $2 \mathrm{a}$

A PERCENTAGE RANKING OF ALL RESPONSES TO PARTS

OF CASE PLANNING SCHEDULE BY FREQUENCY OF (a) RESPONSES

\begin{tabular}{lccccc}
\hline $\begin{array}{l}\text { Section of } \\
\text { Schedule }\end{array}$ & $\begin{array}{c}\text { (a) } \\
\text { Very } \\
\text { Helpful }\end{array}$ & $\begin{array}{c}\text { (b) } \\
\text { Somewhat } \\
\text { Helpful }\end{array}$ & $\begin{array}{c}\text { Neither } \\
\text { Helps nor } \\
\text { Hinders }\end{array}$ & $\begin{array}{c}\text { (d) } \\
\text { Hinders } \\
\text { Somewhat }\end{array}$ & $\begin{array}{c}\text { (e) } \\
\text { Hinders } \\
\text { Much }\end{array}$ \\
\hline $\begin{array}{l}\text { Diagnostic } \\
\text { Statement }\end{array}$ & $34.3 \%$ & $33.4 \%$ & $29.6 \%$ & $2.7 \%$ & 0 \\
$\begin{array}{l}\text { Current } \\
\text { Problems }\end{array}$ & $30.5 \%$ & $42.8 \%$ & $24.0 \%$ & $2.7 \%$ & 0 \\
$\begin{array}{l}\text { Strengths and } \\
\text { Weaknesses }\end{array}$ & $29.6 \%$ & $42.8 \%$ & $24.0 \%$ & $2.7 \%$ & $.9 \%$ \\
$\begin{array}{l}\text { Treatment } \\
\text { Steps }\end{array}$ & $29.6 \%$ & $39.8 \%$ & $29.6 \%$ & $.9 \%$ & 0 \\
$\begin{array}{l}\text { Goals } \\
\text { Characteristics }\end{array}$ & $17.5 \%$ & $36.1 \%$ & $40.7 \%$ & $4.6 \%$ & $.9 \%$ \\
$\begin{array}{l}\text { Potential } \\
\text { Problems }\end{array}$ & $14.8 \%$ & $44.4 \%$ & $37.0 \%$ & $2.7 \%$ & $.9 \%$ \\
\hline
\end{tabular}

STATISTICAL TABLE $2 \mathrm{~b}$

THE MODAL ORDER BY FREQUENCY OF POSITIVE RESPONSES OF ALL CASEWORKERS TO ITEM 23 FOR $\mathrm{H}_{\mathrm{O}} \mathrm{VI}$

\begin{tabular}{lccc}
\hline Sections of Schedule & a & b & a + b \\
\hline Current Problems & 33 & 46 & 79 \\
Strengths \& Weaknesses & 32 & 46 & 78 \\
Treatment Steps & 32 & 43 & 75 \\
Goals & 30 & 44 & 74 \\
Diagnostic Statement & 37 & 36 & 73 \\
Potential Problems & 16 & 48 & 64 \\
Characteristics & 19 & 39 & 58 \\
\hline Total & 199 & 302 & 501 \\
\hline
\end{tabular}

